\title{
FESTIVALS, FESTIVAL FOODS, AND DIETARY ACCULTURATION: A JOURNEY OF HYBRIDIZATION AND IDENTITY FORMATION FOR CHINESE INTERNATIONAL STUDENTS IN OTTAWA
}

\author{
By
}

Shihan Liu

A thesis submitted to the Faculty of Graduate and Postdoctoral Affairs in partial fulfillment of the requirements for the degree of

Master of Arts

in

Communication and Media Studies

Carleton University

Ottawa, Ontario

(C) Shihan Liu, 2019 


\begin{abstract}
Through participant observation at the 2018 Ottawa Night Market Chinatown and interviews with fifteen post-secondary Chinese international students in Ottawa about their dietary acculturation, this research aims to answer the following questions: How does hybridity play out in Chinese students' dietary acculturation? What are the impacts of festivals and festival foods on hybridization and identity formation? The findings suggest that Chinese students do become more "hybrid" in their food practices, but this is less so from incorporating Canadian food habits, and more a result of increased consumption of various Chinese regional cuisines and Asian cuisines. However, becoming more hybrid does not weaken the participants' Chinese identity; rather they retain it through attending the Night Market, celebrating traditional Chinese festivals, and maintaining cultural beliefs related to food choices, health and nutrition. This study suggests that hybridization involves multi-cultural and multi-dimensional influences, and confirms that hybridization is distinct from identity formation.
\end{abstract}




\section{ACKNOWLEDGEMENTS}

My journey of dietary acculturation and ethnic identity all started about three years ago when I met Dr. Irena Knezevic in her Food and Communication class. The short documentary that I made for the class assignment named One Day gave an insight into the lives of two Chinese students, who were also my friends at Carleton. The documentary recorded the foods that Shuang and Yuzhi consumed on a regular Sunday and the stories behind them. Food communicates their living conditions as well as their dreams in this foreign country, and their sweet memories about home.

I was inspired to address the inaccessibility of Chinese food by my own experience as a Chinese student at Carleton. I lived on campus when I first came here. I ate at the café every day and had minimal access to what I used to eat at home. Every time I went out for Chinese food with my Chinese friends was a real treat for me. The gathering was not only about the food but also about coping with culture shock and loneliness. My friends and I only went out for Chinese and other Asian cuisines back then because our stomach and more importantly our heart were not ready for adopting a new culture.

Gradually I got used to the food in Ottawa. I started to get excited about the diverse food choices afforded by this multi-cultural country. I constantly explore new cuisines, and sometimes also mistake the foreignness of the cuisines with authenticity. At the same time, my stomach has become intolerant of some spicy Chinese foods, which were my favourites. Unfortunately, that unique taste of home and the pleasure of sharing those spicy foods with my friends also disappeared. And then there are traditional Chinese festivals, during which my mom always remind me of what to eat. My emotions are complex when I reply to my mom that I have eaten this and that, although, in reality, I have not. A gap has occurred between me and my friends and 
family at home in a sense that things matter to them might no longer relevant to me.

Just like the purpose of revealing the food journey of Shuang and Yuzhi in One Day, I aim to understand the dietary acculturation and the implications on ethnic identity for Chinese international students in Ottawa at large. Again, food not only communicates the Chinese students' life conditions but also illustrates Canada's inclusivity to these young foreign dreamers. I want to thank my fellow young foreign dreamers, who are the participants in my study. This thesis would not have been possible without your generous sharing of personal stories and sentiments.

I also want to dedicate this space to thank my supervisor Dr. Irena Knezevic, who not only inspired me to write about this topic, but also has been extremely encouraging and supportive during the past two years. Your advice and feedback were always constructive, and talking to you always made me feel less anxious and more motivated. I am indeed the luckiest student to have you at my side and to share the same passion for food and communication. I am also truly grateful about the RA opportunities you have provided that made me stronger as an academic in the field.

I am indebted to my second reader Dr. Mike Mopas for his thorough and insightful comments and feedback, as well as his unique sociologist perspective on this topic. My thesis would not have been cohesive and consistent without your critical eyes. It has been a pleasant journey to work with you.

To all my professors in the communications department at Carleton, who have contributed to my growth both as an academic and as a person. To all my dear professors, who have faith in me, who have urged me to push myself to become the better version of me, and whose academic achievements and integrity I respect the most. Although I cannot name each one of you here, I 
am deeply grateful for your help.

A huge thanks to my mom, who has always been the source of inspiration for my academic works. Although you are not aware of it, I appreciate that you make me think about food and life. Of course, I have my friends to thank as well. The foods we partook, as well as the leisure activities we participated, were tremendously nourishing for me in this sometimes-frustrating academic life.

Last but not least, I would like to thank my partner Qinting Cai. Thank you so much for your unconditional support that makes me strong during my ups and downs in grad school. I want to especially thank you for making Ottawa like home through cooking those absolutely delicious Chinese dishes, and your company at many joyful dinner tables. I am very fortunate to have you at my side, and to support you anytime you need me. 


\section{LIST OF TABLES}

Table 1: Basic culinary triangle after Levi-Strauss (1965) ............................................................... 29

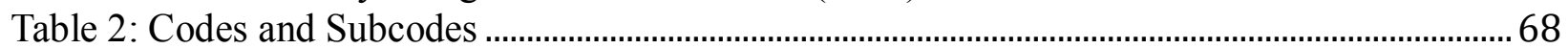




\section{LIST OF FIGURES}

Figure 1 Map of the east end of downtown Ottawa .......................................................................... 57

Figure 2 The crowd at the 2018 Asian Night Market (by Shihan Liu) ........................................... 57

Figure 3 The decoration of the Tofu stand at the Night Market (by Shihan Liu).......................... 58

Figure 4 The all English decoration of the Tibetan food stand (by Shihan Liu).............................58

Figure 5 The Chinese decoration with the simple and small English translation of the Kabob stand

and the BBQ Squid stand (by Shihan Liu). ....................................................................................59

Figure 6 The set-up of the band at the Night Market (by Shihan Liu).............................................59

Figure 7 A screenshot of Kowloon Market's position in Ottawa from Google map (2018) ....... 100

Figure 8 A screenshot of T\&T Supermarket's position in Ottawa from Google map (2018).... 101 


\section{TABLE OF CONTENTS}

ABSTRACT

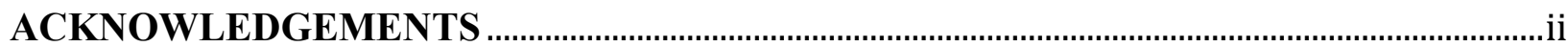

LIST OF TABLES

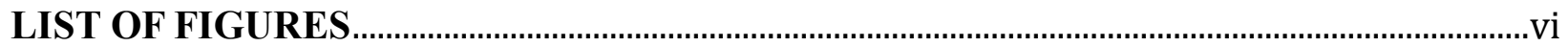

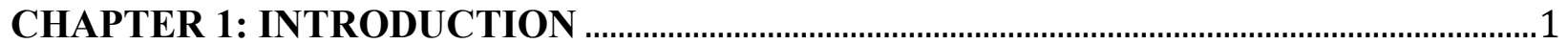

1.1 Challenges in Adaption .........................................................................................................6

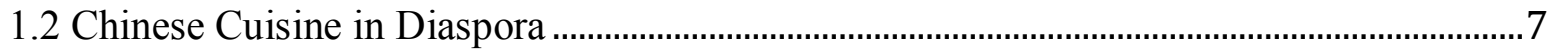

1.3 Chinese Migration to Canada...........................................................................................

1.4 Overview of the thesis....................................................................................................... 11

CHAPTER 2: LITERATURE REVIEW ………….............................................................. 14

2.1 Identity is a Process of Becoming, and Food is a Marker of Identity ................................ 16

2.1.1 Hybrid identity and models of consumer acculturation ............................................ 16

2.1.2 The paradox of food habits..................................................................................... 20

2.1.3 The implications of ethnic festivals on ethnic identities and the collective

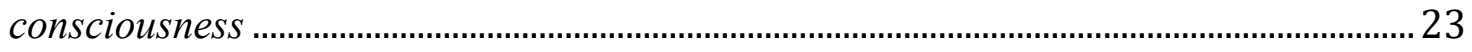

2.1.4 Making ethnic festivals mainstream......................................................................... 26

2.2 Food is a System of Communication and a Cultural Construction ..................................... 28

2.2.1 Structuralism and materialism (or developmentalism) ........................................... 28

2.2.2 The discursiveness of authenticity .............................................................................. 34

2.3 Coping with Dietary Acculturation ......................................................................................... 37

2.3.1 Acculturation and unhealthy diets ........................................................................... 37

2.3.2 Cultural sensitivity in nutrition communication ...................................................... 41

2.3.3 Food accessibility, eating together, and culture learning ........................................ 44

CHAPTER 3: THEORETICAL FRAMEWORK AND METHODOLOGY ............................. 48

3.1 Theoretical Framework ........................................................................................................... 48

3.1.1 Hybridity and models of consumer acculturation ................................................... 48

3.1.2 Social constructivist worldview on ethnicity and food ........................................... 50

3.1.3 Looking at nutrition transition through a cultural lens .............................................52

3.2 Research Design.............................................................................................................. 54

3.2.1 Methodological approaches ……………………................................................ 54

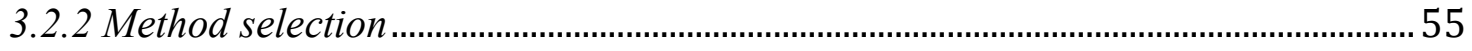

3.2.3 Site selection …………………………………………………………………. 55

3.2.4 Participant selection............................................................................................... 60

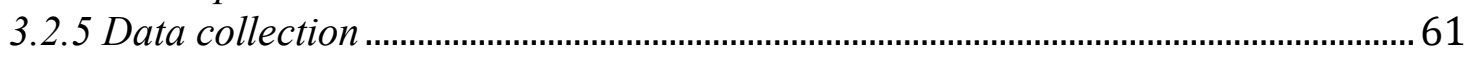

3.2.6 Data analysis ……………………………………………………………………. 66

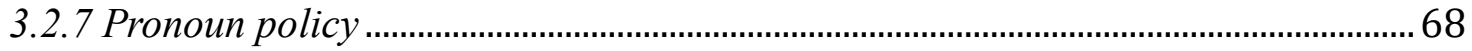

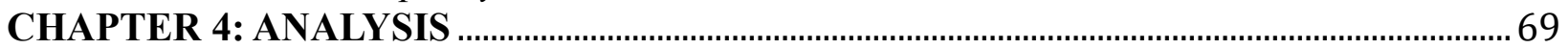

4.1 Hybridity, ethnic identity, and the models of consumer acculturation ................................. 71

4.1.1 Becoming more hybrid, remaining Chinese …………………………………..... 72

4.1.2 Reinforcing ethnic identity at the Night Market ...................................................... 81

4.2 Social constructivist worldview on ethnic festivals .............................................................. 85

4.2.1 Attendance motivations ........................................................................................... 86

4.2.2 Celebrating Chinese festivals in Ottawa ……………............................................. 89

4.2.3 Celebrating local festivals in Ottawa ................................................................... 94

4.3 Food as a cultural construct.......................................................................................... 95 
4.3.1 The choices made in relation to home cooking and eating out ............................... 97

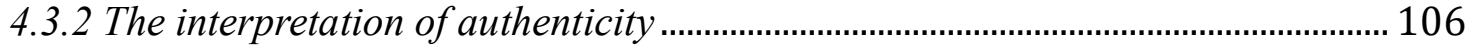

4.4 Looking at dietary acculturation through a cultural lens ..................................................... 112

4.4.1 The role of culture in nutrition transition ................................................................. 113

4.4.2 The meanings of cultural appropriateness ............................................................ 117

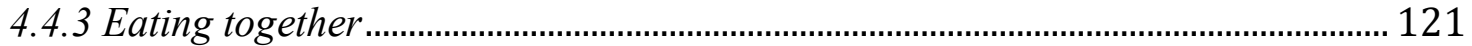

CHAPTER 5: CONCLUSION …........................................................................................... 124

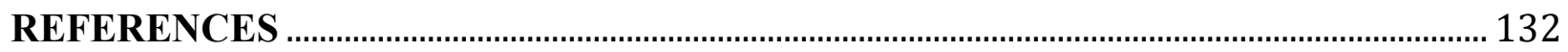

APPENDIX A: CHINESE FOOD, FESTIVALS, AND SLANG TERMINOLOGY ............ 142

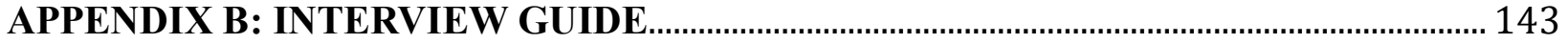

APPENDIX C: LETTER OF INVITATION ........................................................................ 145

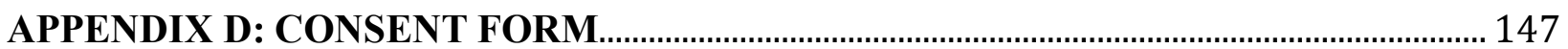

APPENDIX E: CUREB CERTIFICATE OF APPROVAL …............................................. 149 


\section{CHAPTER 1: INTRODUCTION}

It is another Mid-Autumn festival, and just like every other time in the past five years, I get a WeChat message from my mom reminding me of mooncakes. Mid-Autumn festival is a mooncentric harvest festival in China and it is as essential to families as Thanksgiving is in North America. Mooncakes, called Yuebing in Mandarin, are usually baked and shared among loved ones while moon-watching during the festival. My mom usually reminds me of every single Chinese festival, but most of the time I feel resistance to accept the reminders instead of appreciating her kindness. I tell myself that I do not care about what to eat because real authentic Chinese foods are relatively hard to get in Ottawa in terms of time and distance. Moreover, I do not have time to celebrate the festivals on school days. And, most importantly, all the festival practices seem to have nothing to do with the life that I have in Ottawa.

In fact, I do care about having mooncakes, and the desire to eat them here in Canada is even stronger than any time I experienced at home. The sense of resistance is there as well, because the reminders from my mom only amplify the nostalgic feelings. I try to become indifferent so that I can forget how far from home I am. I realize that a gap has developed between me and my mom, and my past connections and experiences in China. I know this gap matters to me, and I wonder whether or not my compatriots in Ottawa feel the same.

Chinese students make up one-third (33\%) of 336,497 international students in Canada (CBIE, 2017). Studies (Li \& Stodolska, 2006; Neri \& Ville, 2008) have shown that despite the sizable population of Chinese students in Canada, the attention and accommodations that they receive in the process of social and cultural adaptation are often lacking. For instance, Chinese students become physically less active because of school and life pressures (Li \& Stodolska, 2006), and internally, many of them experience periods of homesickness and loneliness (Neri \& 
Ville, 2008). As a Chinese student, myself, I can relate to these feelings and find that traditional festivals and their foods sometimes provide me with a temporary sense of reconnection - with my family and with China as a home.

Food festivals and festival foods have been shown to be a significant part of ethnic identities (Jones, 2015). At the same time, the accessibility to culturally appropriate foods reflects social and infrastructural barriers that all migrants encounter (Cappellini \& Yen, 2013; Garnweidner, Terragni, Pettersen \& Mosdol, 2012). Hybridity concerns the mixture of different phenomena such as cultures, nations, ethnicities, and classes while hybridization crosses categories and brings the separate together (Pieterse, 2006). Altered or lost dietary habits are but a common example how hybridity plays out in everyday life of migrants, which might lead to new identity features (Zhang and Guo, 2015). Previous studies tended to frame the role of food consumption in hybridization within the dichotomy of home country food versus host country food (Cleveland, Laroche, Pons, and Kastoun, 2009; Ustuner \& Holt, 2007).

This research explores the roles that ethnic food festivals, traditional festivals, and festival foods play in hybridization and identity formation of post-secondary Chinese international students (referred to as Chinese students throughout the rest of this thesis) in Ottawa, by looking at food festival related activities at the 2018 Ottawa Night Market Chinatown (referred to as the Night Market throughout the paper) and interviewing Chinese students regarding their dietary acculturation process. The guiding research questions are: How does hybridity play out in Chinese students' dietary acculturation? What are the impacts of festivals and festival foods on hybridization and identity formation?

The findings suggest that Chinese students do become more "hybrid" in their food practices, but this is less so from incorporating Canadian food habits, and more a result of increased 
consumption of various Chinese regional cuisines and Asian cuisines. However, becoming more hybrid does not weaken the participants' Chinese identity; rather they retain it through attending the Night Market, celebrating traditional Chinese festivals, and maintaining cultural beliefs related to food choices, health and nutrition. This study suggests that hybridization involves multi-cultural and multi-dimensional influences, and confirms that hybridization is distinct from identity formation.

For the purposes of unpacking the underlying themes in food consumption, as well as to fully understand the social settings of Chinese students, this research adopts a qualitative approach, with participant observation and semi-structured interviews as the methods of data collection. The Night Market, which is a 3-day-long Asian food festival, is chosen as the primary research site. I accessed the site once for the participant observation and adopted a covert role as a participant-observer. Thereafter, I conducted 15 semi-structured, one-on-one interviews, either in person or through phone calls. The interviewees were Chinese students in Ottawa who also attended the Night Market.

Theories such as hybridization and models of consumer acculturation are the bases for considering the relationship between food consumption in the host country and identity formation. I adopt a social constructivist worldview in order to understand the ways in which Chinese students construct meanings associated with ethnic identity through food consumption. Finally, I am interested in the role of cultural beliefs in making food decisions, and thus a cultural lens is applied for the examination of the changes in food habits and the meanings of consuming home culture food.

The main argument is supported by the following findings: The participants become more hybrid from their increased understanding and appreciation of Asian cuisines and other Chinese 
regional cuisines in Ottawa. However, this hybridity of food consumption is still inseparable from the capital resources available to the participants. Namely, all of the participants were pursuing or had recently graduated with a post-secondary degree, and none of them seemed to experience severe financial difficulties, which gave them much freedom in exploring unfamiliar food items while maintaining their home food culture.

A Chinese identity is strengthened through attending the Night Market since it reinforces the participants' collective consciousness as Chinese students in Ottawa, while attaching a sense of belonging to the attendees. Additionally, consuming Chinese food, especially festival food and celebrating Chinese festivals are ways of maintaining a Chinese identity because they reinforce Chinese customs and traditions while strengthening the social ties amongst Chinese students in Ottawa. The participants are cultural outsiders who have a weaker symbolic attachment when celebrating other local festivals, and those celebrations have little impact on their Chinese identity.

Generally, cultural meanings have a more substantial influence on food choices than material conditions. Preexisting social bonds, and cultural beliefs about social hierarchy shaped the participants' food decisions and their perception of authentic Chinese food. The participants also navigated the local restrains on food supply using Chinese food habits and cooking techniques.

Furthermore, social relations and cultural beliefs also prevent nutrition transition. The participants favored nourishment over nutrition, which made home culture food the most popular choice for daily consumption. Having been raised in a collective culture, the participants found a sense of belonging most comfortably in mononational friendship groups (friendship groups consisting only people from the same country, with the members interacting under the similar linguistic and cultural norms (Brown, 2008)), which have irreplaceable emotional and mental 
benefits. Nevertheless, the ways in which a Chinese identity was maintained impeded the participants' language and cultural learning, and thus future research needs to find better explanations for the lack of inter-cultural interaction beyond examining food consumption.

Noteworthily, highlighting a Chinese identity in this study should not be confused with essentializing ${ }^{1}$ Chinese culture in relation to dietary behaviour. Rather, there is a great deal of diversity and the complexity of home culture not mentioned in the participants' discussion of Chinese identity. That complexity is not only embodied in a diverse range of regional customs and traditions, but is also subject to individual performance. I acknowledge that the participants' sometimes seemingly essentialist discussions of identity can be problematic, yet I work with those notions instead of problematizing them, which is beyond the scope of this study. The participants perhaps use those notions as shorthand, and if probed, they would acknowledge them as incomplete and limiting. Nevertheless, at the time of the interviews, probing for those notions seemed unnecessary for the research questions raised in this study.

A larger context of Chinese migration is provided from section 1.1 to 1.3 for the comprehension of Chinese students' life and food consumption in Ottawa. Section 1.1 helps us to understand the complexity of adapting to Western education and the way of life, and the challenges faced by Chinese students in particular. Possible negative outcomes on Western campuses of failing to recognize the dietary differences and requirements of Chinese students are illustrated as well. Section 1.2 scans the development of Chinese cuisines overseas as well as how culinary hierarchy plays out both domestically and internationally. The status of certain Chinese cuisines either at home or abroad brings insights for interpreting the food behaviors of Chinese students. Last but not least, the historical and contemporary composition and social

1 Cultural essentialism is an oversimplified way of defining individual behavior entirely by the cultures the individuals belongs to, while also reducing those cultures to a small set of practices and traditions (Dervin \& Machart, 2015). 
status of Chinese immigrants in Canada are described in section 1.3. That information shows the social environment of Chinese food in Canada, as well as Chinese immigrants' contributions to Canada as a multicultural society.

\subsection{Challenges in Adaption}

Increased liberalization of post-secondary education has given the opportunity for more students to pursue academic achievements abroad (Tafarodi \& Smith, 2001). International university students have also become a major "export" industry that facilitates cultural and intellectual exchanges (Cushner \& Karim, 2004). The competition amongst the key markets of the United Kingdom, Canada, New Zealand, and Australia is fierce, since income from international students is crucially important for the economic health of higher education in these countries (Cushner \& Karim, 2004). Positive word-of-mouth about the academic and pastoral supports students receive from the institutions is crucial for the future recruitment, and the lack of those supports may adversely affect recruitment (Ward, 2001; Brown \& Holloway, 2008; Ryan \& Carroll, 2005). Unfortunately, the accommodation of international students on Western campuses has not proceeded without challenges (Tafarodi \& Smith, 2001).

Prior to entering college, the majority of incoming freshmen students in the United States have some international experience, which includes traveling abroad, having family members moving to other countries, hosting an international student in their home, and learning a foreign language (Cushner \& Karim, 2004). Despite their prior international experiences, most of the students' previous educational experiences in their home country were different (or very different) from the country they had selected for their tertiary education, and these differences are reflected in cultural contexts and languages (Ryan \& Carroll, 2005). Language differences can be a barrier of social and cultural adaptation beyond the ability to speak (Kay \& Kempton, 
1984). Structural differences in different languages lead to nonlinguistic cognitive differences. Namely, language builds a specific worldview into the mind of a native speaker, including the value attached to food (Kay \& Kempton, 1984).

Adaptation to life abroad is often characterized by confusion, loneliness, self-doubt, and greater psychological disturbance than that experienced by local students (Tafarodi \& Smith, 2001). Culture shock is a negative reaction to cultural transition (Ward \& Searle, 1991). In Brown and Holloway's (2008) study regarding the initial stage of the international sojourn, all

the participants experienced symptoms of culture shock. Psychological, emotional, and physical disturbance outweighed feelings of excitement to the sojourners' new life and they suffered mostly at the beginning of their journey (Ward, 2001; Brown \& Holloway, 2008). The intensity of culture shock has been found to positively correlate with the 'cultural distance' between the sojourner and the host country (Ward \& Searle, 1991). Adjusting to a new environment is generally less challenging for students from a geographically closer and ideologically similar country to their host country (Hassanab \& Tidwell, 2002). Therefore, students from other Western countries may experience fewer difficulties in adjusting to Canadian academic systems than a Chinese student (Brown, Edwards, \& Hartwell, 2010; Hartwell, Edwards, \& Brown, 2011).

\subsection{Chinese Cuisine in Diaspora}

In their study about globalization of Chinese of food, Cheung and $\mathrm{Wu}(2004)$ note that Chinese cuisine should not be defined by one national style but by many regional cuisines "due to geographical differentiation and social stratification" (p. 4). Under the influences of the migration within greater China as well as the influences of creolization and globalization, all the regional markers of food habits are also obscured in the post-modern era (Cheung \& Wu, 2004). 
The formation and evolution of Chinese foodways ${ }^{2}$ are also inseparable from the constant encounter with non-Chinese foodways (Cheung \& Wu, 2004). Cheung and $\mathrm{Wu}(2004)$ revealed that some regional cuisines had developed across continental boundaries decades and even centuries prior to the globalization of 'Western' fast food. The global influences of Chinese food started as early as the seventeenth century (Cheung \& Wu, 2004). Overseas trading of goods and labor forces made the cuisines from Southern Fujian and Guangdong (the earliest port cities for international trade) the integral part of foodways in nearby countries like Indonesia and the Philippines and on other continents such as Australia and North America. Foreign and exotic elements were also absorbed into Chinese cuisines, and thus for centuries, Chinese cuisines have been "multicultural, multi-ethnic, and transnational" (Cheung \& Wu, 2004, p. 4).

Starting from the nineteenth century to the most recent global proliferation of Cantonese cuisine $^{3}$ (from Hong Kong), the Cantonese food style has dominated Chinese restaurants in North America, Australia, and London, the UK (Wu, 2004; Tam, 2004). The Cantonese style even altered tastes in places where purveyors claim to serve other Mandarin style dishes (Cheung $\& \mathrm{Wu}, 2004)$. The globalization of Chinese high cuisine is a recent development as opposed to the sidewalk stall food (Cheung \& Wu, 2004). Meanwhile, choosing Chinese food for convenience and economic reasons, either eat-in or take-out, as stated in Cheung and Wu's (2004) study, are still popular in places outside China. In China, the modern practice of dining out, especially in urban centers, has become part of the daily routine and involves people of all classes, and most social events also happen in restaurants (Cheung \& Wu, 2004).

\footnotetext{
2 In The SAGE Encyclopedia of Food Issues, foodways are defined as "food related activities, practices, [and] beliefs" (Albala, 2015, p. 1005).

3 The first wave of Cantonese influence on Chinese restaurants in North America and Australia was brought by Chinese laborer who came from Guangdong province in the nineteenth century (Cheung \& Wu, 2004). The second wave happened during the 1960s to 1970s, when Chinese immigrants introduced cuisines from central and north China to the world (Cheung \& Wu, 2004). The third wave started after the 1980s, and since then the Hong Kong variation of Cantonese cuisine had dominated Chinese restaurants in the 'Western' world (Wu, 2004; Tam, 2004).
} 
However, regional distinctions and hierarchy, both linguistic and cultural, are still at play among the Chinese diaspora. Some of the cuisines have enjoyed a high status in large urban centers, while others have enjoyed a low status and, whether at home or overseas, are deemed unsuitable for consumption at restaurants (Cheung \& Wu, 2004). The hierarchy is also linked to more recent geo-political and economic developments; for instance, despite the global influences of the cuisine from Southern Fujian, gourmets in Mainland China have not counted the cuisine into the regional high cuisines ${ }^{4}$ (Cheung $\& \mathrm{Wu}, 2004$ ). Additionally, the image of exotic ethnic groups is reinforced both overseas and at home. Overseas, Chinese people perceive the architectural design of the Chinese restaurant in Hawaii as hyper stereotypical (Cheung \& Wu, 2004). At home, Xinjiang and Tibetan food in Beijing are popular among the residents because the experience at the restaurants combines exotic visual elements such as the decorations and the costumes with the foreign taste (Cheung \& $\mathrm{Wu}, 2004)$.

\subsection{Chinese Migration to Canada}

In his 2017 book about Chinese migration in Canada, Wong indicated that Canada was home to $1,332,000$ Chinese immigrants in 2009 , which made it the sixth most popular country for overseas Chinese, after four Asian countries and the United States. Canada has been an important region for the Chinese immigrants for their transnational practices, and meanwhile, since the time of Confederation, the Chinese have also been "an integral component of Canadian society" (Wong, 2017, p. 3).

According to Wong (2017), Chinese migration to Canada was divided into five phases. The first two phases, from 1858 to 1884 and from 1885 to 1923 , were characterized by extensive

\footnotetext{
4 Gourmets in Mainland China have argued about the number of major regional "high" cuisines in China, whether it be three, four, six, or eight; the cuisine from Southern Fujian was never included into the categorization (Cheung \& Wu, 2004).
} 
labor migration from Fujian and the Pearl river delta ${ }^{5}$ (Wong, 2017). At the same time, the first two phases were restricted by the federal government's head tax, which charged Chinese laborers from fifty dollars in 1886 to five hundred dollars in 1904 per head (Wong, 2017). Some of the Chinese laborers worked as gold miners in British Columbia, and others had low-paid and dangerous work for the completion of the Canadian Pacific Railway (Wong, 2017).

From 1923 to 1947, the Chinese were excluded from entering Canada by a federal legislation, which according to Wong (2017) also created social and cultural immobility for those who already lived in Canada. More than twenty years later, the overseas Chinese could finally reunite with their family members when the legislation was abolished in 1947, but the total number of Chinese immigrants admitted to Canada during this period was still much lower than the first two phases right up until 1967 (Wong, 2017).

The fifth phase started from the liberalization of Canadian immigration policy in 1967, when noteworthy flows of middle-class Hong Kong immigrants, as well as Chinese entrepreneurs, came to Canada, complementing the continuing migration of Chinese working-class laborers (Wong, 2017). Wong (2017) also revealed a demographic shift in the regional origins of the migrants during this phrase that from 1967 to 1997, most of the Chinese migrants in Canada came from Hong Kong, whereas between 2000 and 2010 most of the migrants came from mainland China.

Although the Chinese merely made up less than four percent of the total population in Canada in 2011, the Chinese population is denser in many metropolitan areas such as Toronto, Vancouver, and Montreal, and in many neighborhoods in these cities (Wong, 2017). In another

\footnotetext{
5 Located in the south of China, the Pearl river delta (PRD) is arguably the most dynamic, open, and innovative region of China (The Economist, 2017). The PRD is home to Hong Kong, Macau, and other nine mainland cities in the Guangdong province, notably Guangzhou and Shenzhen (The Economist, 2017). The PRD contributes 10\% of the GDP in China although its population accounts $5 \%$ of it (The Economist, 2017).
} 
news article, Yang (2017) has shown that Canada's three most dominantly Chinese enclaves are all located in the greater Toronto area. For instance, in a trio of neighboring tracts in Scarborough $87 \%$ of residents identified as Chinese. Chinese people make up $11.13 \%$ of Toronto's population and have become the largest non-white group in the city (Yang, 2017). Higher concentration of particular ethnic groups in certain areas helps immigrants to retain their traditional lifestyles because the market demands would be large enough to support the local market supply of those ethnic goods at a reasonable price (Chiswick \& Miller, 2004). It is in this larger context of Chinese migration that today's students from China experience their life and food in Canada.

\subsection{Overview of the thesis}

The rest of this document is organized into four chapters. Chapter 2: Literature Review has three main sections. The first section considers the fluidity of identity and the role of food consumption in identity formation through applying the concept of hybrid identity, and dealing with the relationship between dietary acculturation and identity formation. The second section of Chapter 2 examines food as communication, as well as the cultural construction of food. Dietary acculturation of international students in a global context is explored in the final section of the chapter.

The theoretical framework of this research is combined in Chapter 3 with the research design. In the theoretical framework, there are three main themes that I use to frame the narratives of the interviewees. As aforementioned, theories such as hybridization and models of consumer acculturation, and frameworks such as a social constructivist worldview and a cultural lens are applied to understand the relationship between food consumption, identity formation, and the cultural significance of dietary changes. 
This research adopts a qualitative approach, with participant observation and semistructured interviews as the methods of data collection. I had accessed the Night Market once for the participant observation and adopted a covert role as a participant-observer. I conducted fifteen semi-structured, one-on-one interviews with the Chinese-student-attendees at the Night Market, either in person or through phone calls. Further details regarding the data collection and the data analysis procedures, as well as the limitations of insider research, are also discussed in the second half of Chapter 3 .

The fourth chapter, which is the analysis, has four sections. The first section investigates food related changes of the participants and finds that the participants became more hybrid from their increased understanding and appreciation of Asian cuisines and other Chinese regional cuisines in Ottawa. Meanwhile, as argued by Cleveland, et al. (2009), identity and acculturation should be treated as two distinct processes since the changes in dietary habits had not affected the Chinese identity of the participants.

This research adopts a social constructivist worldview in the analysis of the implications of festivals and festival foods on hybridization and identity formation of the participants. By looking at the attendance motivations of the Night Market and the festival related changes in the lives of the participants, I have found that attending the Night Market, consuming Chinese (festival) food, and celebrating Chinese festivals are also ways of maintaining a Chinese identity, yet they are not used to resist the host culture.

Section 3 applies the debate between structuralism and materialism as related the sociology of food and eating to flesh out a social constructivist worldview. This section aims to interpret the food consumption choices made by the participants in their daily settings and to uncover the meanings of authenticity to the participants. I found that cultural meanings had a more 
substantial influence on food choices than material conditions. Furthermore, the perceptions of authenticity are also socially and culturally constructed.

The implications of cultural meanings in nutrition transition and health communication are discussed in section 4. Social relations and cultural beliefs are more influential than material conditions in shaping health-related dietary changes and food decisions. Nevertheless, the adverse impacts on language and cultural learning from retreating into mononational friendship groups should be revaluated with the corresponding emotional benefits.

Chapter 5 starts by summarizing the findings of this thesis. The theoretical contributions of this research, such as the contemporary definition of hybridity and the collaboration between structuralism, materialism, and a social constructivist approach are also discussed in the conclusion. The limitations of this research pertaining to the research data, as well as the drawbacks and benefits of insider research are acknowledged thereafter. Lastly, understanding the motivations and barriers for inter-cultural interaction is identified as the potential next step of research in the fields of migration, globalization, and identity formation. 


\section{CHAPTER 2: LITERATURE REVIEW}

This study explores the impacts of festivals and festival foods on Chinese students' hybridization and identity formation, as well as the role of hybridity in dietary acculturation. To contextualize my research, I explore a wide range of literature, which allows us to look at dietary acculturation from different possible dimensions.

This chapter comprises three major sections. Literature on hybrid identity and different models of consumer acculturation help us to understand why a Chinese identity is maintained despite hybridization. Hybridity is positioned within the power relations of the larger social fabric, and this includes the importance of capital resources in acculturation, and the diversity of home culture. Empirical studies regarding dietary acculturation of migrants reveal the relationship between retaining original food habits and identity formation. Overall, such literature explains why the participants become more hybrid from incorporating Asian and regional Chinese cuisines but less so from absorbing Canadian food habits.

Additionally, ethnic festivals are framed as cultural performances, which are constructed in relation to the modern capitalist society. Encouraging social cohesiveness and subverting hegemonic power relationships are also functions of ethnic festivals. These theoretical concepts relate to various attendance motivations, which could inform how Chinese students negotiate membership within their ethnic group and within the host country through attending the festivals.

A social constructivist worldview recognizes the meanings of food as intertwined with social structures, material availabilities, and personal constructions, and thus the debate between structuralism and materialism on food and eating are discussed here, in order to provide a thorough theoretical framework for interpreting the food behaviors of Chinese students. In doing so, Chinese students' dietary acculturation can be understood as a cultural construct, positioned 
within its networks of relations, systemic meanings, social hierarchy, historical trends, and technological advancements, among others. Additionally, meanings of food authenticity not only connect food consumption with power dynamics, but are also strongly linked to ethnic identity, as evident in my interviews. Literature on food authenticity answers two main questions: 1) What food is authentic? This question deals with standards, traditions, locations, exotic cuisines, etc.; and 2) Who is qualified to assess authenticity? This question deals with ethnic identity more explicitly.

Third, literature on immigrant food choices and the barriers of acculturation and food consumption encountered by international university students, especially Chinese students, enrich our understanding of the value of cultural beliefs on perceiving health and nutrition. Nutrition transition is also influenced by acculturation rate and ethnic social networks. Moreover, the nutrition transition happening in contemporary China is indicative of Chinese students' knowledge of Western food and global consumer culture food before they came abroad.

Literature on health communication associates cultural sensitivity with ethnic identity, and it specifically acknowledges the symbolic significance of traditional diets and festival foods in maintaining ethnic identity. The inaccessibility of culturally appropriate foods on campus, consuming home culture food, and strengthening ethnic social ties are identified as reasons for retrieving into mononational friendship groups by empirical literature on dietary acculturation of Chinese students. These reasons and the corresponding impacts on language and cultural learning are crucial for analyzing the interviews. 


\subsection{Identity is a Process of Becoming, and Food is a Marker of Identity}

\subsubsection{Hybrid identity and models of consumer acculturation}

The post-structural perspectives on identities as a process of becoming help us see how identity is "provisional and relational" (Zhang \& Guo, 2015, p. 211). Identities are fluid rather than static, because the sense of the self can shift as individuals shift time and space, and identities are formed through the engagement in symbolic systems, such as the use of language and other social interactions (Zhang \& Guo, 2015). Individuals strive to acknowledge the gap between "who one is and who one could be" as posited by Zhang and Guo (2015, p. 211), which also suggests the provisionality of identity. Furthermore, seeing identities as relational is recognizing the effects of intrapersonal changes on identity formation (Zhang \& Guo, 2015). Zhang and Guo (2015) argue that immigrants are aware of their journey across spaces and cultures, and they imagine themselves as others or in another time and place. The awareness and imagination are thus relational as they allow immigrants to either redefine or disregard their identifications (Zhang \& Guo, 2015).

Chinese students engage in symbolic exchanges when they alter their diet to either adapt to the local food culture or to cope with the local limitations. Their identities are fluid since they become more hybrid to incorporate the migration experience into identity (Zhang \& Guo, 2015). The concept of acculturation also describes the fluidity of identity. In acculturation, at least two cultures interact with each other, and usually the person who comes from a minority culture learns and adopts the norms and values of the host/dominant culture (Cleveland et al., 2009).

Many recent social and cultural analyses concerning the role of consumption in acculturation are associated with John W. Berry's four models of acculturation in his psychological consumer research (as cited in Askegaard, Arnould, \& Kjeldgaard, 2005). In this model, migrants can: 1) 
abandon their minority identity through assimilation; 2) they can combine the two cultures in order to construct a hybrid identity; 3) they can experience rejection from the host culture for defending their home culture; and 4) they can distance themselves from both cultures resulting in deculturation (Askegaard et al., 2005, p. 161).

Prior studies on the construction of hybrid identities have framed the participation of migrants in their new countries as consumers in terms of brand preferences (Vijaygopal \& Dibb, 2012). According to Visser (1999), consumerism is a food metaphor for purchasing, which relates the feeling of always needing more consumer goods such as clothes and bags, to changes in people's appetite for meals. Visser (1999) also reveals that instead of having a freedom of choice, our food choices are tailored by marketing mechanisms, toward the interests of those who have power to promote food around the world. The example Visser (1999) gives is that of the influences that powerful food producers have had on scientific research, which underlined the health benefits of more expensive food items such as olive oil and a good red wine. Likewise, Visser (1999) also found that advertising had created a healthier version of the Mediterranean Diet in the US, containing less red meat but more raw and fresh vegetables, more fish, and more natural materials such as extra virgin olive oil and mineral water. Though this version is very different from the cuisine actually consumed in the Mediterranean, it is adopted by Americans to fit their needs and fears, which are again created, reinforced, and linked to consumerism by advertising (Visser, 1999). Framing Chinese students in Ottawa as consumers, I want to explore how the formation of hybrid identities is affected by food consumption. Moreover, the marketing strategies of commodifying social identity and branding have tightened the connection between identity and commodity now more than ever (Ragusa, 2005; Kimberley \& Parcell, 2014). 
Studies have also shown that the bipolar process of acculturation, namely, the models of deculturation and assimilation could only happen in theory rather than in real life cases the researchers encountered (Cleveland et al., 2009; Ustuner and Holt, 2007). Cleveland et al. (2009) proposed a dual process model of adaptation, and they argued that ethnic identity and acculturation were two distinct processes especially evident in relation to food. Food consumption patterns are complex expressions and they are more independent from the bipolar positions of acculturation (Reilly \& Wallendorf, 1987). People who are rated high in ethnic identity also consume a substantial amount of mainstream food items in the host country, yet their identity is even strengthened (despite acculturation) when they consume food items that are strongly related to tradition and family ties (Cleveland et al., 2009). Food consumption patterns are not clearly defined or limited by national borders. This is evident in the food habits of the Mexican-American minority, since their consumption of certain foods goes beyond the boundaries of both their home food culture and American Anglos' food habits (Cleveland et al., 2009). The intertwining relations of acculturation and identity are challenged by patterns of adopting host cultural products as well as other international consumer goods. These findings also suggest that consuming non-home culture food items does not necessarily promote the formation of hybrid identities.

Ustuner and Holt (2007) have critically assessed the model of hybrid identities in the process of acculturation. Through conducting participant observation examining the lives of Turkish rural women migrating into a squatter part of the city, the authors confirmed the fluidity of identity in the process of acculturation, yet they questioned the capacity of the rural women to autonomously acquire a hybrid identity (Ustuner and Holt, 2007). The existing model of postmodern consumer acculturation described hybrid identities "as a playful and seamless set of 
situational acts" (Ustuner and Holt, 2007, p. 42). However, capital resources are crucial for engaging in seamless culture swapping, which is the ability to unconsciously switch behavior in order to meet different cultural expectations and norms between the home culture and the host culture in various situations (Ustuner and Holt, 2007). Previous studies that mostly explored the formation of hybrid identities of middle-class adults and students did not apply the class lens, which had resulted in generalizing findings that provide only a partial understanding of hybrid identity (Ustuner and Holt, 2007).

Consequently, Ustuner and Holt (2007) proposed the model of the dominant consumer acculturation in addition to the post-modern consumer acculturation model. In this new model, the authors argued that in the Turkish modern consumer culture, squatter women had no other choice but to either pursue the upper-middle-class style of consumption and the associated ideology or to live outside it (Ustuner and Holt, 2007). The rural female migrants simply could not proactively construct hybrid identities, which had been key to prior studies (Ustuner and Holt, 2007).

The diversity and complexity of home culture should not be neglected either. Ustuner and Holt (2007) revealed that the upper-middle-class consumer expression of gender in the dominant urban ideology directly threatened the traditional patriarchal ideology of Turkey's eastern villages for the mother migrants. In contrast, their daughters saw the gender expression as an escape from the patriarchal married life in the village to a more independent Turkish uppermiddle-class femininity (Ustuner and Holt, 2007). Therefore, categories such as social class, age, and gender can generate many variations within the migrant group as opposed to a singular home culture (Ustuner and Holt, 2007). 


\subsubsection{The paradox of food habits}

Food habits are hard, if not impossible to change following the move to a new environment (Warde, 1997). In the process of acculturation, food consumption is not as open to individualizing tendencies as other consumption fields (Warde, 1997). The migrants could maintain food habits "even after a century of geographical and cultural removal from their homeland" (Cleveland et al., 2009, p. 199). Home culture food habits are practically and symbolically meaningful behaviors for a given culture (Fieldhouse, 1995). Indoctrinated early in

life and passed down through generations, food behaviors are signs of membership to the cultural group (Cheung \& Wu, 2004).

At the same time, food habits are part of the changing mechanism in culture. As predictable and stable as they can be, paradoxically, food habits often undergo constant and continuous changes when faced with new ecological and economic conditions (Fieldhouse, 1995). Rao has coined the term 'gastrodynamics' to refer to the changes in dietary styles and food behavior due to the altered availability, discovery, or innovation of foods and the borrowing of food habits from others (as cited in Fieldhouse, 1995).

The paradox of food habits is witnessed in studies investigating the meaning attached to food for international students. As a representation of ethnic ties and a project of nostalgia, food is a powerful antidote in coping with the symptoms of cultural shock (Kim, 2001; Locher, Yoels, Maurer, \& van Ells, 2015). In their study about the food consumption experiences of postgraduate international students in the UK, Brown et al. (2010) found that most students were open to new foods in the host country as well as dishes prepared by other international students. International students are not food neophobes (Dovey, Staples, Gibson, and Halford, 2008), as they do not reject foods just because they are novel or unknown to them. By occasionally trying 
out new cuisines and incorporating local food habits into the native dietary pattern while simultaneously preserving original food habits, students are presenting as well as accepting both the ideal multicultural self and the conservative day-to-day self (Brown et al., 2010).

Home country dishes are still the most popular cuisine when students eat together with their compatriots, which is a popular leisure activity (Brown et al., 2010). The students in Brown et al.'s study claimed that home country food provided emotional and physical sustenance, and they were often comforted by a taste of home as well as the healthier choice of home culture food than what was locally available. The taste of home food transports students to a place and time when they feel safe, and thus home food is nourishing and is helpful in alleviating stress and loneliness (Brown et al., 2010). A World Health Organization study about the food behavior of international students worldwide suggested that food reduced the feelings of grief for leaving behind the happy past as well as the significant others at home, offering students a temporary break from the unhappy present (Zwingmann \& Gunn, 1983). However, the initial level of happiness would not be reached until their return home (Zwingmann \& Gunn, 1983). As a substitute for home, Zwingmann and Gunn's (1983) research confirms, the symbolic significance of consuming home culture food is irreplaceable.

Cappellini and Yen (2013) have interrogated the relations between Chinese international students' social ties in the UK with their food consumption patterns. The authors defined two types of social ties: ethnic (ties with other Chinese international students) and non-ethnic (ties with British students). In addition, both types of social ties were further distinguished by Cappellini and Yen (2013) as either weak or strong. Through conducting four sets of focus group discussions over nine months, the researchers found that food consumption was a way of resisting the host culture as well as a way to maintain a Chinese identity for the participants in 
the study regardless of the types or the strength of their social ties (Cappellini and Yen, 2013). Practices such as preparing a Chinese meal together and sharing the food strengthened the participants' ethnic identity (Cappellini and Yen, 2013).

Nevertheless, the participants' willingness to try local non-Chinese restaurants did grow, as they stayed longer in the UK, so did their knowledge of local food as well as food conventions (Cappellini and Yen, 2013). British food often became an additional market option for the Chinese students, and they were still more likely to choose between Chinese food and global consumer culture food (GCC food) when dining out (Cappellini and Yen, 2013). GCC food is represented by global fast food franchises (franchises that are not originally from China but are popular in contemporary Chinese society) such as McDonald's, Pizza Hut, Burger King, KFC, among others. Cappellini and Yen (2013) have also argued that acculturation started before Chinese students came to Western countries because of the popularity of these franchises in China. The familiarity towards GCC food also makes it part of the group identity. The Chinese students' early interpretations of the host culture food were formed based on that knowledge, yet GCC food was also consumed to resist host food culture (Brown et al., 2010; Cappellini and Yen, 2013). GCC food is considered as the middle ground between 'my' Chinese food and 'their' local food, where cultural diversities cease, and a shared expectations of food conventions and meal structure emerged (Cappellini and Yen, 2013). Furthermore, GCC food also became a compromise when the participants negotiated between Chinese food and British food with their close British friends and romantic partners, and they also radicalized their idea of consuming Chinese food as a way of maintaining their Chinese identity (Cappellini and Yen, 2013). As Cappellini and Yen (2013) demonstrated, despite having a wider knowledge of local food habits, participants who had a British romantic partner did not consume more British food than others. 
Finally, Cappellini and Yen (2013) illustrated the influence of recency of arrival in the participants' food consumption patterns, because the students' willingness to try different cuisines increased with their time living in the UK (Cappellini and Yen, 2013). Nine months may still not be long enough for the participants to fully explore the host food culture. This gap is in part what my research addresses by comparing and contrasting the food consumption patterns of my participants with a wider range of recency of arrival, from one year to seven years. Having said that, next section deals with the ways in which Chinese students negotiate membership within their ethnic group and within the host country through attending ethnic festivals.

\subsubsection{The implications of ethnic festivals on ethnic identities and the collective consciousness}

In their studies about the Cajun festivals in Louisiana, Bankston and Henry (2000) revealed that the historical events of ethnic traditions were selectively interpreted or reinterpreted by people with various political and social purposes, which were then embedded in ethnic festivals. Moreover, festivals are spectacles and staged pubic events, perpetuated by the postindustrial capacity of reproducing and commercializing human experiences (Bankston \& Henry, 2000).

Two concepts of culture coexist. On one hand, culture is a form of heritage and it is promoted as a unique resource by the insiders to invoke ethnic awareness (Bankston \& Henry, 2000). On the other hand, culture is a form of commodity, consumed by the outsiders to the culture, and it also represents the acceptance of the ethnic group within the dominant culture of the society (Bankston \& Henry, 2000). All ethnicity is symbolic, yet despite the shared heritage and cultural expressions, ethnicity is widely accepted as socially constructed (Allahar, 1994; Bankston \& Henry, 2000), and commodified in the context of ethnic festivals (Bankston \& Henry, 2000).

Barkataki-Ruscheweyh's (2013) study about an ethnic minority festival called Wihu Kuh festival celebrated by the Tangsa living in Assam has shown that the celebrations combine 
traditional rituals and contemporary Christian Tangsa practices with the purpose of creating a common pan-Tangsa identity. The author argued that the Wihu Kuh festival transformed traditional rituals into cultural performances, which provided a commercialized yet superficial understanding of culture (Barkataki-Ruscheweyh, 2013).

More cultural performances are presented in the Cajun festivals of southwestern Louisiana. The traditions are not the continuity of an existing traditional festival, but are invented in response to the modern context while making references to the old situations (Hobsbawm, 1983; Bankston \& Henry, 2000). The timing of the festivals is set around the modern workweek hence the main events are always scheduled on the weekends starting Friday evening (Bankston \& Henry, 2000). According to Bankston and Henry (2000), every month has its own festival because the timing is more driven by marketing calculations than by agricultural or traditional calendar. In their arrangement of space, Bankston and Henry (2000) have said that the festivals resemble other commodified public spaces such as shopping malls, where a stage is set at the center of the festival with free performances for all the festival attendees, and the vendors sell ethnic foods and crafts in booths under small tents. Festival attendees consume ethnicity by ingesting foods that are explicitly associated with certain ethnicity (Bankston \& Henry, 2000). In general, the content is traditional nostalgia regardless of the forms of consumption (Bankston \& Henry, 2000).

Festivals are public by definition (Schuster, 1995). The social function of a festival is related to the values that a community recognizes as essential to its ideology so that the citizens can participate in the shared life of a community through maintaining and celebrating the activities (Arcodia \& Robb, 2000; Falassi, 1987; Usyal, Gahan \& Martin, 1993). The recurring nature of festivals also facilitates the development of social capital through promoting social cohesiveness 
and encouraging public celebration (Arcodia \& Whitford, 2006). Ethnic, linguistic, religious, and historical bonds unite members of the community, but the dominant culture in the area still has a heavier influence on the ethnic society (Arcodia \& Whitford, 2006). Arcodia and Whitford (2006) have shown that Australians are attending festivals for celebrating and preserving the vividness of cultural diversity in Australia, and this awareness is underpinned by the dominant ideology of multiculturalism.

The festivals of the dominant culture, however, also unite individuals and their culinary culture to the wider social fabric (Wood, 1995). This is made clear by Wood's (1995) argument that the idea of feasting at Christmas and Thanksgiving, for instance, brings people from different culinary cultures together in the shared symbolic experiences through a common understanding of cultural conventions. Nevertheless, if the common understanding of the cultural conventions is absent, the symbols will no longer signify cultural meanings and they will merely contribute to a superficial understanding of the culture as the above studies on ethnic festivals suggested.

Arguably, festivals are also sites where hegemonic power relationships are temporarily reversed through the festive frame, and this is the case in LGBT + festivals. The festival space is shielded from homophobia frameworks so that the ambivalent tourists can also be involved in the pleasure of the strange (Mason \& Lo, 2009). This is important because festivals are opportunities for enacting a collective consciousness (Durkheim, 1995), which allows the attendees to either confirm or contest the collective identification that they have in the mainstream discourse (Jamieson, 2004; Quinn, 2003; Shin, 2004). 


\subsubsection{Making ethnic festivals mainstream}

Understanding the motivations of festival attendees, we are able to explore the role of the festival in the process of acculturation from different perspectives. Studies have shown that although the attendance motivations of the insiders to the culture can be different from the motivations of other festival attendees, some of the motivations do overlap and they are no longer just about identity formation or cultural exploration but also about entertainment and relaxation (Backman, Backman, Uysal, \& Sunshine, 1995; Formica \& Uysal, 1996; Mohr, Backman, Gahan, \& Backman, 1993; Savinovic, Kim, \& Long, 2012; Usyal et al., 1993). More importantly, ethnic festivals could also be an integral part of the host country when the country is already multi-cultural and multi-ethnic (Arcodia \& Whitford, 2006), and in this case the ethnic festivals are more than a wake-up call of the collective consciousness. The question that should be asked here is to what extent do ethnic festivals confirm the collective identity of the ethnic group versus the membership within the host society?

Studies point to several common factors of festival attendance motivations in North America, which include 'socialization', 'family togetherness', 'event novelty', 'escape', and 'excitement' (Backman et al., 1995; Formica \& Uysal, 1996; Mohr et al., 1993). Different types of festivals emphasize similar needs but to different degrees. First time visitors tend to report lower satisfaction than repeat visitors; socialization is a more motivating factor for residents than for non-residents; the novelty of the event is more important for older age groups (Lee, 2000). Lee (2000) has also revealed that domestic and foreign visitors are significantly different in motivational factors such as 'socialization' and 'novelty', wherein the former motivation attracts more domestic visitors while the latter motivation resonates more with foreign visitors. Foreign visitors also are more likely to reach a high satisfaction as compared to domestic visitors (Lee, 
2000). Moreover, Savinovic et al. (2012) found a moderate to strong correlation between the festivalgoers' motivations, their overall satisfaction, and the likelihood of re-visiting the event. Surprisingly, culture is not the central theme of international food events for both domestic and foreign visitors (Lee, 2000), yet food still occupies a cardinal position in ethnic festivals (Savinovic et al., 2012). Unpacking the motivations of my participants in this research could potentially provide a deeper understanding of the role of food in ethnic events.

Although people who identify as members of the ethnic group are more likely to attend the events than others, the most conspicuous ethnic display of authenticity attracts more outsiders than insiders (Bankston \& Henry, 2000). Bankston and Henry (2000) have also revealed that within the ethnic group, younger people are more likely to attend than older people. Taking a similar perspective, McClinchey's (2008) research examining the ethnic street festivals in Toronto raises more questions on the issues of marketing and authenticity. McClinchey (2008) found that ethnic festivals could evoke positive emotions in the visitors while the visitors were creating their own interpretations of whether or not the promotional activities were culturally authentic. McClinchey's study notes the importance of multiculturalism in Ontario, and highlights the value of asking festival attendees' directly about their interpretations on the festival content. Equipped with this understanding of the migrant experience and ethnic festivals, in the next section I develop a thorough theoretical framework consisting the debate between structuralism and materialism, in order to situate dietary acculturation within the larger scholarly debates. 


\subsection{Food is a System of Communication and a Cultural Construction}

\subsubsection{Structuralism and materialism (or developmentalism)}

There are two dominant approaches found in the sociological study of food and eating: structuralism and materialism (which is more recently known as developmentalism).

Structuralists see the cultural significance of food as derived from its networks of relations, which are conventionalized as a result of social interactions (Wood, 1995). Meanings are signified to social actors, and such meanings may change over time. The signifying entities, which are the foods themselves, do not have intrinsic meanings (Wood, 1995). Citing Roland Barthes, Wood uses the example of wine, which signifies a refreshing substance in France, while seen as creating drowsiness in England (Wood, 1995).

Materialists, who are in more recent literature called developmentalists, are known for critiquing structuralists in terms of their lack of consideration for the biological needs and the materials conditions that shape food habits, and they argue that food should be treated as a substance first (Wood, 1995). Furthermore, developmentalists are interested in the influences that historical trends and data have on the contemporary understanding of food. They believe that food supply is influenced by an array of biological, geographical, and technological factors within a given social context (Wood, 1995).

Taking the binary opposition in meaning construction as the basis for his analyses, Claude Levi-Strauss (1965) was concerned with the universal characteristics of cooking. Based on the proposition that most societies cook, Levi-Strauss (1965) indicated that cooking acts as a cultural transformation that turns raw ingredients into cooked food, whereas rotting is the natural process that transforms both raw and cooked food into something uneatable. The three of them form a culinary triangle that intertwines them (Table 1). The meaning in food is understood from the 
oppositional qualities between cooked and raw food, and between eatable and uneatable rotten food (Levi-Strauss, 1965). The knowledge of the process of transformations also reflects human perceptions of nature (see further developments of the culinary triangle in Lehrer, 1969; 1972; Levi-Strauss, 1965). However, the universality of cooking has been criticized for its insufficient empirical evidence (Wood, 1995). The preference for cooked food also varies from culture to culture (Garnweidner, Terragni, Pettersen, \& Mosdøl, 2012; Luo, 2002; Wobber, Hare, \& Wrangham, 2008).

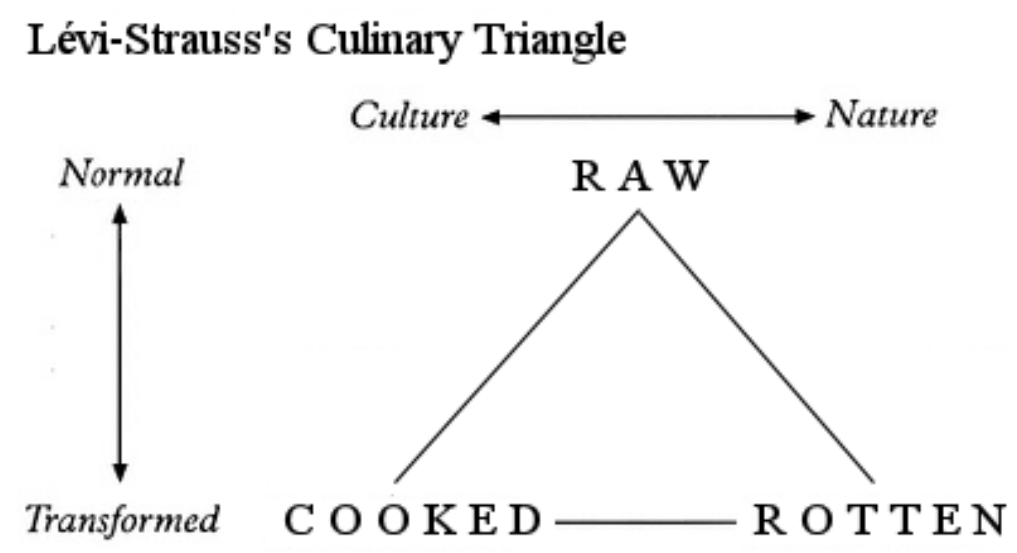

Table 1: Basic culinary triangle after Levi-Strauss (1965)

Motivated by the rejection of the universality of cooking, Mary Douglas' (1984) work emphasized the symbolic aspect of food and eating and argued that food is a symbolic system of communication. Aiming for the theoretical grounding of the study of food, Douglas (1984) adopted a bottom-up instead of a top-down approach and examined the dietary consumption patterns in local households of particular social groups. Food is linked to other systems of communication such as the care of the body and the choice of clothing (Douglas, 1984). Accordingly, the taste of food is discursively framed based on class and to a lesser extent, gender (Douglas, 1984). 
Agreeing that food is a system of communication, Roland Barthes (1997) has argued that food itself has no intrinsic meaning, but the food products, the associated preparation techniques and the related habits create meaning. Barthes (1997) stated that the physical form of food had become less meaningful than the image it signified. Food signifies cultural meanings, and advertising elicits the shared meanings in its consumers; for example, coffee was once considered a stimulant and later was associated with relaxation in advertising (Barthes, 1997). The stimulatory effects were not denied, yet the traditional concept of what coffee stood for was supplanted by the mythology attached to it, which was considered more culturally valuable at the particular time for the specific social group (Barthes, 1997).

Barthes looked at food advertising to reveal the historical development of values, the feelings of inferiority/superiority, and the concept of health as related to food at a systemic level (Barthes, 1997). However, food can be as significant at a personal level as it is at a collective level. Food is a reflection of personal taste, yet the personal meanings associated with a particular food are still positioned within the systemic meanings of the food. This is evident in Barthes' (1997) example of the menu, which is the substantial expression of the alimentary language. The alimentary language determines the foods that are available for consumption, which is based on the existing rules of mores and taboos of what is eatable and what food combinations are legitimate (Barthes, 1997). The consumers are left with an even narrower system of options, within which they need to position their personal preference.

Taste is socially constructed (Bourdieu, 1984). The hierarchy of taste is a reflection of the class hierarchy, and the standards are determined by the taste exhibited by the social elites (Bourdieu, 1984). The bourgeois code of eating is behavioral instead of nutritional through elevating the meal to an aesthetic dimension (Bourdieu, 1984). However, attaching symbolic 
meanings and ritualistic behaviors heavily to the bourgeois meals while ignoring the importance of rituals in proletarian meals also reinforces social hierarchy and makes the concept of cultural capital only real for the bourgeoisie (Wood, 1995). Meanwhile, taste can be used as a form of cultural resistance to the standard of a good taste determined by the upper class, when tastes of necessity are still maintained despite a greater freedom of consumption (Bourdieu, 1984). Bourdieu has characterized his work as constructivist structuralism (Mahar, Harker, \& Wilkes, 1990). Being a constructivist, Bourdieu emphasizes the subjective aspect of his interpretation while by drawing on structuralism, Bourdieu also acknowledges the pre-determined structures and patterns of social practice (Mahar et al., 1990).

Gender differences are also marked on the plate and during preparation. Female cooks are often absent in the public, but in domestic settings the cook is typically a she (Bourdieu, 1984). In other situations, men do not completely disappear but cook to perform for the guests in the domestic settings (Wood, 1995). Being critical of structuralism, Jack Goody has (1982) argued that in Western industrial capitalism, men cook in public or for the elite as chefs. However, public food provision and consumption are very closely associated with the domestic family food systems. The culinary structure mirrors, distorts, or reworks the social structure, which is the structure between gender relations and classes (Wood, 1995). Therefore, dining out can be a special occasion for many, but for others it is an integral part of the daily food consumption (Wood, 1992).

Another anti-structuralist writer on food, Marvin Harris (2007), is often credited as developing the concept of cultural materialism. According to Harris, "sociocultural evolution is an instance of selection by consequences" (Harris, 2007, p. 39). In other words, individual behaviors are either selected for or selected against with respect to their efficacy in serving basic 
human needs through a set of cultural components such as hunting, collecting, agriculture, and manufacturing (Harris, 2007). Cultural materialism rejects the causal relationship between preexisting mind-sets and external behaviors but is open to general scientific principles and solutions, and thus Harris (2007) emphasizes the rationality of people when developing food customs. Rational people respond to their material environments, and weight benefits versus costs over a range of criteria. For instance, they consider whether or not some foods are worthy of producing in terms of economics and effort, and also, if the benefits of the nutritional value exceed the costs of the environment impacts (Harris, 2007). This rationality of food consumption has been harshly criticized by structuralists (Wood, 1995), for whom the definition of eatable food is not a material matter but a social matter (Douglas, 1984; Meigs, 1997).

In her study about the food prohibitions among the Hua people of the Eastern Highlands of Papua New Guinea, Meigs (1997) found that the exchanges of food were linked to social bonds and at the same time they facilitated social solidarity. In a small-scale society, the exchanges of food symbolize relationships of self and other, and the food products are seen as the labor of the known individuals instead of the commercial goods from somebody unknown (Meigs, 1997). Moreover, the relationship an individual has with food can exist independently from the nature of the food, but is determined by the social relationship between the two (Meigs, 1997). Meigs (1997) has illustrated that for instance, the Hua people are forbidden to take food from people who are one generation younger, since food is a medium of exchange that is supposed to be given from the older generation to the younger generation to help them grow. Eating food from the younger generation is symbolically treated as cutting their life span according to the food prohibitions (Meigs, 1997). 
The foodways of a culture reflect its understanding of the basic categories of the world (Douglas, 1984), and thus the prohibitions of the Hua people are consistent with their underlying system of social classification (Meigs, 1997). Furthermore, according to Douglas (1984), setting rules of food prohibition is to protect established categories within the symbolic system of the social group and to avoid violations, as well as to emphasize the group distinction. Pollution is a violation of the category boundary (Douglas, 1984), yet it is also defined discursively in different cultures. In the case of the Hua people, for example, a stranger preparing the food is polluting the food, while in working-class households in the UK that Douglas studied, dirt is a "by-product of a systematic ordering and classification of matter" (Meigs, 1997, p. 101) that pollutes the relatively clean food in a biomedical sense. This cultural distinction also confirms the ambiguity of the meanings attached to food.

Structuralist writers are critiqued by Stephen Mennell (1985) for emphasizing merely here and now while ignoring history. Mennell (1985) called the structuralist approaches an example of process reduction, which depicts the patterns of social relations as stasis and structure, but the society is always changing. Mennell (1985) insisted on the use of the term developmental in contrast to the label materialist. In his own historical survey, Mennell (1985) found that the contrast between seasonal eating patterns and everyday eating habits diminished due to the technological advances that allowed more varieties of food to be available in a longer time.

Mennell partially confirms what Harris has to say about cultural materialism that technological components of the culture enable the exploitation of natural resources, and it is also the specific conditions of the environment that make the exploitation achievable by that culture (Harris, 2007). However, in terms of the diminishing contrast between elite cookery and everyday cookery, Harris (2007) has argued that the members in a given cultural system do not 
share the same weight of the cost-benefits of selected cultural components. For Harris (2007), social hierarchy has a powerful influence in the selection process since the cost-benefits may be calculated to the advantage of superordinate individuals although it does not necessarily lead to adverse consequences for subordinate individuals. Wood disagrees with Harris on this matter and indicates that the standard of a 'good' cookery is still determined by the elite, and the incorporation of peasant cuisine into haute cuisine does not erase the boundary between the two (Wood, 1995). In general, "the stratification of the modern hospitality industry focuses divisions, divisions of class, of gender and of taste" (Wood, 1995, p. 36). The proliferation of such inequalities in the construction of cultural meanings attached to food is once again confirmed by the studies in this area.

The debate between structuralists and developmentalist underpins much food studies scholarship and reveals the complicated nature of human relationship to food. To what extent social norms and material conditions determine our food practices is of particular interest for the study of migrant foodways, where the migrants' cultural norms change slowly over time (if at all) while their material conditions are subject to drastic and abrupt change the moment they arrive in their host country. I next turn to authenticity, a concept prominent in considerations of globalized and migrant foodways.

\subsubsection{The discursiveness of authenticity}

Analyzing the role that authenticity plays in food consumption can provide a rich sense of the discursive strategies in food communication. The concept of authenticity is understood as both "socially constructed and relational" (Johnston \& Baumann, 2010, p. 70). Authenticity is not an objective criterion but is constructed through the perceptions of food producers and consumers and linked to expectations (Johnston \& Baumann, 2010; Lu \& Fine, 1995). In respect 
of the relational aspect, authentic food is often characterized in relation to inauthentic foods (Johnston \& Baumann, 2010). At the same time, authenticity is signified by factors such as the geographic context, the ethnicity of the food producers, the simplicity of the production process, the personal connection with the food producer, the consistency to the established conventions and traditions, and last but not least, the popularity within the corresponding ethnic group (Johnston \& Baumann, 2010).

Culinary authenticity is inseparable from specific geographic context as well as the ethnicity of food producers. Foodies ${ }^{6}$ value foods with specific geographic referents and confer weaker sense of authenticity to placeless foods because they believe that place-specific food represents the version of the food that is different from elsewhere, and the characteristics of that version are best known to the people from that place (Johnston \& Baumann, 2010). Talking about placespecific authenticity is indeed reflecting on the unique flavor of that particular place beyond the food itself (Trubek, 2005). As a result, places are often used as signifiers of authentic foods, which could lead to a superficial and stereotypical understanding of certain places. These signifiers also automatically classify the same food from other places as inauthentic, and narrow the possibilities of innovation and cultural exchange. Nonetheless, global flows of ingredients, and food producers and consumers make it harder to apply the geographically based principle of authenticity in an age of global cultural homogenization (Johnston \& Baumann, 2010).

Simple food is authentic, because it is distanced from the manufactured quality of industrialized food (Johnston \& Baumann, 2010). Food simplicity is characterized by small-scale food production operated by family farmers, cooking with unprocessed ingredients, and selling handmade, labor-intensive foods for passion but not for profits, such as artisanal foods or

\footnotetext{
6 Foodies are defined by Levy and Bar (as cited in Johnston \& Baumann, 2010) as people who are passionate about food and consider food as a form of art.
} 
craftspeople (Johnston \& Baumann, 2010). Simplicity creates nostalgia, and then leads to an emotional bond with the food. For a similar reason, Johnston and Baumann (2010) have found that foodies tend to treat food that is made by an identifiable producer as authentic as opposed to food that is made by unnamed producers in huts or by anonymous laborers in factories. This kind of connection is prevalent in the representation of celebrity chefs in popular media as well because their plates are often linked to their personalities (Johnston \& Baumann, 2010). However, underlining the importance of personal connections overlooks the economic and cultural privileges of eating outside the industrial food system, which is the way that the majority of North American people are fed today (Johnston \& Baumann, 2010).

Personal connections with food producers become less important when assessing the authenticity of food being produced in roadside stands in the context of developing countries (Johnston \& Baumann, 2010). Applying the lens of the exotic other, people mistake their interest in the discovery of a new food for the appreciation of an authentic cuisine (Heldke, 2005). Accordingly, the food that people identify as authentic in the specific culture is often simply what is foreign to them (Heldke, 2005). In this case, defining authenticity becomes an exclusive task that only the insiders to the cuisine are qualified for. The ethno-cultural definition of authenticity leads to its next characteristic that authentic food should be prepared to a set of established standards, conventions, and traditions, and should not be modified in response to new local conditions and ingredients (Heldke, 2005). Heldke (2005) indicated that the tradition was often a reference point to an authentic ethnic cuisine. This notion of authenticity again, has limited how far a cuisine can go by romanticizing traditions while overlooking the complex influences that the new local conditions can have on food habits. More importantly, modifications made in order to respond to new conditions are common in the history of almost 
every cuisine on the globe, and there is no such a thing as a cuisine free from outside influences (Heldke, 2005).

When describing the strategy of choosing an ethnic restaurant, consumers often say that if the crowd in the restaurant is mostly comprised by people from that culture, then the place must be good and authentic because the members of the ethnic group know the real taste (Johnston \& Baumann, 2010). Therefore, authentic food of an ethnic cuisine should not only be made by, but also eaten by the corresponding ethnic group (Johnston \& Baumann, 2010). All in all, authentic food is not only a matter of taste, but also a visible quality that could be communicated by a series of discursive strategies that overlap with one another. Authenticity is also sentimental, as cited in Heldke (2005), Carolyn Korsmeyer in her Making Sense of Taste illustrated that "we understand taste as a cognitive activity involving memory, experience, emotion, etc., then we must necessarily be dissatisfied with any thin notion of authenticity that reduces it to a purely sensory and replicable quality of the food itself' (p. 357). As will become apparent later in this thesis, the notion of authenticity features prominently among those who seek their home culture food while abroad. Despite it being an elusive and problematic term, authenticity proves to be a defining characteristic of "good" home culture food. Beyond the meanings of authentic food, cultural beliefs also determine the definition of health and nutrition, which I discuss in the next section.

\subsection{Coping with Dietary Acculturation}

\subsubsection{Acculturation and unhealthy diets}

Studies concerning the health issues of migrants have pointed out a positive correlation between acculturation and chronic diseases. Wu and Smith's (2016) study exploring the factors contributing to weight gain during Chinese students' stay in America have found that a higher 
rate of acculturation is associated with increased body mass index (BMI), calculated based on height/weight data. This includes "speaking English, having lots of American friends, and liking American food, along with the length of stay in the USA" (Wu \& Smith, 2016, p. 332). Eating more American foods was directly associated with weight gain according to Wu and Smith's (2016) findings.

Similarly, the less acculturated students were less likely to gain weight during their stay in the USA, and their friends were mostly of Chinese origin (Wu \& Smith, 2016). Noteworthily, the participants of Wu and Smith's (2016) study were exclusively born and raised in Mainland China, and the reason under the recruitment criterion was that people from Mainland China experienced similar economic, political, and cultural environments, which were different from Chinese people born elsewhere. This recruitment criterion confirms the correlation between cultural beliefs and the perception on health and nutrition.

Wu and Smith' (2016) findings have been supported by other diaspora studies on acculturation and health. In a study examining the interrelationship between environmental, behavioral and personal factors and BMI, a higher rate of language fluency was also found to associate positively with BMI because language fluency was highly correlated with overall acculturation (Himmelgreen, Perez-Escamilla, Martinez, Bretnall, Eells, Peng, and Bermudez, 2004). Among the Puerto Rican women living in the United States, those who spoke fluent English had significantly higher BMIs than those who did not (Himmelgreen et al., 2004). Same result also occurred amongst second generation Hmong children living in the United States (Franzen-Castle \& Smith, 2014). In the Canadian context, on average, immigrants are less likely to be obese in their early days in Canada (Cairney \& Ostbye, 1999). Moreover, Cairney and Ostbye (1999) found that ethnic group social network had a substantial influence on the 
overweight members of the group for most ethnic minorities. This influence tempers the adaptation to the norms of a Canadian lifestyle, which is associated with excess weight gain with additional years in Canada (Cairney \& Ostbye, 1999; McDonald \& Kennedy, 2005).

Directly linking a North American lifestyle with weight-gain is problematic, because targeting behaviors that are consistent with the dominant food culture in the host country such as consuming sweetened drinks or energy dense snacks could impede the migrants' opportunity to fit in (Anderson, 2003). Furthermore, studies have also denied the inherent healthfulness of some home diets (Bush, Williams, Bradby, Anderson, \& Lean, 19987; Garnweidner et al., 2012 ${ }^{8}$ ), including Chinese diet. In their research comparing the dietary habits of Taiwan-born Chinese women living in America and American-born Chinese women, Schultz, Spindler, and Josephson (1994) found that both of them exceeded the recommended kilocalories as fat per day by $30 \%$, challenging the notion that Chinese people consume diets that are lower in fat. Nevertheless, the authors were critical of this finding and acknowledged that the diet patterns of these participants may not be typical of the diet patterns in China because they resided in relatively affluent areas (Schultz et al., 1994).

Adults in China were shifting toward consuming higher fat and lower carbohydrate diets (Popkin, Horton, Kim, Mahal, and Shuigao, 2001). Under the analysis of diet-related noncommunicable diseases run by the World Health Organization, the costs of undernutrition and the costs of diet-related non-communicable diseases such as diabetes, hypertension and stroke were of similar significance since 1995, but the latter will rapidly grow by 2025 (Popkin et al., 2001). The greater market availability of fruit and vegetables starting in the late 1980s in China had contributed to the stabilization of the cost of undernutrition; however, research had shown that

\footnotetext{
7 See the study about family hospitality between South Asian and Italian population living in the west of Scotland.

8 See the study about Asian and African female migrants' perception on the host country's food.
} 
children and adolescents in China were nevertheless shifting toward overnutrition due to high intake of foods from animal sources and edible oil (Popkin et al., 2001). According to Popkin et al. (2001), nearly half of the adults in China consume a high-fat American diet. Industrially produced trans fatty acid (IP-TFA) is present in Chinese diet, supported by the popularity of French fries, fried Chicken products, micro-oven popcorn, and packs of biscuits (Astrup, 2008). Further impeding a healthy lifestyle, the level of energy expenditure is low since half of the urban workers spend their days in the office or at the assembly line (Popkin et al., 2001). Popkin et al. (2001) have concluded that the globalization of a western lifestyle and especially the American diet might explain the nutrition transition.

As discussed in Chapter 1, GCC food is an integral part of the contemporary Chinese diet, and although less popular than their home culture food, Chinese international students tend to choose GCC food over local cuisine (Cappellini and Yen, 2013). Moreover, the consumption of GCC food might even increase among international students during their stay in the host country because of the limited access to their home culture food (Wu \& Smith, 2016). Barriers for consuming home culture food such as restrained cooking facilities, busy class schedule, limited access to transportation, as well as the cost of food together made GCC food more appealing for international students (Wu \& Smith, 2016).

Negative health impacts caused by an increased consumption of GCC food should not be overlooked. Fast-food from major chains in most countries is characterized by large portion sizes, high energy density, high levels of industrially produced trans-fatty acids, sugar-rich beverages, low fiber and starch, and little low-energy nutrient-dense contents (Astrup, Dyerberg, Selleck, and Stender, 2008). Portion sizes have increased in fast-food outlets over the last 50 years, and studies have shown that the bigger the portion size, the more people consume (Astrup 
et al., 2008). This is true even for foods that people do not find appealing. Wansink and Kim (2005) found that people still consumed 30\% more of stale popcorn when served in big buckets compared to popcorn served in medium-sized buckets. While fast-food chains have been offering healthier choices in recent years, nutritional labels are not very helpful in choosing them. More than $40 \%$ variation can happen in the same product prepared by the same provider in terms of fat calorie content, and thus the nutritional labels provide a limited means for guidance to healthier choices (Astrup et al., 2008). The global prevalence of GCC foods became an apparent dietary factor in my study as well, where participants seemed to favor types of local food that they were already familiar with through GCC. However, nutrition is a complicated social issue, which I discuss next.

\subsubsection{Cultural sensitivity in nutrition communication}

Dietary acculturation occurs when members of a minority group adopt the foodways of the dominant culture (Satia-About, Patterson, Neuhouser, \& Elder, 2002). However, Satia-About et al. (2002) have illustrated that the dominant group can adopt some of the eating patterns and food choices of the minority culture, which explains the popularity of ethnic food markets and restaurants in North America. In relation to the negative health impacts of dietary acculturation, the studies exploring the dietary habits of immigrants living in Europe continued to underline the increased risk of obesity, diabetes, and other cardiovascular diseases from adopting the energy dense and low in nutrition dietary patterns in the host country (Gilbert \& Khokhar, 2008). Immigrants consumed more processed foods from the mainstream market in Europe while giving up some of the healthy components in their native diet such as grains, fruits, and vegetables (Gilbert \& Khokhar, 2008). However, in contrast to the claims asserting the positive correlation between acculturation and chronic diseases, Gilbert and Khokhar (2008) explained that this 
nutrition transition was actually influenced by previously held culinary knowledge and food beliefs of the immigrants. On top of that, the nutrition communication that immigrants received in the host country was also insufficient in terms of cultural sensitivity (Foronda, 2008).

As discussed in section 2.2 , food is culturally constructed, and thereby the definition of a healthy meal could have huge variations from culture to culture. Luo (2002) has found that cold (e.g., on the go sandwiches), raw (e.g., uncooked vegetables), sweet, or large portion sized American foods are not culturally appropriate for most Chinese students. Chinese agricultural practice of utilizing human excreta as fertilizer since ancient times had embedded the preference of cooked food (both meat and vegetables) into the food culture, and the practice is also necessary for food safety purposes (Luo, 2002). Thinking from a biomedical stand-point, the preference of cooked food in China reduces food toughness, which allows for less chewing and easier digestion, and thus Chinese students might fare poorly on raw diets (Wobber, Hare, \& Wrangham, 2008).

Consuming too much cold foods and beverages were also perceived as unhealthy for Chinese students, especially for females (Wu \& Smith, 2016). This perception is heavily influenced by traditional Chinese medical belief system and the principle of "Yin-Yang", which value the balance between positive and negative elements in the body (Wu \& Smith, 2016). Consuming too many cold items that are responsible for the negative elements could break this balance and cause illnesses such as diarrhea, cold, and painful cramps for women (Wu \& Smith, 2016). The preference of warm meal over cold food items is also prevalent in other studies on diaspora and dietary acculturation. Garnweidner et al. (2012) have shown that female immigrants from Asia and Africa think the typical breakfast in the host country, which is bread with spreads, is not a proper meal and is not filling. This is because the female participants were raised in a 
warm meal breakfast culture (Garnweidner et al., 2012).

When assessing nutrition or energy intakes in their meals, immigrants tend to apply different rules respectively to their traditional hospitality meals and to what Bush et al. (1998) called 'alternative cuisines' that contain food items and habits that are not native to the immigrants. Health was mentioned as neither a major nor a minor concern when discussing the logic behind the preparation of their traditional hospitality meals (Bush et al., 1998). For the participants in that study, a good traditional meal should be "filling, nourishing, and giving strength" (Bush et al., 1998, p. 375). In contrast, a completely different language was used when describing what is a healthy alternative cuisine, which was assessed in biomedical terms as balancing in vitamins and proteins (Bush et al., 1998).

Azar, Chen, Holland, and Palaniappan (2013) were interested in the reasons for the overconsumption of festival foods, and they argued that festival foods contributed to the emotional, social and psychological wellness of the immigrants. Furthermore, festival foods were preferred by new immigrants, as they found such foods were tastier than western foods (Azar et al., 2013). However, new immigrants also misconceived festival foods as healthier when they were actually often high in carbohydrates, animal protein, sugar, and fat (Azar et al., 2013). For this reason, Azar et al. (2013) have concluded that the overconsumption of festival foods has increased the risk of developing cardiometabolic disorders.

According to Yates-Doerr (2012), not all communities accept the Western notions of nutrition and some value nourishment over nutrition. When immigrants say that the host country food is not filling, they are in fact contrasting the host country food with the definition of proper meals they have in mind. The unfamiliar food items might be enough for proving nutrients to the body, but they are insufficient in nourishing the mind. Unlike nutrition, which is a technical and 
scientific approach that is "centered upon vitamins and minerals" (Yates-Doerr, 2012, p. 294), nourishment is indeed personal to the individual taste, familial to the tradition, and communal to the culture (Yates-Doerr, 2012). Nourishment undergirds the pleasure and comfort of eating, which "will never be 'a modern fact'” (Yates-Doerr, 2012, p. 310). In this sense, practical dimensions in shopping and cooking should be tailored toward the meaning and value of food held by the ethnic group, in a way beyond the biomedical considerations of nutrition (Anderson, 2003). Adopting cultural sensitivity in health communication is acquiring the knowledge of cultural differences, understanding the significance of certain belief and value, showing consideration and respect, and tailoring to fit the group (Foronda, 2008). This could avoid the potential of "victimizing the ethnic minority" when their traditional recipes or cooking practices are targeted in nutrition communication as unhealthy (Anderson, 2003, p. 313). Being culturally sensitive in health communication could indeed match the advice given by local health practitioners with the native food culture and daily eating patterns (Fagerli, Lien, \& Wandel, 2005). All in all, a culturally sensitive approach can lead to effective communication, effective intervention, and satisfaction in all stakeholders (Foronda, 2008).

\subsubsection{Food accessibility, eating together, and culture learning}

Neglecting food conventions creates barriers for immigrants to access culturally appropriate foods, and more importantly, these barriers have further hindered international students from participating in language and culture learning. Most Chinese students consumed more Chinese

foods for dinner than the other two meals, which resulted from their busy schedule and the lack of Chinese foods on campus (Wu \& Smith, 2016). Likewise, a participant in Cappellini' and Yen's (2013) study has described food on campus as “[representing] an absence of familiar dishes, ingredients, brands and meal conventions" which she could not tolerate on a daily basis 
(p. 972). Wu and Smith (2016) have suggested that a list of grocery stores and transportation options need to be provided during new student orientation; however, other studies have revealed that Chinese students tend to be well informed about where to get Chinese ingredients and which local Chinese restaurants serve good food, and in this case they might even have a better knowledge than local students (Cappellini \& Yen, 2013; Welsh, 1998). Therefore, the source of information is not as big a burden as the time and effort that required for getting Chinese food (Welsh, 1998). Learning to cook is the only route to emotional and physical sustenance considering the limited access to Chinese food (Brown et al., 2010), although many Chinese students never cooked before in China or they recently learned a bit as part of the preparation of living abroad (Giddens, 1991). In their study, Wu and Smith (2016) found that the accessibility to a kitchen and other cooking facilities could make big differences in the food intake of the students. Increased sense of self-efficacy and independence are resulted from the students' capacity to cook (Cappellini \& Yen, 2013; Giddens, 1991; Kim, 2001; Wu \& Smith, 2016).

The pleasure of eating is often initiated in groups, and this is particularly true for collectivist cultures in East Asian countries that value shared experiences and group interactions (Triandis, Bontempo, \& Villareal, 1988). Therefore, Chinese students often felt that their home culture food was not meant to be eaten alone but to be shared with their compatriots (Counihan \& Van Esterik, 1997), even though they were aware of the adverse influences on their language and culture learning (Brown, 2008). Moreover, students have also noted the influence of roommates on food choices (Wu \& Smith, 2016). Food constructs and maintains social relationships (Counihan \& Van Esterik, 1997). People invite those they have no kin relationships to partake a meal while sharing personal stories within their private space, "they are engaging in forms of sociability, delineating lines of intimacy and distance" (Julier, 2013, p. 13). Thorough but loose 
social networks could be established through shared meals at home and also through eating out as a group (Julier, 2013).

When Chinese students cooked together, not only the content of the meal was Chinese, but they also recreated the Chinese meal structure, serving all dishes at the same time and serving meat, vegetables, soup, and rice (Cappellini \& Yen, 2013). Over time the students made cooking Chinese food every night a routine, and some local products were also being integrated into their meals (Cappellini \& Yen, 2013). Similarly, Garnweidner et al. (2012) also found that along with the increased years of residence, the immigrants adopted some local ingredients and modified them with their native preparation methods, and in doing so transformed the foreign elements into culturally appropriate meals.

Nevertheless, the adverse impacts on language and culture learning due to eating home country food within the mononational friendship groups require more attention from the host country. The importance of culture learning has been emphasized in fields of cross-cultural psychology and intercultural training (Cushner \& Mahon, 2002). According to Cushner and Mahon (2002), international students need to develop such skills in order to work and live effectively among individuals from cultures other than their own. The development of culture learning skills requires long-term, direct, and meaningful interactions with people from different cultural backgrounds and in contexts that are unfamiliar to them (Cushner \& Mahon, 2002). Unfortunately, international students often feel disadvantaged by poor spoken English, which leads to feelings of anxiety, shame and inferiority (Brown, 2008). Students also suffer from feeling less confident to engage in class discussion and to perform social interactions in English (Brown, 2008). As a result, students choose to retreat into mononational communication with their compatriots in order to avoid the stress caused by language problems, which further 
discourages language learning (Brown, 2008). Educational institutions aim to facilitate language and culture learning thus need to take the physical and mental benefits of consuming home culture food within the mononational friendship groups into consideration.

Through drawing on literature on hybrid identity and different models of consumer acculturation, this study explores the impacts of festivals and festival foods on hybridization and identity formation. Additionally, literature on ethnic festivals broadens our understandings of the symbolic and the commodified natures of ethnic festivals, and the possible attendance motivations. From the sociological literature on food and eating, we have seen that food consumption is shaped by both social structures and material conditions, and the meanings of food are connected to social hierarchy and power dynamics. The cultural beliefs about health and nutrition, as illustrated by literature on immigrant food choices, and the barriers of acculturation and food consumption encountered by international university students, have complicated our understanding of the relationship between dietary acculturation and language and cultural learning. 


\section{CHAPTER 3: THEORETICAL FRAMEWORK AND METHODOLOGY}

\subsection{Theoretical Framework}

The theoretical framework for this study comprises three conceptual lenses. First, the study utilizes the concept of hybridity and its place in the process of identity formation. Assessing the fluidity of identity using different models of consumer acculturation, I aim to understand the influences of food consumption in identity formation. Further, the study adopts a social constructivist worldview in order to interpret Chinese students' perceptions of ethnicity and food in Ottawa. Here, I illustrate that meanings are both subjectively constructed by the individuals and conferred upon them by culture. Finally, I apply a cultural lens to examine the changes in food habits and the meanings of consuming home culture food. In other words, I am interested in the role of cultural beliefs in making food decisions, and how they may differ from the scientific notions of health and nutrition.

\subsubsection{Hybridity and models of consumer acculturation}

The concept of hybridity is useful for unpacking the process of identity formation of Chinese students. According to Pieterse (2006), hybridity concerns the mixture of different phenomena, and the categories can be cultures, nations, ethnicities, and classes, among others. Hybridization is the site that crosses categories and brings the separate together, which also destabilizes or even subverts the hierarchical relationship between hegemony and minority (Pieterse, 2006). In the process of hybridization, separate categories can co-exist without merging with one another.

Studies have shown that Chinese students tend to form mononational friendship groups and interact mostly with their compatriots in order to consume home culture food together as well as to avoid stress and the feeling of inferiority due to language barriers (Brown, 2008; Cappellini and Yen, 2013). Home culture food is often consumed to reinforce a Chinese identity or to resist 
the adaptation to the host country (Cappellini and Yen, 2013). Anderson (1983) had coined the term 'imagined community' to explain this sense of belonging. According to Anderson (1983), the nation is an imagined political community that is both "inherently limited and sovereign" (p. 6). Not only nations, but all communities that are too large to have face-to-face interaction with every single member are imagined because the communion only exists in the minds of the members (Anderson, 1983). Nations are understood and distinguished through the associated and pre-existing cultural systems.

At the same time, Chinese students also interact with the non-Chinese population in the host country and encounter non-Chinese life-ways. As mentioned earlier, Brown et al. (2010) had shown that international students were also open to dishes prepared by each other and new foods in the host country. Additionally, many Chinese international students regularly interact with their families and friends in China through social media (Hall \& Sivakumaran, 2014), and the interaction enhances the transnational link they have with China as a home (Huang \& Yeoh, 2005). According to Zhang and Guo (2015), encountering different cultural life-ways generates new identity features. The bonds that Chinese students have with their loved ones at home might also be influenced by altered or lost food-related customs. Hybridity plays out in everyday life through intertwining with these social bonds and dietary behaviors. The term 'gastrodynamics' coined by Rao (as cited in Fieldhouse, 1995) is used to specifically explain the changes in dietary patterns of the Chinese students caused by altered food availability, discovery, and innovation.

Framing Chinese students in Ottawa as consumers, I aim to use their experiences with food consumption to assess Cleveland et al.’s (2009) dual process model of adaptation, which separates ethnic identity and acculturation as two distinct processes. In addition, I also assess Ustuner' and Holt's (2007) model of the dominant consumer acculturation, which questions the 
capacity for migrants to construct a hybrid identity due to their insufficient capital resources. Looking at the food consumption patterns of the Chinese students through these two lenses, I aim to understand: to what extent does food consumption influence identity formation; and also, how do the Chinese students mix their Chinese identity with the host culture through food consumption and attending ethnic food festivals? In doing so, I try to unpack the impacts of economic, social, and cultural capital on the Chinese students' food choices as well.

\subsubsection{Social constructivist worldview on ethnicity and food}

According to Creswell (2014), a social constructivist worldview relies as much as possible on the participants' interpretation of the social context in which they live and work. However, subjective meanings are not simply imprinted on individuals but are shaped historically and socially (Creswell, 2014). This research relies on a social constructivist worldview about ethnicity and food, and argues that meanings associated with both ethnicity and food are results of social and cultural construction. In terms of ethnicity and ethnic festivals, I treat them as both the heritage of the culture and the commodity of the culture. Seeing culture as a form of heritage allows us to consider the social and historical influences on Chinese students in Ottawa, since individuals construct meanings through social interactions, and through historical and cultural norms conferred upon them (Creswell, 2014). Seeing culture as a commodity is again allowing us to frame Chinese students as consumers, and this frees them from seeking understanding of the social context merely within ethnic ties. The concept of cultural performances achieved through the commercialization and marketing of place and culture can also be addressed. All ethnicity is symbolic, and although the constructivist worldview of ethnicity emphasizes subjective interpretation of the cultural symbols, the interpretation cannot exist in isolation from the power relations within the larger social fabric. 
The debate between structuralism and materialism in the sociological study of food and eating are also incorporated into the constructivist worldview of food. The boundaries between these three theoretical frameworks are challenged and re-described in this research, and this practice is widespread in the realm of literary theory (Culler, 1982). Recognizing the meanings of food as intertwined with social structures, material availabilities, and personal constructions provides better interpretations on the food behavior of Chinese students.

The constructivist worldview would agree with structuralists that the cultural significance of food is established through social interactions (Wood, 1995). Food is not only a material matter but also a social matter, and it is a medium of expression of the relationships within the family or within the larger social group (Douglas, 1984; Meigs, 1997). However, the constructivist worldview would also agree with materialists and the developmental theory that the contemporary understanding of food is influenced by biological factors and historical trends within a given social context (Wood, 1995). Namely, the collective stomach must be fed before feeding the collective mind (Harris, 2007). As much as the theories are distinct, they cannot exist in isolation from one another and hence this research utilizes all three of them in the analysis of the food choices made by the Chinese students.

To be more specific, this research adopts Douglas' (1984) theory regarding the influences of social relations on food consumption. This theory is used to understand the choices the Chinese students made for home cooking and eating out. Dietary patterns are not only associated with social relations but also are connected to other systems of communication such as class and gender (Bourdieu, 1984; Douglas, 1984). The gendered division of labor and the hierarchy of taste associated with class are not necessarily maintained to the same degree in the contemporary culinary world, but the existence of such inequalities should be used to frame the analysis. 
Furthermore, I agree with Barthes (1997) that food has no intrinsic meaning yet it signifies cultural meanings that are far more significant than its physical form. At a personal level, individuals can reflect their personal taste through food consumption; however, the personal meanings are embedded within the systemic meanings of the food (Barthes, 1997). The influences of the systemic meanings should be acknowledged when interpreting the meanings constructed by the Chinese students. In addition, even though Harris' (2007) cultural materialist perspective regarding the rationality of people in making food decisions has been harshly criticized, I still find it useful in interpreting the amount of deliberateness that goes into the food consumption patterns of Chinese students in Ottawa considering the challenges imposed by moving into a new environment.

The basic understanding of authentic food in this research is established upon the notion that authenticity is constructed through individual perceptions and linked to expectations (Johnston \& Baumann, 2010; Lu \& Fine, 1995). The signifiers of authenticity, revealed by Johnston and Baumann (2010), such as geographic context, food producers' ethnicity, simplicity in production, personal connection, true to pre-existing conventions and traditions, and popularity within the corresponding ethnic group are used to unpack the Chinese students' perceptions of authentic food.

\subsubsection{Looking at nutrition transition through a cultural lens}

The definition of a culturally appropriate and healthy meal often varies from culture to culture, and is based on historical practices in agriculture, traditional belief systems and principles of food and nutrition, and social relations (Garnweidner et al., 2012; Gilbert and Khokhar, 2008; Luo, 2002; Wu \& Smith, 2016). Thereby, instead of applying a biomedical lens, 
I look through a cultural lens in assessing the correlation between cultural beliefs and nutrition transition.

According to Visser (1999), "food is closely interwoven with culture — change the diet and you will change the culture, and vice versa" (p. 2). Food change can lead to an enrichment of availabilities, and an increased security when the original food habit of the culture is no longer self-sufficient (Visser, 1999). However, food change also has unforeseeable consequences that are not necessarily beneficial for the culture (Visser, 1999). This is a made clear by Visser's (1999) example of the consumption of sugar by the British working class during the Industrial Revolution, which the goal was to be energized cheaply and quickly. The food changes are continuing to affect today's food culture in Britain, as sugar is present in so many aspects that characterize the British cuisine (Visser, 1999). Adopting another culture's diet often fulfills the functions that the culture expects the food to serve beyond nutrition purpose, and in the case of the British laborers, sugar was seen as fuel in the maintenance of labor force due to its economic efficiency (Visser, 1999).

More profound implications of food change were predicted by Visser (1999), saying that the introduction of hamburgers into China would increase the importation of meat because the land resource for raising cattle was scarce in China. Thereafter, since the diet structure has changed from sharing dishes to individuals eating their own hamburgers, the Chinese would eat alone more with less food variety (Visser, 1999). All in all, Visser (1999) believed that Chinese culture would not remain untouched after adopting hamburgers into its diet.

Informed by Visser, I am interested in knowing the role of cultural beliefs play in food production and consumption, rather than evaluating the role of scientific knowledge in making food decisions. The negative impacts on health illustrated in Chapter 2, such as the increased risk 
of developing chronic diseases are still relevant for this analysis as they revealed the drawbacks of the existing means of food communication and the consequences of inaction.

In general, the understandings about the barriers in accessing both healthy and culturally appropriate foods are inferred from the empirical studies in Chapter 2. The educational institutions in the host country are somewhat indifferent about the home food culture of the international students, which is reflected by the limited food choices on campus (Cappellini and Yen, 2013; Wu \& Smith, 2016). Moreover, the consumption of GCC foods is often increased in the host country because they are more familiar to international students compared with host country foods (Cappellini and Yen, 2013; Wu \& Smith, 2016). Additionally, nutrition communication in the host country is often inappropriate for guiding migrants due to the different meanings and values associated with food in different cultures (Azar et al., 2013; Bush et al., 1998; Yates-Doerr, 2012). Lastly, consuming home culture food with compatriots contributes to emotional benefits yet it has adverse influences on language and cultural learning (Azar et al., 2013; Brown, 2008; Cappellini \& Yen, 2013; Counihan \& Van Esterik, 1997). These findings are used to compare and contrast with the narratives about the Chinese students' everyday food consumption.

\subsection{Research Design}

\subsubsection{Methodological approaches}

Relying on a constructivist worldview, this research aims to unpack the ways in which the participants construct meanings in their social settings (Creswell, 2014). Rather than starting with a theory, this research inductively develops patterns of meanings by focusing on the specific historical and cultural contexts of the participants and relying on the views of the participants. This project adopts a qualitative approach to explore the roles that ethnic food festivals and 
festival foods play in the lives of Chinese students in Ottawa. In addition to considering festival attendance, attention is also given to the ways in which the Chinese students celebrate traditional festivals at home, by purchasing or making of traditional Chinese festival foods. Moreover, decoding the Chinese students' daily food consumption patterns can help us to understand the social and infrastructural barriers they encounter in everyday life. A qualitative approach is more adequate than a quantitative approach in elucidating issues of emotion and identity from foodrelated topics, because participants could raise additional or complementary issues through answering open-ended questions, and these issues enrich the study's findings (Beardsworth \& Keil, 1992; Lupton, 1996).

\subsubsection{Method selection}

The methods chosen for the data collection include participant observation and semistructured interviews. Since this research aims to understand how the participants construct meanings regarding festival activities and food consumptions, being a participant is essential for understanding the social settings and interpreting the audience experiences. In terms of conducting interviews, according to Brown et al. (2010), only in conversation are participants able to fully express their experiences in dietary acculturation. Furthermore, participants can also reflect on the feelings about the food they consumed in conversation, because food is intertwined with emotion (Locher et al., 2005). While focus groups can create an environment for such discussions, they also run the risk of bias due to people's differences in talkativeness, which is not a risk associated with in-depth interviews (Cappellini and Yen, 2013).

\subsubsection{Site selection}

The 2018 Ottawa Night Market Chinatown (the Night Market) is the primary site for the participant observation and the interviewee recruitment. The Night Market is a 3-day-long Asian 
food festival hosted by the non-profit organization Asian Food Fest and it is sponsored by local businesses (Ottawa Asian Fest, 2018). Chatime is the 2018 head sponsor, which is a bubble tea franchise shop located next to the Royal Arch of Chinatown in Ottawa (Ottawa Asian Fest, 2018). Other sponsors are local Chinese restaurants, local Chinese media, and local businesses such as Costco, Casino du Lac-Leamy, and Bank of Montreal, among others (Ottawa Asian Fest, 2018). The Asian Food Fest has hosted Asian food festivals several times in Ottawa in the last couple of years, however, according to their Facebook page the 2018 version was set to be the biggest one yet in Chinatown (Ottawa Asian Fest, 2018).

The 2018 Night Market started on Friday, July 27 at 6 pm and it lasted through the whole weekend until Sunday the $29^{\text {th }}$ at night. The timing of the Night Market resonated with Bankston' and Henry's (2000) finding that the festivals were always scheduled on weekends in order to respond to the modern workweek. The whole Royal Gateway of Chinatown was blocked for the Night Market in front of the Royal Arch on Somerset and Bronson (see Figure $1 \& 2$ ). Entry to the festival was free, and the attendees could buy food as they chose. Vendors lined up on the sides of the streets, making and selling mostly Asian foods and drinks in booths under small tents while sponsors occupied some booths for display. Some vendors were also selling crafts and foods that would be considered non-Asian such as silver jewelry and gelato. 


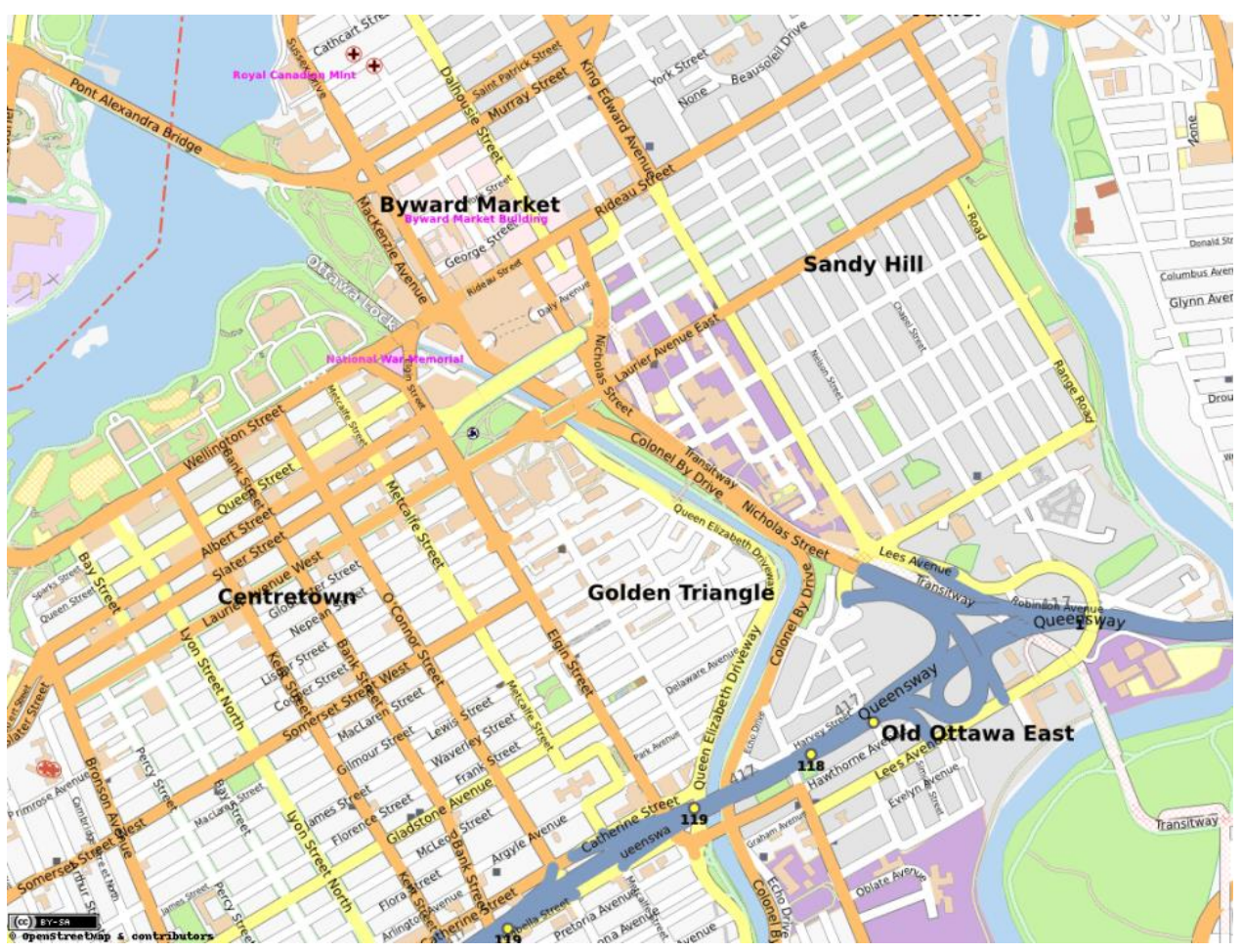

Figure 1 Map of the east end of downtown Ottawa

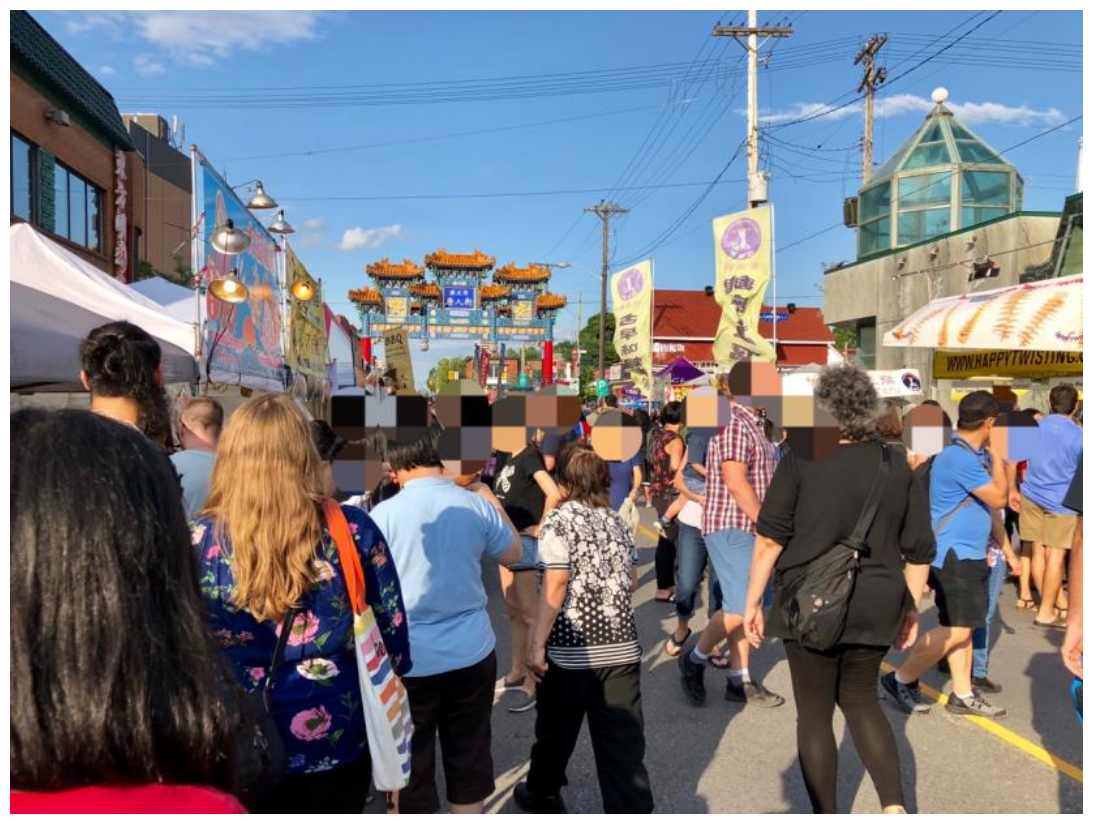

Figure 2 The crowd at the 2018 Asian Night Market (by Shihan Liu). 


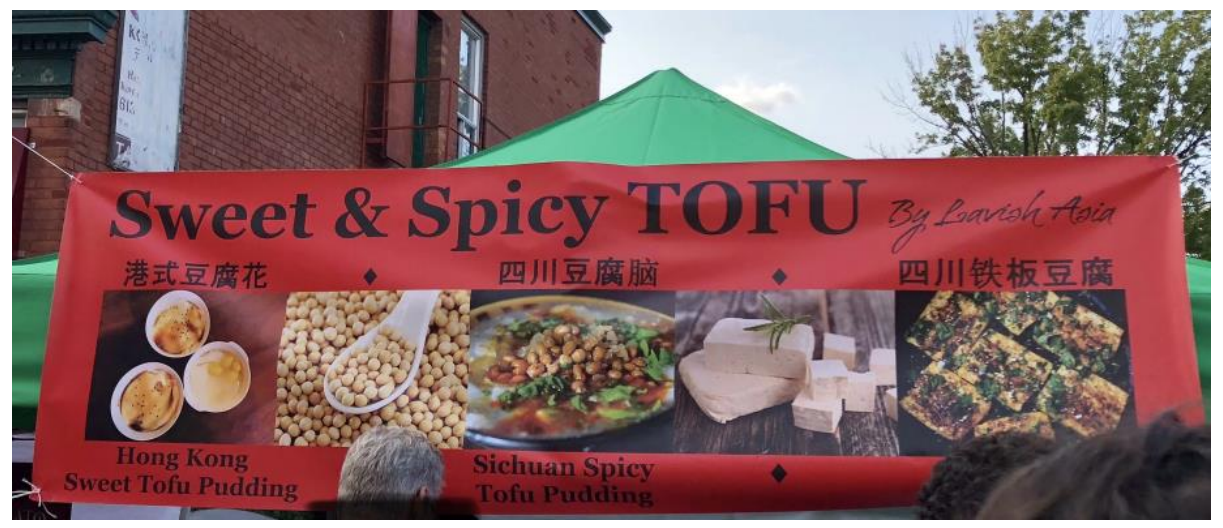

Figure 3 The decoration of the Tofu stand at the Night Market (by Shihan Liu).

The names and the pictures of the foods were used to decorate the booths (see Figure 3). Some of the names were written in English only and some of them were written in Chinese with simple English translations (see Figure 4 \& 5). The vendors were mostly Asian, and many of them could speak both English and Mandarin to their customers. Resembling the spatiality of modern shopping malls (Bankston \& Henry, 2000), the Night Market also had free performances for everyone usually staged at the center of the festival space, including street shows put on by acrobats, hip hop dancers, and musicians (see Figure 6).

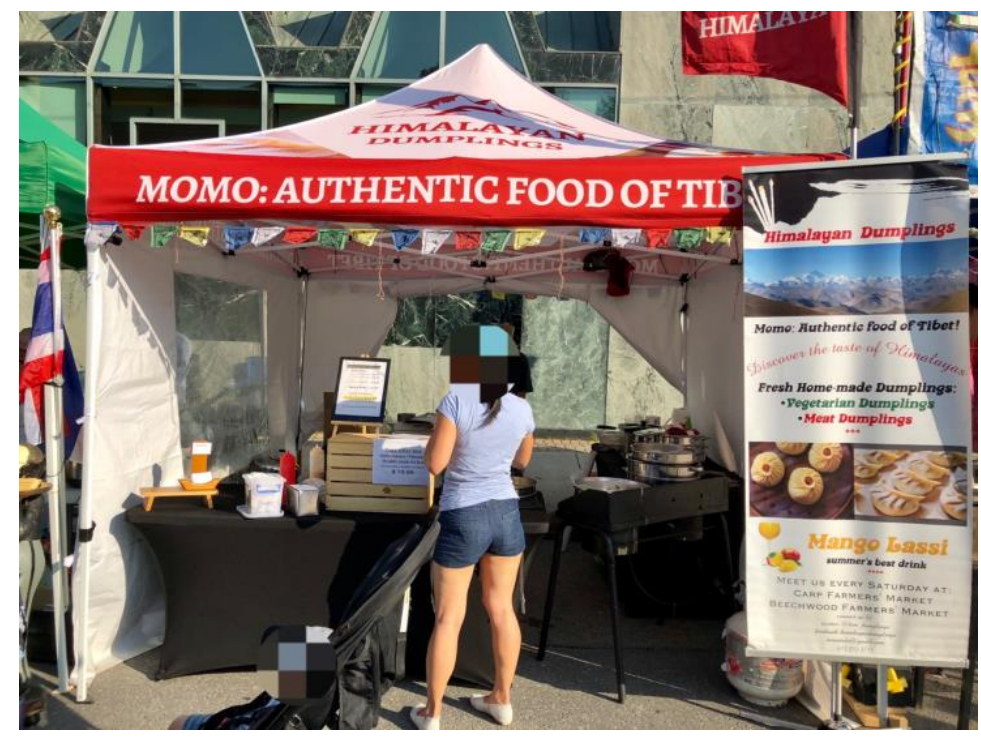

Figure 4 The all English decoration of the Tibetan food stand (by Shihan Liu). 


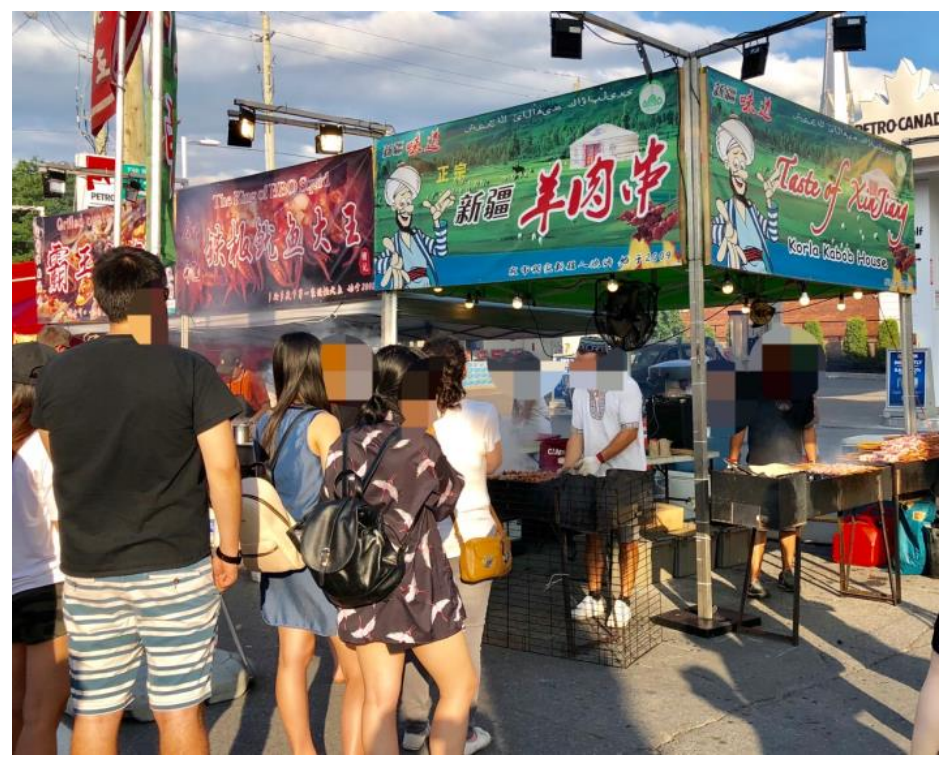

Figure 5 The Chinese decoration with the simple and small English translation of the Kabob stand and the BBQ Squid stand (by Shihan Liu).

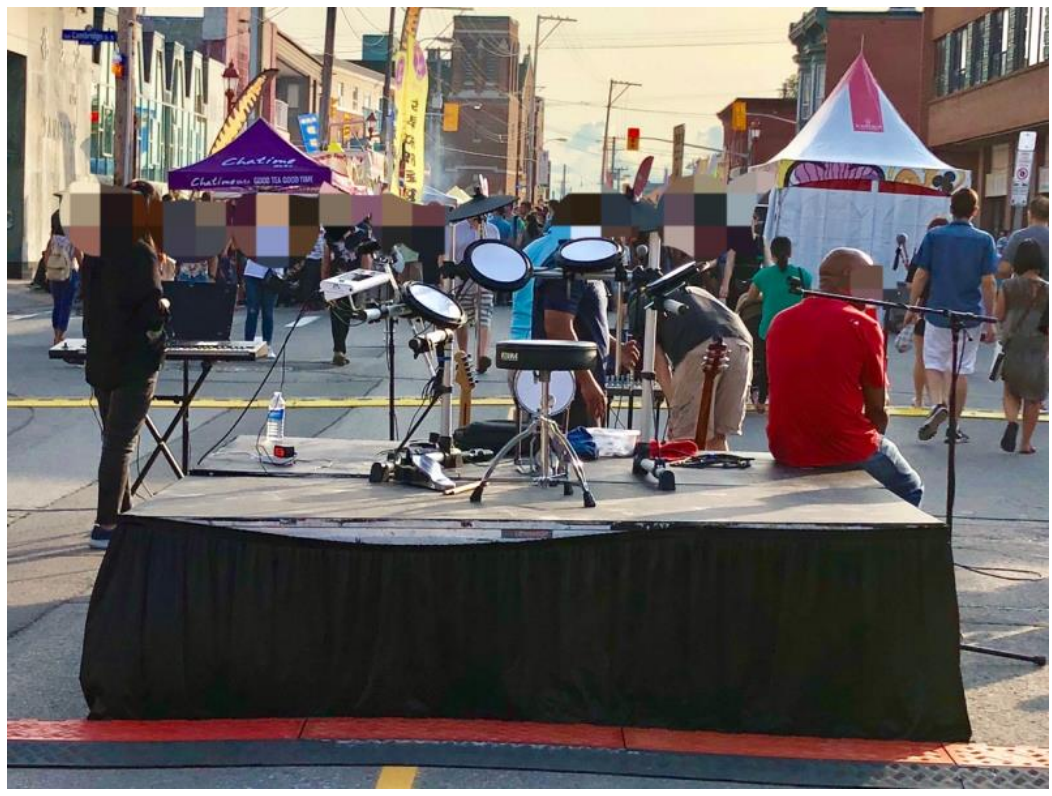

Figure 6 The set-up of the band at the Night Market (by Shihan Liu).

The Night Market was chosen because of its popularity as an Asian food festival in Ottawa amongst Chinese students, which maximizes the chance of collecting a rich amount of data relating to attendee experiences. During the interviews, the Night Market served as an icebreaker 
of the conversation between the researcher and the interviewees. Sharing experiences at a food festival creates a laid-back environment for the interviewees to reflect on their daily food habits that are more abstract and personal. Additionally, the signifiers of authenticity presented by visual elements such as the decoration of each booth and performances during the festival provide opportunities for exploring the concept of cultural performances (Barkataki-

Ruscheweyh, 2013), which describes the situation when a culture is presented and interpreted in a stereotypical and superficial way. Likewise, the Night Market is a relevant site for examining what McClinchey (2008) has termed as the commercialization and marketing of place and culture.

\subsubsection{Participant selection}

The interviewees for this research were either post-secondary Chinese students in Ottawa, or those recently graduated from post-secondary educational institutions in Ottawa. All fifteen of them were over the age of 18 and spoke both Mandarin and English. Attending the 2018 Night Market was a pre-condition for participation in research interviews. All genders were included and there was no other relevant quota to be applied. I recruited a total of nine female and six male participants. The interviewees' recency of arrival varied from one year to seven years. The interviews were conducted from the end of July to the middle of August 2018, and they were done in mutually convenient public locations such as coffee shops and libraries or through phone calls.

Defining Chineseness was a problem that I faced when deciding the criteria for interviewee recruitment. The contemporary meaning of Chinese is more complicated than ever due to immigration and the emergence of the idea of 'greater China,' which recognizes the political and cultural differences between Mainland China, Hong Kong, Macau, and Taiwan. The meaning of 
Chinese is indeed characterized by "deterritorialized, transnational, and translocal 'communities"” (Cheung and Wu, 2004, p. 1). As mentioned in Chapter 2, in their studies exploring the dietary acculturation of Chinese students in America, Wu and Smith (2016) addressed this problem by only recruiting students who were born and raised in Mainland China. My approach was to rely on the students' self-identification. First of all, the interviewees should be self-identified as Chinese, which was the first thing I asked during the recruitment. However, some students were born and raised in China, yet they might have given up their Chinese citizenship for a Canadian citizenship after they came to Canada since dual citizenship is illegal in China. In this case, I still treated them as Chinese nationals if they identified themselves as Chinese, because their post-secondary educational experiences would not be very different from other Chinese international students.

\subsubsection{Data collection}

\section{Participant Observation}

For participant observation, I had accessed the site only once and adopted a covert role as a participant-observer in the Night Market. The covert role required additional ethics approval, and I received ethics clearance from the Carleton University Research Ethics Board-A (CUREB-A) before conducting any fieldwork. The research participants were not a vulnerable population, and by adopting a covert role, I did not impose any additional risk than what they would experience in their daily lives. Moreover, adopting an overt role has the potential of altering the behavior of the festival attendees, and hence a covert role was necessary.

During the time as a participant-observer, I took notes regarding my own experience as well as my observations of other festival attendees, the set-up of the festival, the foods and the vendors at the festival, and the overall environment, on a cellphone from entering the site until 
exiting. The whole process lasted one and a half hours. Once I exited the site, I immediately converted the jotted notes into detailed descriptions, which were narrative notes with my selfreflections on my perceptions and feelings as a participant. I also took photos of the foods, the attendees, and the environment, which was not something that would have given me away as a researcher - many attendees were documenting their experiences too, since the festival was a public site. I ensured that the photos of attendees were non-identifying, by taking a photo from behind and from a distance, and by blurring the attendees' faces. Photos were taken in order to remind myself about the details of the festival, and also, for illustration purpose in the analysis.

\section{Interviews}

From the end of July 2018 to mid-August 2018, fifteen semi-structured, one-on-one interviews were conducted after organizing the field notes, and in this way my own experience could provide the background knowledge for understanding the experiences of my interviewees. As this is a qualitative study with a specific population and a mostly predetermined set of questions, saturation is reached with a relatively small sample - commonly accepted saturation estimate for a single group of participants is approximately fifteen interviews. In my interviews I noted that no new themes or findings were emerging in the last few interviews, suggesting that saturation was reached (Fusch and Ness, 2015). Some of the interviewees were randomly recruited on site during the festival because it was hardly possible to obtain a list of the festivalgoers considering practical and ethical issues, and there was no relevant quota to be applied either. This was not to suggest that every person at the Night Market had an equal chance at being selected because this research only targeted Chinese students. Therefore, every festival attendee who fit the aforementioned recruitment criteria had a random chance. Nonetheless, the representativeness of the interviewees by no means could be guaranteed under this sampling 
method, and thus I was being self-reflexive in order to minimize bias such as only talking to people who seemed friendly. Since I am also a member of the Chinese student community in Ottawa, I did encounter someone I knew at the festival. In this case, I explained my research to them the same way as I did for other festival attendees and I especially reminded them that their participation is voluntary. Nevertheless, I was primarily aiming for non-friend festival attendees. I accessed the site twice for the interviewee recruitment. During the first day of the Night Market, I went there with a male companion who was a visible non-Asian. I approached several attendees, explained my study and asked if they met the criteria and would be interested in participating. If they answered yes to both those questions, which five of them did, I asked if they would share their contact information. No one refused, and I got five names and email addresses during the first day. However, I could not guarantee that all of them would actually respond to my email in the future. The first five potential interviewees were all females, since there seemed to be more female attendees at the festival than male attendees.

The second day of the recruitment went easier than the first day. This time the festival was even more crowded than the first day, and I went there with another male companion who was Chinese. We got ten names down easily within approximately thirty minutes, and I got only one rejection during the second day. Unlike the first day, the ten potential interviewees were composed by a good mix of females and males, and all of them went to the festival with one or more companions.

However, as I expected, only six out of the 15 interviewees recruited onsite actually agreed to be interviewed, and thus I posted the recruitment poster on my WeChat "moment" (the most popular social media platform among Chinese students), where the message could be seen and be shared by my WeChat friends. In the WeChat post, I asked the users to not respond directly on 
my "moment" but to email me directly if interested. Snowball sampling was also used as I asked my interviewees to tell other festival attendees they knew about the research, and I directly responded to those who indicated interest through email. As mentioned above, six out of the 15 interviewees were recruited onsite, five were recruited through WeChat and four joined through snowball sampling.

My sample also responds to Cappellini' and Yen's (2013) call of overcoming the geographical homogeneity of participants, since the participants in their research all came from similar urban areas in China and they all studied in the same university in the UK for a one-year business program. The participants in my research, though not selected purposefully, come from various areas in China and also attend different post-secondary institutions in Ottawa. Additionally, the wider range of their recency of arrival of my participants helps us to understand the role of temporality in dietary acculturation.

I also knew eight of the 15 interviewees due to the low response of the onsite recruitment. I acknowledge that the participants whom I know might feel closer to me than those I do not know, which could make their willingness to share private stories higher than the others. However, a higher willingness to share personal stories can also enrich the data and thus benefit the research. Finally, eight interviews were conducted through phone calls whereas seven interviews were conducted in person. The consent forms were sent to the interviewees through email, asking for their consent to be audio-recorded during the interviews. The interviewees were also given the option of being interviewed either in person or by phone, as well as the option of doing the interview either in Mandarin or English, and all of them chose Mandarin. My supervisor and I decided not to translate the entire transcripts but to translate the phrases that were directly used in the thesis, since the time spent on translating the entire transcripts would 
not contribute much to the research results. Each participant received a $\$ 10$ Starbucks gift card as a token of gratitude, and I believed that it was necessary to reward the interviewees for their time and the willingness to share personal stories.

Each interview took 30 to 40 minutes to complete, and the interviewees were asked to reflect on their own experiences at the festival, including the foods they tried, the activities they participated in, and their observations of other festival attendees and the festival environment in general (see Appendix B for the interview guide). Later on, I also asked the interviewees to share the ways in which they celebrated both Chinese festivals and local festivals in Ottawa. The interviewees revealed some of their leisure activities during this exercise and they were also asked to compare those with the things they do during festivals in China. In the last section of the interviews, I asked questions regarding the daily dietary pattern of the interviewees. The interviewees talked about their perceptions on the restaurants in Ottawa, and some of them also shared their cooking skills with me. This section provides insights on the ways in which the interviewees construct meanings associated with authenticity, health, and other food and ethnicity related concepts.

As a member of the Chinese community in Ottawa, I also recognize that my own background has shaped my interpretation of the interviews. However, the benefits of being an insider exceed the drawbacks of insider bias, since my historical and cultural experiences have equipped me to understand the social settings of the interviewees better than non-Chinese researchers would. Moreover, the interviewees were able to express themselves more fully in Mandarin with me, as Kay and Kempton (1984) have shown that language barriers are beyond the ability to speak because cultural norms and values are coded in language. Still, I was 
constantly cautious of the potential bias I was bringing to this project, and discussed this with my (non-Chinese) supervisor regularly.

\subsubsection{Data analysis}

The research data comprising my field notes of the participant-observation and the fifteen interview transcripts were coded and analyzed with the help of NVivo ${ }^{9}$. I choose to code my field notes together with the interview transcripts set, although the latter contains much more information than the former. Basically, I treated myself as another participant at the Night Market since my field notes merely described my thoughts and feelings as a festival attendee.

Informed by the theoretical framework, the findings were divided into four sections, and Table 2 shows all the codes and subcodes applied in the analysis. In order to understand the place of hybridity in the process of identity formation of the Chinese students in Ottawa, I coded the research data around the food-related changes in the lives of the participants and the collective consciousness of the participants as Chinese students. I used food-related changes to evaluate the different models of consumer acculturation and to understand whether or not the participants became hybrid, and if yes, to what extent? Thereafter, I also unpacked the influences of food consumption on their collective consciousness as Chinese students in order to interpret any influences on identity formation.

Applying a social constructivist worldview to ethnic festivals, the interview data were coded around the attendance motivations of the Night Market and the festival-related changes in the lives of the participants. These two codes are used to answer the question of why do the participants attend local Chinese festivals and what are the impacts of festivals and festivals foods on the participants' identity and wellbeing.

9 NVivo qualitative data analysis Software; QSR International Pty Ltd. Version 12, 2018. 
I also developed the code for choice making, which includes subcodes such as home cooking, food retail store choosing, and restaurant picking. The code and its subcodes were used to answer the question of how and why the participants made their food consumption choices regarding home cooking and eating out. The influences of social, cultural, and material conditions on the decisions were taken into consideration as well. Finally, the code related to standards for food authenticity is applied, so that we could interpret the ways in which the participants constructed authenticity as well as its role in food consumption.

To unpack the role of cultural meanings in the perception of healthiness, the next code in the analysis pertains to food-related health concerns. The code of "cultural appropriateness" was used to uncover the meaning of that phrase from the participants' experiences at the Night Market and in other food-related situations. The code of group activities was divided into two subcodes involving food consumption activities and non-food related activities, and at the end of this section, I aimed to evaluate the benefits of forming mononational friendship groups with its impacts on language and cultural learning.

\begin{tabular}{|c|c|c|}
\hline Code & Definition & Subcode(s) \\
\hline Food-related Changes & $\begin{array}{l}\text { Food-related changes in the } \\
\text { lives of the participants. }\end{array}$ & Not applicable. \\
\hline Collective Consciousness & $\begin{array}{l}\text { Collective consciousness of } \\
\text { the participants as Chinese } \\
\text { students in Ottawa. }\end{array}$ & Not applicable. \\
\hline Attendance Motivations & $\begin{array}{l}\text { The attendance motivations } \\
\text { of the Night Market. }\end{array}$ & Not applicable. \\
\hline Festival-related Changes & $\begin{array}{l}\text { Festival-related changes in } \\
\text { the lives of the participants } \\
\text { pertaining to foods and } \\
\text { celebratory methods. }\end{array}$ & Not applicable. \\
\hline Choice Making & $\begin{array}{l}\text { The participants make their } \\
\text { food consumption choices } \\
\text { regarding home cooking and } \\
\text { eating out. }\end{array}$ & $\begin{array}{l}\text { Home cooking, food retail } \\
\text { store choosing, and restaurant } \\
\text { picking. }\end{array}$ \\
\hline Food Authenticity & $\begin{array}{l}\text { The meanings of authentic } \\
\text { food for the participants. }\end{array}$ & Not applicable. \\
\hline
\end{tabular}




\begin{tabular}{|c|c|c|}
\hline Food-related Health Concerns & $\begin{array}{c}\text { The health concerns } \\
\text { expressed by the participants } \\
\text { related to food consumption. }\end{array}$ & Not applicable. \\
\hline Cultural Appropriateness & $\begin{array}{c}\text { The meanings of cultural } \\
\text { appropriateness for the } \\
\text { participants, which are } \\
\text { revealed from their } \\
\text { experiences at the Night } \\
\text { Market and in other food- } \\
\text { related situations. }\end{array}$ & Not applicable. \\
\hline Group Activities & $\begin{array}{c}\text { The group activities of the } \\
\text { participants in Ottawa. }\end{array}$ & $\begin{array}{c}\text { Food consumption activities } \\
\text { and non-food related } \\
\text { activities. }\end{array}$ \\
\hline
\end{tabular}

\subsubsection{Pronoun policy}

\section{Table 2: Codes and Subcodes}

In place of a pseudonym, I assigned one number to each one of the participants, from participant \#1 to participant $\# 15$. The participants are cited in the paper by their assigned numbers. In cases where I worried that cross-referencing personal information across the mentions of and quotes from participants could lead a reader to identify that participant, I cited participants as "a participant" without their assigned number in order to protect their identity. I did the same in cases where the description of a participant might have negative impacts on them. In these situations, the participants were described as 'they.' In other cases, the participants were described either as 'he' or 'she' depending on their self-identification, and all of the participants were self-identified within the gender binary. I decided not to use 'they' as the only pronoun in this paper because some of the findings were relevant to the gendered aspects in food consumption, and in this case, revealing the participants' self-identified gender was necessary for the interpretation. 


\section{CHAPTER 4: ANALYSIS}

The analysis chapter utilizes the findings from the participant observation and the interviews to support the main argument that Chinese students become more hybrid from their increased consumption of various Chinese regional cuisines and other Asian cuisines, but less so from incorporating Canadian food habits. At the same time, Chinese students who become more hybrid can also retain their ethnic identities. The findings with regard to hybridization and identity formation are discussed in the first section of Chapter 4. Thereafter, how Chinese students retain a Chinese identity through attending the Night Market as well as celebrating traditional Chinese festivals, making food decisions relying on cultural beliefs, and preventing nutrition transition are illustrated respectively in sections 4.2, 4.3, and 4.4. Before providing a detailed analysis, I first offer a summary of the main findings of each section.

In exploring the relationship between dietary acculturation and hybridization, my interviews reveal that the participants have become more hybrid from their increased understanding and appreciation of other Chinese regional cuisines and Asian cuisines served in Ottawa. To a lesser extent, several 'Western' food habits are also integrated into their daily food consumption. The capital resources that the participants obtain have nonetheless facilitated this hybridity. However, becoming more hybrid in food consumption does not weaken the participants' Chinese identity since identity and acculturation are two distinct processes in consumer acculturation.

Unpacking the participants' attendance motivations of the Night Market and the impacts of festivals and festival foods on their identity formation, I have found that a Chinese identity is strengthened through attending the Night Market. The festival attendance reinforces the participants' collective consciousness as Chinese students in Ottawa while attaching a sense of belonging to the attendees. In addition to invoking ethnic awareness, the Night Market is also 
enjoyed by the participants as a site of socialization with compatriots. Consuming Chinese food, especially festival food, and celebrating traditional Chinese festivals are ways of maintaining a Chinese identity, but they are not used to reject the host culture. Through mostly consuming festival related commodities, celebrating festivals rooted in local traditions has little impact on the participants' Chinese identity.

The symbolic importance of culture in celebrating festivals links the findings back to the implications of cultural beliefs on food consumption. Generally, the influences of cultural meanings exceed the influences of material conditions on food choices. Food was linked to other systems of communication such as social bonds and social hierarchy, and to a lesser degree, food choices were also influenced by material conditions such as location, taste, efficiency, and price, as well as the skill and information available for food preparation. Likewise, the perception of authentic Chinese food for the participants is also socially and culturally constructed since it is signified by factors such as the symbolic significance to the Chinese identity, the geographic context, the consistency to the established conventions and traditions, the ethnicity of the food producers, the simplicity of the production process, and the popularity within the Chinese community.

Social relations and cultural beliefs transcend material conditions in shaping nutrition transition, and they are also significant in understanding the different perceptions toward nourishment and nutrition. Chinese students' beliefs concerning food and health were sometimes contradicting the western notion of health and nutrition, which has reaffirmed the urgency of adopting a culturally sensitive health communication strategy. Because of the shared cultural beliefs about food, as well as the friendship strengthened through food consumption, Chinese students tend to retreat into mononational friendship groups, which is beneficial for their mental 
health. Nonetheless, the adverse impacts of this on language and cultural learning still need to be addressed so that the students could better navigate cultural norms in the host country.

4.1 Hybridity, ethnic identity, and the models of consumer acculturation

Section 4.1 has two sub-sections. In 4.1.1, Chinese students are revealed to become hybrid from exploring unfamiliar Chinese regional tastes and different Asian cuisines, which lead to not commonalities but understanding of people from different regions in China. The degree of hybridization amongst the interviewees various and thus the diversity of home culture should still be recognized. Culinary choices mirror the regional hierarchy amongst Chinese diaspora overseas, which is supported by the popularity of Cantonese cuisine. Original food habits and a Chinese identity are maintained as Chinese students become more familiar with the Chinese food environment in Ottawa despite hybridization. Home cooking, interestingly, contributes to both hybridization and the maintenance of original food habits, where culinary boundaries are blurred. Chinese students' knowledge of local food and food conventions did grow as they stayed longer in Ottawa, which is nevertheless facilitated by their economic and cultural capital. Local food becomes another market choice rather than a dietary staple.

How a Chinese identity is retained and even strengthened through attending the Night Market is discussed in 4.1.2. The Night Market reinforced the participants' collective consciousness as Chinese students in Ottawa and facilitated a sense of belonging. The participants self-identified as cultural insiders at the Night Market, and they treated it as a site of the home culture experience. In an apparent contradiction, the Night Market also amplifies the participants' weak sense of belonging within the host country because of other local attendees, and the food as well as the environment, which are tailored according to local conventions. Therefore, as argued by Cleveland et al. (2009), identity and acculturation should be treated as 
two distinct processes in the analysis of consumer acculturation.

\subsubsection{Becoming more hybrid, remaining Chinese}

As discussed earlier, hybridity concerns the mixture of cultures, nations, ethnicities, and classes, among others (Pieterse, 2006). According to Pieterse (2006), hybridity also destabilizes or even subverts the hierarchical relationship between hegemony and minority. I found that the first step that the participants went through in becoming more hybrid was incorporating different Chinese regional cuisines as well as different Asian cuisines into their diets, yet the process of hybridization did not subvert the culinary hierarchy, which mirrors, distorts, or reworks the structure between gender relations and classes (Wood, 1995).

When the participants shared the changes in their dietary habits, many of them revealed that the consumption of various Chinese regional cuisines had increased, especially Cantonese cuisine. According to the participants who did not come from Guangdong province or places that near the province, Cantonese cuisine had been unfamiliar to them. Some of the participants had never eaten at a Cantonese restaurant before they came to Canada because the presence of Cantonese restaurants at home was rare. Cantonese restaurants, however, had become the new favorite places to eat in Ottawa for some participants. The reason for this change, as agreed upon by some participants, was the higher accessibility of Cantonese restaurants as well as the Cantonese style food items in Chinese food retail stores, which reasserts the dominant position of Cantonese cuisine in Chinese restaurants overseas (Wu, 2004; Tam, 2004). Regarding other Chinese regional cuisines, the Night Market was also a site for the participants to explore unfamiliar regional tastes, as revealed by participant \#2: "I used to consume only sweet tofu pudding until I tried the spicy one last year at the Night Market. I loved it and was not able to switch back ever since." 
These findings confirm Cheung' and Wu's (2004) argument about the differences in Chinese regional cuisines. More importantly, these findings reveal that in an imagined community, as explained by Anderson (1983), the imagined communion existing within the minds of the community members does not necessarily lead to commonalities and understanding. Many participants had few or no opportunities to interact with their compatriots from Guangdong province, because of both the geographical distance and the language barrier ${ }^{10}$.

Therefore, before the participants who had no interaction with people from Guangdong province came to Canada, the Cantonese Chinese was only imagined by their compatriots by emphasizing similarities and neglecting differences between them. The actual differences in dietary habits might be unexpected for the participants at first, yet it was through food consumption that the participants were able to communicate and interact with people from different areas in China despite the differences. They became more hybrid, not by absorbing other regional characteristics into their own identity, but from understanding, respecting, or even appreciating the distinctions of other Chinese who might eat or even speak differently.

Nevertheless, no other regional cuisine was as influential as Cantonese cuisine in reshaping the dietary habits of the participants, which revealed that regional hierarchy was still at play among the Chinese diaspora in Ottawa, and this hierarchy affected the formation of hybrid identities. The dominant position of Cantonese cuisine in Chinese restaurants overseas was linked to geopolitical and economic developments. As mentioned earlier, the noteworthy flows of middle-class Hong Kong immigrants after the 1960s were followed by the global proliferation of Cantonese cuisine (Cheung \& Wu, 2004). However, the consumption patterns of Chinese food

10 Guangdong province is one of the southernmost provinces in mainland China, and people from the province speak Cantonese, which is a different dialect from that spoken in the rest of mainland China. Although the differences among other Chinese dialects are also very considerable, the official language used in the rest of mainland China is still Mandarin. 
in Canada might change along with the demographic changes of Chinese migrants, as more and more Chinese mainlanders have been arriving since the beginning of the 21 st century (Wong, 2017).

In addition to consuming a variety of Chinese regional cuisines, having different Asian cuisines was also a big part of the dietary changes amongst the participants. The participants claimed to consume a more diverse choice of Asian cuisines than they used to in China, including Korean, Japanese, and Vietnamese pho. Previous studies tended to analyze the role of food consumption in identity formation within the dichotomy of home country food versus host country food (Cleveland et al., 2009; Ustuner \& Holt, 2007). The participants' food consumption patterns were indeed more complex than that in a culturally diverse country like Canada. The popularity of Asian cuisines among the participants could be explained by the fact that the countries were geographically closer and culturally similar to China (Brown et al., 2010; Hartwell et al., 2011). However, some of the participants still counted the limited access to their home culture cuisine as the main reason for this type of change. As participant \#5 put it, "I couldn't get any true authentic Chinese food here even if I really wanted to, and then if I compared the Chinese food here with the cuisines from other countries, I'd rather have the other cuisines."

Talking about food choices in Ottawa, participant \#13 said that he had more choices compared with what he had in China, because he did not miss the food he used to eat and he did not care about authenticity either. According to participant \#13, the Chinese understanding of western cuisines (or cuisines outside China) was monotonous whereas in reality cuisines from other countries were also distinct in their own ways. In addition to consuming more Chinese regional cuisines and different Asian cuisines, participant \#13 also explored Spanish, Portuguese, 
and Greek cuisine, among others. In general, when dining out with friends in Ottawa, participant \#13 felt that he had more options compared with only having several regional cuisines as options in his hometown in China, although his personal preference for Chinese food had not changed in general (participant \#13).

In their studies examining the factors influencing international students' food consumption decisions, Tirelli, Pilar, \& Gómez-Ladrón-De-Guevara (2013) found that the limited accessibility of foods from the students' country of origin was less likely to have negative impacts on their psychological well-being when they did not miss their own country's food. In this sense, when participant \#13 said that he did not care about authenticity, he was talking about his low ethnocentrism in food. According to Tirelli et al. (2013), students with low ethnocentrism in food cared little about consuming home culture food, and their food consumption patterns were influenced by other factors such as appearance, accessibility, and flavor, among others. The low ethnocentric attitude in food consumption explained the diversity of participant \#13's food choices.

This research also confirmed Warde's (1997) finding that food habits were the hardest to change following the move to a new environment. I analyzed food eaters as consumers in this research because the marketing strategies of commodifying social identity and branding have tightened the connection between identity and commodity now more than ever (Ragusa, 2005; Kimberley \& Parcell, 2014). However, Warde (1997) also revealed that food consumption was not as open to individualizing tendencies as other consumption fields in the process of acculturation. In my research, the participants tended to consume more Chinese food as they became more familiar with the food environment in Ottawa, and their original dietary habits were also maintained through home cooking. 
Some participants who had come to Ottawa for four or more years claimed to consume more Chinese food compared to their early years in Ottawa because the number of Chinese restaurants had increased in the past couple of years. Thus, trying different cuisines was more of an appetite change than a survival strategy. Learning to cook was significant for keeping the participants' original dietary habits and food preferences. Many of them learned how to cook, after they came to Canada, from culinary apps. Familiar dishes they consumed at home were replicated, and this self-sustaining lifestyle also made the participants feel emotionally satisfied. Some of them had tried to make dishes that they had never made before and gradually they became good at cooking.

Several participants occasionally mentioned the cost of food as a catalyst for home cooking. For instance, the price of not only local foods but also Chinese foods was deemed as unacceptable by participant \#12 at the beginning of her sojourn especially when considering the exchange rate ( 1 to 5 or more) between Canadian Dollar (CAD) and Chinese Yuan (CNY). Whereas exchange only creates perception of price difference (the price is still relative to the amount of disposable income, exchanged or not), this seems to factor into purchasing decisions. In order to solve this problem, participant \#12 chose to cook more, which also contributed to the maintenance of her original food habits and she explained home cooking as more cost-effective comparing to dining out. The price of food generally became more acceptable over time for participant \#12 and the other participants, yet they still tended to consider the exchange rate when making their food consumption decisions.

As shown by Giddens (1991), many Chinese students rarely cooked before they went abroad, and after the students discovered that they could be good cooks, their sense of selfefficacy and independence would increase (Cappellini \& Yen, 2013; Giddens, 1991; Kim, 2001; 
Wu \& Smith, 2016). Moreover, learning to cook is a vital route to both emotional and physical sustenance (Brown et al., 2010). This statement was also true for the participants in this research not only because cooking helped them in coping with the limited accessibility to Chinese food in Ottawa, but also because the participants were able to incorporate local food ingredients into their dietary habits.

New dishes from different regional cuisines in China were learned from culinary apps and prepared at home. Beyond cooking Chinese food, Korean ingredients that were flavorful and requiring minimum effort to cook such as Korean hot sauce and kimchi also became popular choices among the participants. Additionally, some participants had incorporated more nonAsian ingredients into their daily food consumption patterns, and they claimed to also sometimes cook western cuisines in Ottawa. Eight of the participants explicitly expressed their appreciation of a few local food habits. The popular western dishes that the participants made were pasta, sandwiches, and salads. Moreover, the participants also adopted and modified local ingredients with familiar preparation methods, which resonated with Garnweidner et al.'s (2012) finding that immigrants transform foreign elements into culturally appropriate meals through cooking local ingredients in ways that fit the food habits of their country of origin. Some participants described their dishes as neither Chinese nor western but an Asian fusion. As revealed by participant \#11: "I just stir-fry everything but I would still describe my dishes as more Chinese than western because you wouldn't add soy sauce into a western dish." Not only the ingredients, but also new cooking techniques and facilities were incorporated into the dietary habits of the participants; for example, participant \#7 said that the range oven ${ }^{11}$ had extended her cooking skills and food options.

11 Many of the participants live in rental apartments that have a range with multiple burners and an oven. 
These findings have partially supported Harris' (2007) concept of cultural materialism since the food availability in Ottawa inevitably influenced the food choice of the participants. In addition to that, technological advances or discoveries that provided new information on food preparation, in this case, the culinary apps, as well as the oven, also increased the flexibility of food choices. However, I would argue that cultural appropriateness played a bigger role than material availability in making food decisions, because the participants searched for and cooked foods that were either already familiar to them or similar with their home culture food such as the Asian cuisines. Some of the participants were willing to put more effort into finding their ingredients of choice, and resisted being limited by what was immediately available to them whenever the extra effort was affordable. Many participants were also familiar with the western dishes that they made at home such as pasta, sandwiches, and salads because these dishes have been popularized in China for decades by GCC food chains (Popkin et al., 2001). Cultural appropriateness was the priority when the participants cooked with unfamiliar ingredients, and thus Harris' (2007) concept of cultural materialism was only partially supported. Harris' (2007) arguments about the implications of rationality on food consumption are discussed later in section 4.2.

With respect to consuming unfamiliar food items, this research also supports Cappellini' and Yen's findings (2013) that the Chinese students' knowledge of local food and food conventions did grow as they stayed longer in their host country. Participant \#5 shared her exploration with different kinds of cheese as well as her new joy in tasting fresh basil. Likewise, participant \#8 said he started to like pastries, which he would never think of eating back home. Participant \#8 also identified that he could tell the differences between hamburgers and sandwiches served in different restaurants, which used to taste all the same for him. In another interview, participant 
\#10 claimed to enjoy the variety of new food options in Ottawa especially steaks, although he still liked the foods in China. All in all, many participants were not food neophobes, confirming Dovey et al.'s (2008) argument that international students did not reject foods just because they were novel.

Some participants felt that although their dietary habits had altered based on the local food resources, their food preferences had not changed, which were still shaped by what many of the participants called "the taste of home." As illustrated by Brown et al. (2010), the taste of home could transport students to a place and time when they felt safe, which is helpful in alleviating stress and loneliness. Therefore, the taste of home constantly reminded the participants of their good memories at home. Similar to how Zwingmann and Gunn (1983) discuss the symbolic significance of consuming home culture food, the absence of the taste in Ottawa also enhanced the feelings of grief for leaving behind the happy past as well as the loved ones at home. In this case, changes in food habits could also be frustrating for many participants. For instance, participant \#3 shared her resignation with the prevalence of sweet taste in foods in Ottawa, especially in food court dishes such as Pad Thai. Participant \#3 felt that she was forced to accept the food simply because "there is no better choice." Choosing Pad Thai for participant \#3 was convenient because of her inability to cook as well as her busy school schedule, and besides, the time and effort to get more culturally appropriate foods were not always affordable. For other participants who were influenced by the similar factors as participant \#3, dining out was not ideal. What many participants did is compromise their personal preferences or lower their expectations in order to cope with the local limits. As participant \#7 put it:

I know that my expectation for Chinese food in Canada could not be the same as my expectation for Chinese food in China; for instance, the stinky tofu served at the Night Market just cannot be as good as the stinky tofu in China. Yet the food in 
general (served at the Night Market) matched my expectation for good Canadian Chinese food.

Likewise, participant \#15 also indicated that:

After spending all these years in Ottawa, the authenticity (of Chinese food) has become gradually less important to me because it is indeed hard to find any. As long as the food is good or not too bad I'll be okay with that. Having authentic Chinese food used to mean a lot to me, but now it is not that important anymore.

Some participants did not go out for Chinese food in Ottawa as much as they did in China mainly because they were unhappy with both the quality and the price. The participants thought that it was not worth it to spend money on bland, oily or simply inauthentic Chinese food at the restaurants, and hence they would instead cook Chinese food at home. For similar reasons, some of the participants consumed fewer deliveries than what they used to do in China, while recalling the convenience of consuming food deliveries in China as good memories.

In Ustuner' and Holt's (2007) model of the dominant consumer acculturation, they argued that capital resources were necessary for forming hybrid identities. Therefore, the Turkish squatter women that we mentioned in Chapter 2, who were rural migrants and lacked capital resources were unable to construct hybrid identities but to either pursue the upper-middle-class style of consumption or to live outside it (Ustuner and Holt, 2007). In the case of the participants' dietary changes in my research, some of the changes were made with reluctance and participants even felt compelled to make them. Yet, they all possessed some economic and cultural capital, since all of the participants were either pursuing a post-secondary degree, or they recently graduated with a post-secondary degree, and none of them expressed severe financial difficulties. This gave them much freedom in exploring exotic food items and cuisines while maintaining their home food culture. It was indeed that by occasionally trying out new cuisines and 
simultaneously preserving original food habits, the participants, like the participants in Brown et al.'s (2010) studies, were presenting as well as accepting both the ideal multicultural self and the conservative day-to-day self. The participants preserved their Chinese identity from primarily living off Chinese food while other culture identities were also absorbed through ingesting the cuisines. Moreover, as illustrated earlier, they became more hybrid since they had more understanding and respect for other Chinese who had a different culinary or even linguistic culture than their own, through consuming a more diverse choice of Chinese regional cuisines in Ottawa.

Ustuner and Holt were correct about the significance of cultural capital in forming a hybrid identity, yet they failed to consider the difficulties of completely retaining the home country culture, which could be even harder than adopting the host country culture. For international students like my participants, retaining their original food habits would require either a much higher accessibility to a variety of Chinese regional cuisines than what they had in Ottawa or the time and skill to purchase familiar ingredients and to cook at home - if not both. Nevertheless, the importance of recognizing the diversity and the complexity of home culture as argued by Ustuner and Holt (2007) was relevant in examining the changes in dietary habits in this case, since Chinese cuisine is defined by many regional cuisines due to "geographical differentiation and social stratification" (Cheung \& Wu, 2004, p. 4).

\subsubsection{Reinforcing ethnic identity at the Night Market}

Despite the dietary changes that had made the participants more hybrid, the ethnic identity of the participants was still retained and was even strengthened through attending the Night Market. The Night Market reinforced the participants' collective consciousness as Chinese students in Ottawa and attached a sense of belonging to the attendees. Moreover, no case of cultural 
swapping was found in their festival experiences or in the daily food habits and festival celebration activities of the participants. Cultural swapping is defined as playfully and seamlessly switching behaviors in keeping with cultural norms (Ustuner \& Holt, 2007). On the one hand, this finding was surprising since cultural swapping was not uncommon for migrants who formed hybrid identities through acculturation as noted by Ustuner and Holt (2007). On the other hand, these findings confirm that identity and acculturation are two distinct processes, and migrants who become more hybrid through consumer acculturation can also retain their ethnic identities (Cleveland et al., 2009).

The Night Market triggered a collective consciousness when the participants found out that the number of non-Chinese or even non-Asian attendees was surprisingly higher than what they expected. As noted by participant \#7: "I was expecting many Asian people and some Waiguoren ${ }^{12}$, yet it turned out that there were lots of white people and black people there [at the Night Market]. Anyhow, I saw much more local people than Asian faces.” Additionally, this environment made one participant feel a weaker sense of belonging than she would feel at the Night Markets in China, as she explained: "Surrounded by white people, it triggered my consciousness of being in a foreign country." Moreover, this participant also felt that many of the Chinese vendors at the Night Market were more welcoming toward Chinese customers because the vendors could feel more affinity from interacting with Chinese customers than with nonChinese customers, and they illustrated it through an example: "As soon as the vendor, who came from Toronto, discovered that my friend also lived in Toronto, they gave us one extra scallop."

\footnotetext{
12 Literally means foreign person in Chinese, a commonly used phrase referring to Western tourists or foreigners in China (Rodgers, 2018).
} 
According to Arcodia and Whitford (2006), ethnic festivals could be an integral part of the host country when the country is already multi-cultural and multi-ethnic, and as members of the ethnic group, the participants were actively seeking a sense of belonging in the host country through attending the Night Market. The participants felt they belonged when they were no longer the cultural outsiders, as one participant shared that they enjoyed watching Waiguoren being either confused or surprised by the foods served at the Night Market. Rather than consuming the food, one participant claimed that many of the Chinese students attended the festival expecting to see their friends or acquaintances. As they put it: "I felt like that at least half of the Chinese students at the festival were just hanging out and socializing with people there, and they didn't necessarily expect the food to be good." This participant rarely tried any food at the Night Market, but the festival for them was pretty close to the Night Markets in China because unlike other participants, they felt like that they were surrounded by Mandarin-speaking attendees. This participant also saw many acquaintances at the Night Market, who were also Chinese students in Ottawa.

Attending ethnic festivals could also provoke homesickness, as revealed by participant \#11, the differences between the Night Market and the Night Markets in China were neither about the food quality nor the price, but the festival itself reminded her of the weak sense of belonging she had in the host country: "The fact that the Night Market was hosted in Canada made it inherently different for me. You know, I still wanted to go back to China for those foods. Especially the minute I had the sweet Shaobing ${ }^{13}$ and the lamb kabob, I wanted to go back to China so badly." As a substitute for home, the symbolic significance of consuming home culture food is irreplaceable (Zwingmann \& Gunn, 1983). This has been exemplified by participant \#3, who

13 A baked Chinese flatbread made with either sweet or savory stuffing, or it could also be made unstuffed. 
hoped to feel a connection with home at the festival when she was not able to visit China during the summer, as she said: "Although people were complaining about the food quality and the price, they still went there because of the sense of belonging." For participant \#6, the Night Market provided a unique opportunity to Luchuan ${ }^{14}$ on the street, because this cultural practice was hard to recreate in other Chinese restaurants in Ottawa.

Cleveland et al. (2009) proposed their dual process model of acculturation in the examination of ethnic Lebanese residing in urban area in Quebec. They found that patterns of adopting host culture/mainstream products were also found with "low-cost, high-visibility items, absent of any language barrier" (p. 198) while traditional consumption activities were "retained when they were strongly linked to the maintenance of cultural and family ties" (p. 198). Food consumption is ambiguous since it could be easily adopted as a mainstream product as shown in the dietary changes of the participants, but at the same time, consuming Chinese food at the Night Market is strongly linked to the maintenance of ethnic identity for the participants.

Beyond consuming home culture food, the Night Market was also a site for the participants to gain a collective consciousness by reflecting on their identity as Chinese students in Ottawa. Talking about the festival visitors, one participant reflected on the changes they had witnessed during the past six years, and they described the population of Chinese students in Ottawa as both growing bigger and getting younger. This participant also linked the popularity of the Night Market to the growing population of Chinese students as they explained: "This is a good thing because the bigger population stimulates the consumption of Chinese food. It was only them (the younger Chinese students) that made food festivals like the Night Market possible." Concerning the relatively small number of Chinese students at the festival, participant \#10 analyzed the

\footnotetext{
14 Luchuan literally means sliding the meat off the skewer, and the Chinese phrase describes the practice of eating kabob with a group of people on the street.
} 
situation based on his own experience and observation as a member of the Chinese students in Ottawa: "Chinese students might be busy preparing for their finals during the time of the Night Market. If they were neither taking any classes nor visiting China in the summer, they would visit bigger cities like Toronto, Vancouver, and Montreal instead of staying in Ottawa.”

All in all, despite the participants' dietary changes, their ethnic identity was still retained through either reinforcing a collective consciousness as Chinese students or through gaining a sense of belonging at the Night Market. Therefore, identity and acculturation have been confirmed as two distinct processes by this research, and ethnic identity can be retained or even strengthened despite acculturation (Cleveland et al., 2009).

\subsection{Social constructivist worldview on ethnic festivals}

A social constructivist worldview relies as much as possible on the participants' interpretation of the ethnic festivals, yet the meanings are also shaped historically and socially (Creswell, 2014). Adopting this worldview, I aim to understand the implications of festivals and festival foods on identity formation. The purpose of this section is to demonstrate that hybridization does not impact identity formation, and I do so through examining the attendance motivations of the Night Market, and the ways in which the participants celebrate Chinese traditional festivals and local festivals. This section consists of three sub-sections. In 4.2.1, I argue that a Chinese identity is strengthened through intercultural exchanges, consuming home culture food, and socializing with compatriots. Section 4.2.2 shows that consuming Chinese food, especially festival food and celebrating Chinese traditional festivals are ways of maintaining Chinese customs and traditions, strengthening the social ties with other Chinese students in Ottawa, and ultimately maintaining a Chinese identity. However, Chinese foods are not necessarily consumed to resist the host culture since the participants are open to celebrate 
festivals rooted in local tradition as well, which is shown in 4.2.3. In most of the cases, the participants consume local culture as a form of commodity and have a weaker symbolic attachment to the festivals, and thus the celebration has little impact on their Chinese identity. There is an exception with one participant whose identify is not constrained by the nation states, yet their identity is not altered by acculturation either.

\subsubsection{Attendance motivations}

Bankston and Henry (2000) have shown that two concepts of culture coexist. Culture is a form of heritage and a unique resource for the cultural insiders to invoke ethnic awareness (Bankston \& Henry, 2000). The ethnic awareness was evident in several festival motivations of the participants at the Night Market such as intercultural exchange, consuming home culture food, and socializing with compatriots.

In terms of attending Night Markets, it was less a special event in China than it was for the Night Market in Ottawa. The participants often depicted the Night Markets in China as just a regular place to hang out while consuming street foods with friends and family. The street foods were more familiar to the participants and the Night Markets were open every day. Except for this major difference, many participants felt that the Night Market did a fair job on mimicking the content of a typical Chinese Night Market. Both the time and the physical space of the Night Market, as explained in Chapter 3, is invented in response to the modern context. Through mimicking the content of a typical Chinese Night Market, the Night Market, resembling other invented ethnic festivals, also makes references to the traditions (Hobsbawm, 1983; Bankston \& Henry, 2000).

Examining the specific attendance motivations of the participants, I was able to explore the implications of the Night Market had on their identity in the process of acculturation from their 
perspectives. This research confirmed the findings from previous studies that the attendance motivations of the insiders to the culture were not only about invoking the ethnic awareness but also about socialization (Backman et al., 1995; Formica \& Uysal, 1996; Mohr et al., 1993; Savinovic et al., 2012; Usyal et al., 1993). However, in my research I am not able to compare and contrast the motivations between cultural insiders and outsiders, and between residents and non-residents as previous empirical studies have done (Bankston \& Henry, 2000; Lee, 2000) since my focus is on how the Chinese students as cultural insiders of the Night Market and residents in Ottawa construct the meaning of it.

First of all, three attendance motivations that strengthen a Chinese identity are intercultural exchange, consuming home culture food, and socializing with compatriots. The role of food in intercultural exchange is prominent as it allows students to promote their cultural identity by offering it to other international students (Brown et al., 2010). For one participant, attending the Night Market was about introducing Chinese food to their non-Chinese romantic partner who never had Chinese food before. This participant also specified the role of the Night Market as connecting them to their home in China. Consuming Chinese food could be more strongly linked to maintaining a Chinese identity for the participants who had a non-Chinese romantic partner as demonstrated by Cappellini and Yen (2013). For another participant, the gathering of different kinds of Chinese street foods gave them the chance to introduce Chinese food to their graduate school cohort, as they illustrated, "some of them came from other countries like Korea and Nepal, and some of them went to school in other cities or other provinces in Canada. I invited them to come to the Night Market because I thought that it would be a great experience for them too." Thus, unlike what Lee (2000) argued in their research, I found that culture could be a 
central theme of international food events when food is treated as a representation of cultural identity.

Another attendance motivation that ties to ethnic awareness is consuming home culture food. Some participants went to the Night Market more than once mainly because some of the food items were hard to find elsewhere in Ottawa. Participant \#3 went all three days because the lamb kabob was better than the lamb kabob she could find in any Chinese restaurants in Ottawa. The number of food vendors also made it impossible to try everything in one day, according to participant \# 3. Similarly, participant \# 15 went to the Night Market twice because she liked the savory tofu pudding served there. The Night Market, once again, was remarked on as a unique opportunity to Luchuan by several participants, because this cultural practice was nearly impossible to recreate in Chinese restaurants in Ottawa. As can be seen, regardless of how hybrid the participants' food consumption has become, the enthusiasm of consuming home culture food can hardly be replaced.

Socializing with compatriots is also a key component of a sense of belonging for several participants. Festival satisfaction was enhanced by the joy of friend togetherness and the gesture of sharing. Participant \#1 felt that she would not have any fun if she went to a Night Market alone, as she said: "We could buy different things and try each other's food, and then critique which food is good and which is bad. For me, that's the fun part." For participant \#8, the feeling of being together with his friends was more important than the food quality, as long as the food was not too bad. Moreover, going with friends could also shorten the time for lining up since several participants had friends waiting at different food stands and buying different food items, and they would all share. Visser (1999) suggests that meals have always been "an essential medium for social sharing and relationship" (p. 4). When the participants were part of this 
relationship, they felt at ease and they felt belonged. In summary, from examining the attendance motivations of the participants, I find that the Night Market strengthens the ethnic identity, and at the same time facilitates a sense of belonging among the participants.

\subsubsection{Celebrating Chinese festivals in Ottawa}

In Cappellini' and Yen's (2013) studies about the correlations between Chinese international students' ethnic social ties (with other Chinese students) and non-ethnic social ties (with British students) in the UK and their food consumption patterns, they found that food consumption was a way of resisting the host culture as well as a way to maintain a Chinese identity regardless of the types or the strength of their social ties. Likewise, the findings of my research have shown that Chinese food, especially festival food is consumed to maintain Chinese customs and traditions during the festivals, and they are seldom consumed as daily substances. Moreover, Chinese food is also consumed in order to strengthen the social ties with other Chinese students in Ottawa, and thus consuming Chinese food is ultimately a way for the participants to maintain a Chinese identity. However, as argued earlier in this thesis, acculturation and ethnic identity are two distinct processes for the participants, and therefore consuming Chinese food is not necessarily a way of resisting the host culture.

Unsurprisingly, the most important Chinese traditional festival that the participants celebrated in Ottawa was still Chinese New Year considering the significance of Chinese New Year in Chinese culture (Liu, 2011). Some of the participants thought that celebrating Chinese New Year in Ottawa was not very different from celebrating it at home since they were able to retrieve some of the festival customs such as preparing and consuming festival foods with compatriots. A typical Chinese New Year in Ottawa for many participants was consuming the 
festival foods, of which Jiaozi ${ }^{15}$ was the most popular (although it was not a festival tradition for all of the participants), or just having dinner together with their compatriots, either at home or a Chinese restaurant. Thereby, some participants claimed that the only notable difference would be the absence of family members and relatives. However, there were also participants saying that they celebrated Chinese New Year very differently in China than they did in Ottawa.

The lack of the festive atmosphere was indicated as the first difference by some participants. A Chinese New Year atmosphere, as described by participant \#1, should be composed by various visual and auditory elements such as firecrackers, fireworks ${ }^{16}$, and Chunwan ${ }^{17}$ on TV with the company of family and friends. However, for some participants, the festive atmosphere could only be constructed and experienced when people around them also celebrated Chinese New Year as participant \#1 put it: "If nobody else celebrates Chinese New Year in Ottawa but only Chinese people, I still cannot feel the festive atmosphere." The absence of the festive atmosphere makes the minority position of Chinese festivals hyper-visible for the participants, which links the celebration greatly to a Chinese identity.

Some participants also felt that because Chinese New Year was a family-oriented festival, the physical absence of family members reduced the participants' motivation of celebrating. Additionally, the festival foods that the participants made together with their compatriots in Ottawa were not as good as the foods they consumed at home because according to some of them, the older generations, especially the elders in their family were much more experienced in

15 Dumplings, which are a more commonly homemade dish in China compared with other festival foods (Liu, 2011).

16 As part of the New Year customs, Chinese people set off firecrackers and fireworks on New Year's Eve, which symbolize the start of a new Chinese lunar year. The neighborhoods are usually immersed in the sound and the light of the celebration. 17 The Chinese New Year Gala, called Chunwan in Chinese is a 4-hour variety show broadcast by the central television broadcaster of People's Republic of China on New Year's Eve, which has been a tradition embraced by Chinese families since 1983. As one of the most-watched shows in the world, the show contains as much overt political messages as entertainment (Chin, 2015). 
making festival foods. Therefore, the participants were trying to retain the ritual of making festival foods at home through mimicking their parents and grandparents.

Although the strength of social ties with compatriots cannot affect the relationship between food consumption and maintaining an ethnic identity as revealed by Cappellini and Yen (2013), it can affect the motivation of celebrating traditional festivals. One participant mentioned that they used to celebrate traditional Chinese festivals a lot with their Chinese friends when they first came to Ottawa. They used to spend a lot of time together in order to cope with the unfamiliar environment, and because they did not know many people besides each other. As the individuals in this friendship group became more comfortable with the life in Ottawa and met more people, they hung out with each other less often. As many of their close friends also went back to China after graduation, this participant felt less motivated to celebrate traditional Chinese festivals. Likewise, another participant claimed to have never really celebrated Chinese New Year in Ottawa also because of their loose social network with compatriots. In contrast, the participants who claimed to have more prominent social networks with other Chinese students in Ottawa, especially those who were actively involved in the Chinese community, tended to go out multiple times with different groups of people during Chinese New Year, which was described as an opportunity for socialization.

Some participants preferred to cook at home during the traditional festivals because eating outside would be inappropriate for mostly family-oriented festivals, as participant \#15 noted: "I just like the feeling of having everybody at home, sometime I would cook some dishes and my friends would bring over some dishes." Some participants also celebrated with their roommates, and everyone contributed to the food preparation. Watching Chunwan or playing it as the background sound was how the participants created a festive atmosphere while eating with 
compatriots at home. In terms of festival foods, only Jiaozi was commonly made at home, while other food items were often purchased from local Chinese retail food stores because of the time and effort associated with making them. Besides Jiaozi, the participants rarely incorporated other festival foods into their daily food consumption patterns. This finding was inconsistent with Azar et al.'s (2013) finding that new immigrants tended to over-consume festival foods because they contributed to their emotional, social and psychological wellness. Thus, the negative health impacts of the overconsumption of festival foods would not be considered either when examining the relationship between cultural beliefs and nutrition transition in section 4.4. The demographic differences between the participants in Azar et al.'s study (2013) and my research may explain the different attitude toward festival foods, which is beyond the scope of this research.

Time constrains and the limited access to traditional foods are common obstacles for celebrating Chinese festivals, yet the participants often find alternative ways to cope with the limits. If not, these limits impact the bonds with loved ones at home, which is another example of how hybridity intertwines with social bonds and dietary behaviors. Some of the participants chose to skip the food preparation procedure and to eat in Chinese restaurants during the festivals because of their limited cooking skill and their busy class schedule as one participant put: "There were too many people in my house, yet only a few of us could cook." For participant \#13, having class during Chinese festivals was a barrier for him to celebrate or even to remember the date of them because schoolwork was the priority. The class schedule also disconnected participant \#13 with his family because his family was feasting while he was preparing for an exam on the New Year's Eve. However, some participants also mentioned that in the past several years Chinese 
New Year happened during winter reading week, which gave them the opportunity to fly back to China to reunite with friends and family, but this case was rare amongst the participants.

The participants also negotiated or compromised their customs for the convenience of celebrating Chinese New Year as well as other traditional festivals with their compatriots from different regions in China. Since Chinese cuisine is defined by many different regional cuisines, customs and traditional foods also are varied depending on the regions. For instance, eating Jiaozi is the most significant feature of a northern Chinese New Year (Liu, 2011), whereas eating Tangyuan $^{18}$ is practiced by many Chinese living in the southern areas. Additionally, the differences in traditional foods are way more complex than the north/south dichotomy. For instance, participant \#6 engaged in an intra-cultural (within the Chinese culture) exchange with his Chinese friends through appreciating the different flavors of mooncakes from different regions, and also found it interesting to make Jiaozi on Chinese New Year with his friends for his very first time.

Many participants also compromised their customs because of the limited availability of

Chinese festival foods in Ottawa. Participant \#11 noted:

In my hometown, we eat something called Ningbo Niangao ${ }^{19}$ during the Chinese New Year, which they don't sell in Ottawa. I could only follow the majority and eat what they eat, like Tangtuan or Jiaozi, although this is my first time knowing the custom of eating Jiaozi in Chinese New Year. [The Chinese retail food stores] only carry mainstream traditional food items and they don't carry any unique regional food items.

Likewise, participant \#15 also noted:

Zongzi $^{20}$ that is sold at $\mathrm{T} \& \mathrm{~T}^{21}$ is different from what we consume in my hometown. We like Zongzi with plain white glutinous rice or maybe adding a little bit of salt.

18 Glutinous rice balls made with sweet/salty fillings or with no filling, and are usually served in a bowl of soup in which the rice balls were boiled. Tangyuan is also called Yuanxiao or Tangtuan in Chinese. For a list of terms and translations of these traditional food items please refer to Appendix A.

19 Sticky rice cakes from Ningbo, a southern city in China.

20 Glutinous rice cakes wrapped in reed leaves, which could also have sweet/salty fillings.

21 A Canadian supermarket chain that sells primarily Asian groceries. The T\&T in Ottawa was opened in 2009 and was the $3^{\text {rd }}$ or 
We might also add a little bit of shredded aged sausages into our Zongzi but nothing more. So, it's not like the Guangdong style Zongzi that they sell at T\&T which has various fillings.

Like participant \#11 and \#15, several other participants had never heard about certain customs in other regions or tried the traditional foods prepared in ways that were unfamiliar to them until they met more Chinese people in Ottawa who came from different regions of China.

Nevertheless, through participating in the celebration with their compatriots and communicating the intra-cultural differences, the social ties between them were strengthened.

\subsubsection{Celebrating local festivals in Ottawa}

Culture is also a form of commodity, consumed by the outsiders to the culture (Bankston \& Henry, 2000), and this is clear in the ways in which the participants celebrate local festivals in Ottawa. When celebrating local festivals, the participants transform traditions and customs into commodities, and the symbolic significance of such traditions is less meaningful for them because the common understanding of the cultural conventions is absent. Some participants chose to travel with friends during Christmas. For Thanksgiving, the participants consumed festival foods such as roasted turkey, and during Halloween, they participated in festival activities such as the haunted walks and carving pumpkins. In addition to consuming unique festival products, some participants claimed to celebrate local festivals by eating out with friends with no particular cuisine preference and thus they felt that celebrating local festivals had few distinctions from celebrating Chinese festivals in Ottawa.

One participant had expressed the concern that as Chinese students they may not know the real stories or rationales behind the festivals, and thus they could only participate through consuming festival foods and attending commercialized activities. Moreover, this participant

the $4^{\text {th }}$ largest among the total of 18 T\&Ts in Canada (Eade, 2009). 
indicated that they would love to participate in the locally traditional ways of celebration yet the limited social and cultural capital hindered them from doing so. Having stronger non-ethnic ties could potentially influence how the Chinese students celebrate local festivals. As demonstrated by one of the participants who had more non-Chinese friends than Chinese friends, during Chinese New Year, they invited their non-Chinese friends over to make and eat Jiaozi together. Similarly, they also got invited to parties at their friends' place during local festivals. For Thanksgiving or Christmas, this participant often attended family parties of the friends who were close to them. Because their friends had various religious or ethnic practices and customs, they did not necessarily stick to the mainstream way of celebration. Rather than identifying themselves as merely Chinese, this participant reveals that their sense of humanity exceeded the boundaries defined by cultures and nation states even before the multicultural experiences in Canada. Thereby for this participant, celebrating local festivals is a way of appreciating the abundance of humanity, while reinforcing their own sense of humanity.

In conclusion, both attending the Night Market and celebrating festivals rooted in Chinese traditions are strongly linked to the maintenance of a Chinese identity for the participants. Moreover, for most of the participants, celebrating local festivals has little impact on their Chinese identity because of the absence of symbolic meanings. Although the Chinese identity is not reinforced for the participant who identifies more as a global citizen than as a Chinese, celebrating local festivals still has little impact on their pre-existing sense of identity.

\subsection{Food as a cultural construct}

In addition to Chinese festivals and festival foods, maintaining a Chinse identity is also salient in the food consumption choices concerning home cooking and eating out made by the participants, and their perception on the authenticity of Chinese food. The first part of this 
section considers the significance of cultural beliefs in relation to food consumption, and applies the debate between structuralism and materialism to food and eating, while considering through the social constructivist worldview how and why the participants made their food consumption choices.

The findings in this section reiterate that the participants become more hybrid through consuming Chinese regional cuisines and other Asian cuisines. Moreover, cultural beliefs had a more substantial influence on food choices than material conditions. The participants' choices of food are often shaped by Chinese food habits, while local limits are navigated through these habits. Materials factors are selected in order to retain the original food habits, both in in terms of home cooking and eating out. The limited availability of Chinese retail food stores and the lack of diverse regional cuisines also perpetuate the social hierarchy within the Chinese community in Ottawa. The standards of a good taste in the host culture are also adopted and make the participants more hybrid, but have little impact on their Chinese identity.

The second part of this section unpacks the ways in which the participants constructed the authenticity of Chinese food so that we could interpret the role the authenticity played in food consumption. For the participants, authenticity of Chinese food is signified by factors such as the symbolic significance to the Chinese identity, the geographic context, the consistency to the established conventions and traditions, the ethnicity of the food producers, the simplicity of the production process, and the popularity within the Chinese community. The definition of authenticity nonetheless reinforces the idea of Chinese food the participants' have in mind, while overlooking the outside influences on Chinese food in a global context. More importantly, my findings imply the common nostalgia that the participants have for their home culture food, which is unique to their identity as Chinese students in Ottawa. 


\subsubsection{The choices made in relation to home cooking and eating out}

A social constructivist worldview posits that meanings associated with food are results of social and cultural construction, and the individual interpretation of food cannot exist in isolation from the power relations within the larger social fabric. I have argued that the constructivist worldview would agree with structuralists that the cultural significance of food is established through social interactions (Wood, 1995) while also agreeing with materialists and the developmental theory that the contemporary understanding of food is influenced by biological, historical, and technological factors (Wood, 1995). Therefore, some of the aspects of the three worldviews on food are indeed intertwined, and I utilize all three of them in the analysis of how and why the participants made the food choices related to their daily food consumption in terms of home cooking and eating out.

I found that food was linked to other systems of communication such as social bonds and social hierarchy, whereas gender dynamics had no evident influence on the participants' food preparation habits. At the same time, the participants' food choices were also, though to a lesser degree, influenced by material conditions as well as the skill and information available for food preparation. Harris' (2007) notion of rationality, positing that individual behaviors are either selected for or selected against for their efficacy in serving basic human needs, however, is still an over-simplistic term that neglects the full effect of culture on food consumption.

\section{Home cooking}

Cooking Chinese food at home required motivation since a Chinese meal often consisted several dishes plus the staple food, and recreating that meal structure was often time consuming for the students. The participants who cooked Chinese food at home, and more importantly, recreated the structure of a Chinese meal, were the individuals who liked cooking in general and 
could share the dishes as well as the labor of dishwashing with roommates rather than eating alone. Likewise, the participants who lived with their romantic partner also were more likely to cook Chinese food. Previous empirical studies had shown that for students raised in cultures that embraced sharing meals, reduced social contact acted as a barrier for being motivated to cook (McIntosh \& Kubena, 1999).

As Douglas (1984) revealed, foodways of a culture reflect its understanding of the basic categories of the world, and they emphasize group distinction. When the food habit violates the basic categories established within the symbolic system of the social group, the group distinction can be blurry. Eating alone changed the structure of a Chinese meal, since many participants who did not often eat with others may still cook using Chinese ingredients, but they tended to integrate various ingredients into one dish instead of making several dishes. As described by participant \#10: "I just make noodle soup and throw lots of meatballs and vegetable into the pot." Eating alone also led to the adoption of non-Chinese food items like sandwiches and pasta, which were ideal for eating alone although many of these foods were altered using Chinese cooking habits as mentioned earlier. One of the participants saw cooking at home as merely for survival rather than something enjoyable, and they described the process as not cooking but just making things edible, which they said: "Most of the time, I would just boil some vegetable and chicken breasts and season them with salt." The Chinese meal structure not only shapes food choices, but also determines the definition of a proper meal.

The gendered division of labor in home cooking was not reproduced by the participants, since several participants who self-identified as a male also cooked in their romantic relationships or with roommates, although only a few participants mentioned the gender of the cook in their relationship. In general, the gender dynamics in home cooking were not as apparent 
as Bourdieu (1984) depicted, and gender inequalities were not necessarily maintained to the same degree in the contemporary culinary world, because social relations were always changing (Mennell, 1985). However, I acknowledge that the participants in this research were international students living with their peers, and the absence of the economic and generational hierarchy in the domestic setting could contribute to this condition of seeming gender equality. A further interpretation of this difference found in gender relations, and more importantly, the possible influence of gender norms as well as domestic labor division in contemporary China on this finding are beyond the scope of this research.

When examining the choices made for purchasing ingredients, I find useful Harris' (2007) argument that individual behaviors are either selected for or selected against with respect to their efficacy in serving basic human needs, and in this case, the basic needs are the pre-existing food habits of the participants. The participants weighed benefits versus costs over criteria such as location, food availability, and price when choosing retail food stores; however, these findings also challenged Harris' (2007) arguments about social hierarchy and rationality. 
Chinese retail food stores such as T\&T Supermarket and Kowloon Market were the popular places where the participants could get Chinese seasonings, Chinese frozen foods, Chinese meat cuts, Chinese vegetables, and Asian snacks and soft drinks, as well as Chinese festival foods mostly during the festivals. Transportation was mentioned as a barrier to shopping at the Chinese retail food stores. According to some participants, because Kowloon Market was located in Chinatown, it was more convenient for the participants who worked part-time at the restaurants in Chinatown and for those who lived near the downtown area (Figure 7). T\&T Supermarket was described as offering more variety of choices than other stores, and the participants usually went on weekends because it is located farther away from where most of the participants resided (Figure 8).

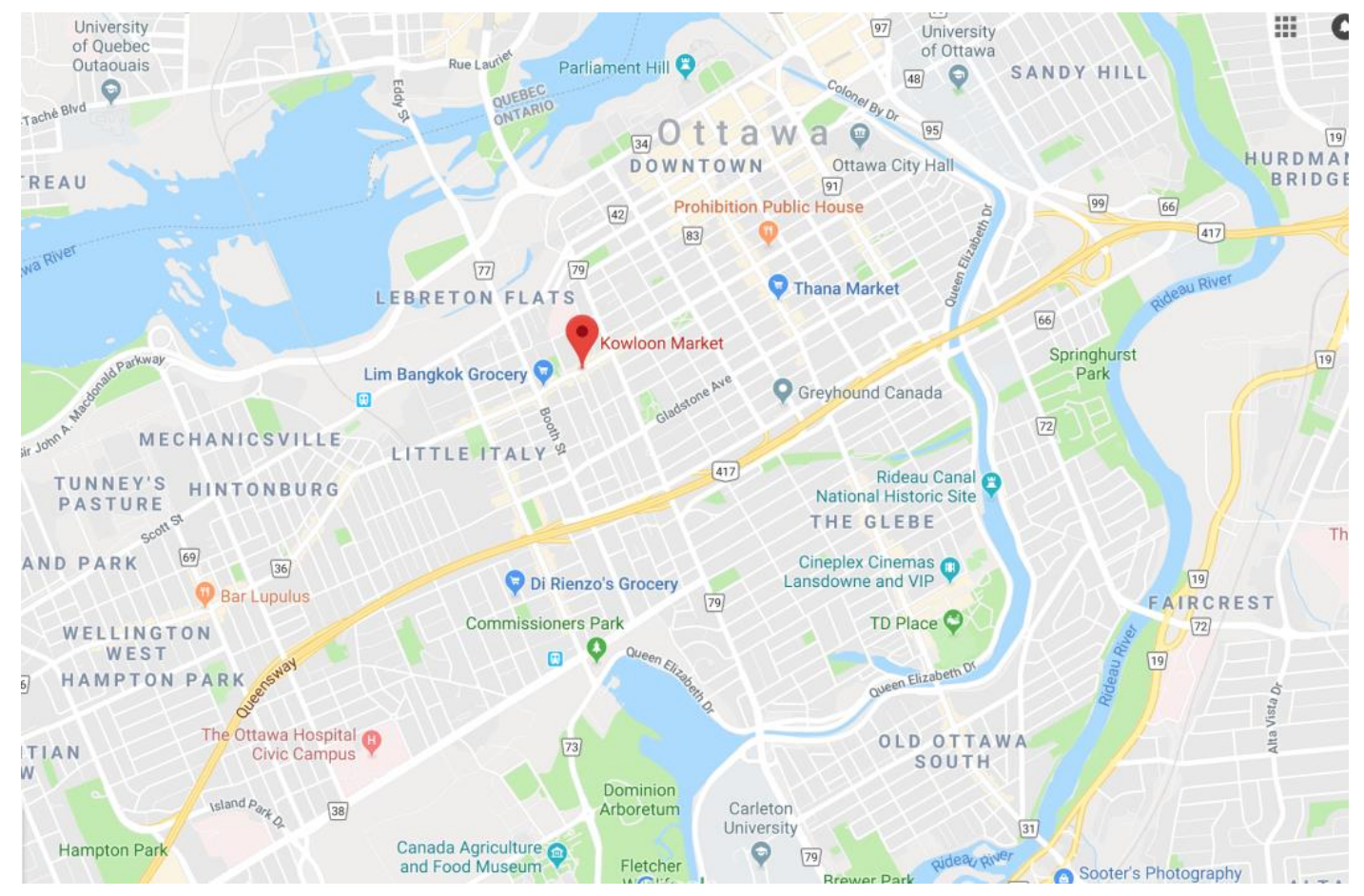

Figure 7 A screenshot of Kowloon Market's position in Ottawa from Google map (2018) 


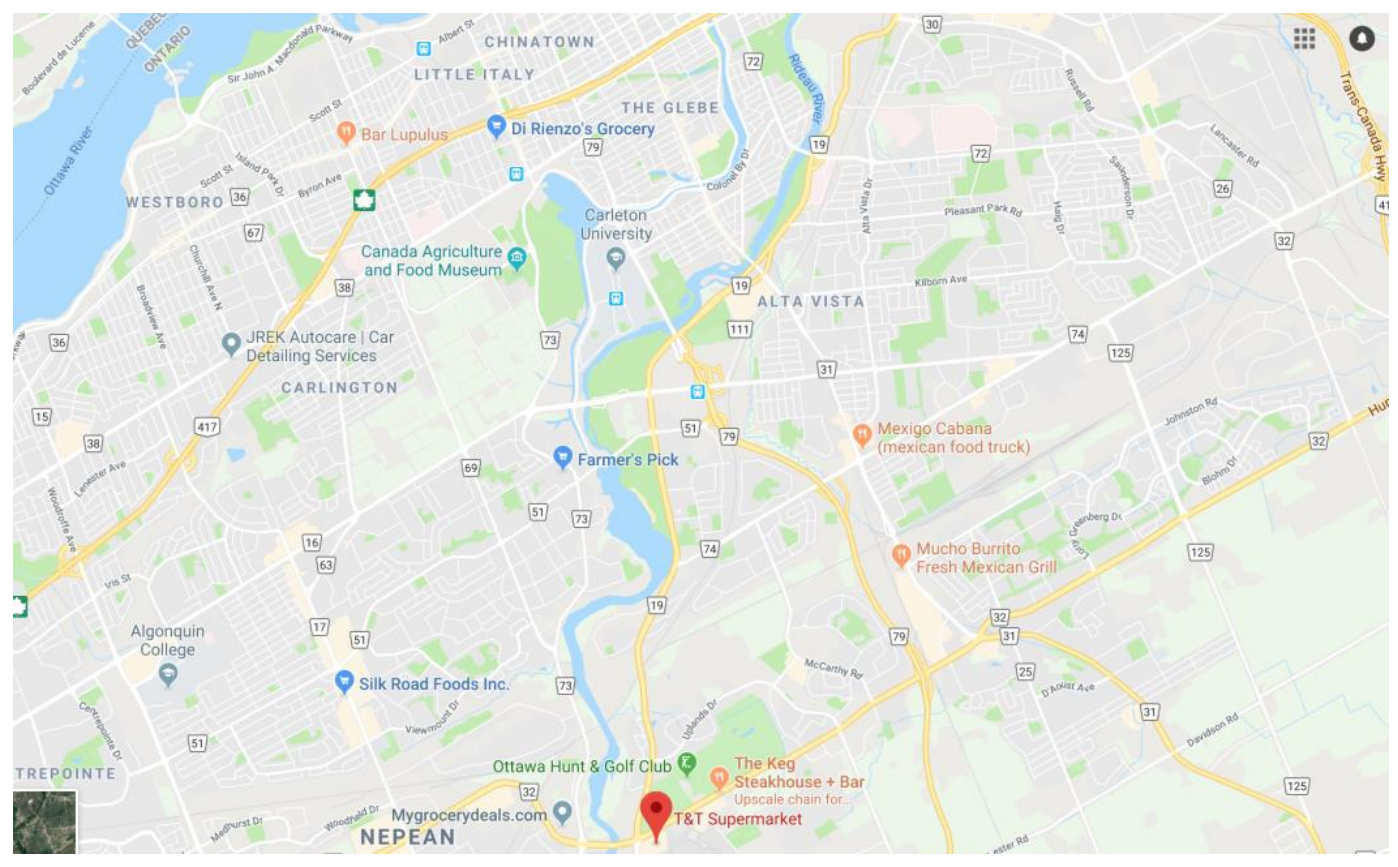

Figure 8 A screenshot of T\&T Supermarket's position in Ottawa from Google map (2018)

These findings confirm the argument that social hierarchy has a powerful influence in the selection process (Harris, 2007) since the individuals who are already privileged with respect to transportation have more advantages in choosing retail food stores, while the others tend to go less frequently and putting more effort into their shopping trips. The hierarchy is derived from the need to retain the original food habits, which made it unique to a Chinese identity. Arguably, the only way to opt out of this hierarchy is to abandon Chinese identity through assimilation or to distance themselves from both the home and the host cultures (as cited in Askegaard et al., 2005), yet neither approach is possible outside theory (Cleveland et al., 2009; Ustuner and Holt, 2007).

In terms of shopping at other retail food stores like Loblaws, Walmart, and Farm Boy ${ }^{22}$, among others, the participants said that most of these stores fulfilled the requirements of daily

22 A Canadian food retailer based in Ottawa. Farm boy is recognized for its fresh produce and high quality, private label food products (Berkshire Partners, 2012). 
home cooking, whether it was Chinese cooking or fusion cooking and, of lesser importance to them, western cooking. These stores were primarily chosen because of their location, and additionally, the student discount that some of them offered during Tuesdays and Thursdays, which were proper incentives for the participants. Shopping at Chinese food retail stores helped the participants to maintain their home food culture since the food items were familiar and culturally appropriate, but when extra time and effort were needed, the participants developed shopping strategies that were more realistic and at the same time occasionally recreated their home food culture. Nonetheless, rationality, as underlined by Harris (2007), was by no means the only factor in shaping the food consumption patterns, and if it were, the participants would not make any additional effort for purchasing Chinese ingredients. The symbolic significance of consuming home culture food, such as maintaining a Chinese identity and strengthening the social ties with compatriots as demonstrated in section 4.2, made the extra effort worth taking.

\section{Eating out}

The cooking ability was one of the most influential factors determining the food choices of the participants. The participants who barely knew how to cook usually consumed frozen Chinese foods at home such as frozen dumplings (purchased from Chinese retail food stores) and they also were more likely to eat out than those who had better knowledge and skill on cooking. Therefore, as Wood (1992) argued, dining out can be an integral part of the daily food consumption for some, and this is a consequence of a combination of cultural and material aspects. On the one hand, the inability to cook hinders the participants from having certain dietary habits, and this resonates with the argument made by cultural materialists such as Visser (1999) that the obtaining a new skill in food production or preparation affects diet habits. On the other hand, the extra effort made to buy frozen dumplings, instead of consuming other more 
accessible local frozen food items, reasserted the significance of culture in food consumption. Moreover, eating out has nothing novel for Chinese students since it has already become a part of the daily routine and involves people of all classes in China, especially in urban centers (Cheung $\& \mathrm{Wu}, 2004)$.

Furthermore, public food consumption was very closely associated with the domestic food systems when the participants weighted benefits versus costs over criteria such as location, taste, efficiency, and price when choosing restaurants, because the criteria are also set in order to retain the participants' pre-existing food habits. Food quality and location were combined factors when choosing restaurants. For example, one participant liked the Korean food in Ottawa because of the taste and also because of the high availability of Korean restaurants in downtown Ottawa (where they resided). Likewise, another participant also noted: "I live near Merivale Road where many good Chinese restaurants opened during the last couple of years, so I eat mostly at these places." The location became less important only when the food quality at the restaurants was worth the time and effort spent on getting them. The participants who ate out less often at Chinese restaurants, because of their dissatisfaction with the food quality, chose food based on efficiency, such as having fast food at food courts. Price was another influential factor, as one participant said that their friends liked McDonald's and sushi because they were both filling and affordable. These findings reaffirm the main findings in section 4.1, and the findings in the empirical studies cited in Chapter 2, namely that Chinese students' major food choices lay between Chinese foods, Asian cuisines, and to a lesser degree, GCC food (Brown et al., 2010; Cappellini \& Yen, 2013; Wu \& Smith, 2016).

Similar to home cooking, social bonds also influenced the choices of eating out, and the preferences of the group were especially important in Chinese culture as it embraced sharing 
food. For participant \#14, ordering food at Chinese restaurants was essentially a social activity as he put it: "The group members order dishes respectively, and we share everything in the end." The meal was constructed by a group effort, which not only satisfied the individual preference but also contributed to the eating experience as a group. The preference for sharing also applied to the choices of non-Chinese restaurants for the participants, as participant \#13 said that he liked Korean BBQ because it was easier to share. Participant \#13 also said that eating out was a social activity for him and hence he rarely ate out besides socializing or hanging out with friends or going out for a date. Participant \#11 revealed that the company of friends was more important than what to eat when she felt stressed and eating out with friends was emotionally comforting. For participants \#13 and \#11, the social bonds established between friends meant a lot more than the food itself.

Although the relationships that the participants had with food did not exist as independently as Meigs (1997) argued in her studies about food prohibitions among the Hua people of the Eastern Highlands of Papua New Guinea, the exchange of food was nonetheless linked to social bonds and facilitated social solidarity. The physical form of food, as Barthes (1997) argued, became less meaningful than the image it signified, and the associated habits created the image. In this case, eating together signifies socialization and belonging as embodied in Chinese dishes and the Korean BBQ, yet the dishes do not intrinsically convey these meanings. This finding resonates with the goal of socializing with compatriots found in the participants' motivation for attending the Night Market discussed in section 4.2.

Concerning the role of culinary hierarchy in eating out, I found that the participants positioned their personal preference within the hierarchy of Chinese cuisines overseas. Food is a reflection of personal taste, yet the personal meanings associated with a particular food are still 
positioned within the systemic meanings of the food (Barthes, 1997). As Barthes (1997) illustrated through the example of the menu, food consumers need to position their personal preference within the existing rules of mores and taboos of what is eatable and what food combinations are legitimate. I discussed that many participants preferred consuming Chinese food more than consuming western food when eating out, yet many of them were still dissatisfied with the Chinese restaurants in Ottawa because of the limited availability and the low quality of their regional cuisine. Again, the dominance of Cantonese cuisine in Chinese restaurants overseas, and even in places where they claim to serve other Mandarin style dishes, (Cheung \& Wu, 2004) inevitably shaped the options for Chinese food in Ottawa as participant \#3 said: "I went to places for northern cuisine more often because the food tasted closer to the food in my hometown [not a northern province in China] than the food at Cantonese restaurants." Participant \#15 also mentioned that, although she liked Sichuan cuisine in her hometown, she barely ate at Sichuan restaurants in Ottawa because the food all tasted like Cantonese cuisine regardless of the style the restaurants claimed to serve.

Moreover, the dominance of Cantonese cuisine is linked to more recent geo-political and economic developments, which in the Canadian context, are represented by the noteworthy flows of middle-class Hong Kong immigrants after the liberalization of Canadian immigration policy in 1967 (Wong, 2017). Therefore, the dominance of Cantonese cuisine overseas is a reflection of the class hierarchy in the culinary world. Moreover, the decision of reserving fancy western restaurants for special occasions was also influenced by the class hierarchy in the host country. One participant and their Chinese romantic partner liked to celebrate Christmas in restaurants that exceeded their daily food consumption budget, and they also liked to enjoy this romantic meal in other cities like Montreal. Another participant also chose to celebrate Christmas as well 
as some other non-Chinese festivals with their Chinese romantic partner in western restaurants, especially French cuisine because of the romantic atmosphere.

These findings resonate with the argument that the bourgeois code of eating is behavioral instead of nutritional through elevating the meal to an aesthetic dimension (Bourdieu, 1984). However, I am not criticizing the participants for attaching symbolic meanings and ritualistic behaviors only to the bourgeois meals and thence reinforcing social hierarchy, as Wood's (1995) critique of Bourdieu does. I argue that the participants construct their understanding of good taste through learning the standards in the host country, which are at the same time determined by the social elites (Bourdieu, 1984). Cultural outsiders, as mentioned earlier, often celebrate ethnic festivals through consumption because the symbolic significance is less meaningful to them. Hence as cultural outsiders, the participants exhibited the standards of a good taste that they learned in the host country through food consumption, while unconsciously positioning their taste within the class hierarchy of food and taste in the host country. Adopting this culinary manner has made several participants more hybrid, but has not impacted their Chinese identity.

\subsubsection{The interpretation of authenticity}

Authenticity is constructed through the perceptions of food producers and consumers and linked to expectations (Johnston \& Baumann, 2010; Lu \& Fine, 1995). At the same time, authentic food is often characterized in relation to inauthentic foods (Johnston \& Baumann, 2010). Understanding how the participants discursively construct the authenticity of Chinese food in Ottawa, this section uncovers the role that authenticity plays in food consumption. Chinese food items that were distinctive to Chinese culture were deemed authentic by the participants because they were symbolic of a Chinese identity. Moreover, Chinese foods with specific geographic referents, which were consistent with the established standards, were 
authentic for the participants due to the limited accessibility to high quality Chinese food in Ottawa. The ethnicity of food producers signified authenticity as well, and authentic Chinese food was also followed by the notion of simplicity. Last but not least, some participants believed that authentic Chinese food was more likely to be consumed by Chinese customers.

For some participants, certain Chinese food items at the Night Market could hardly be seen as inauthentic. These food items such as stinky tofu and Shaobing were deemed as unique to Chinese culture, and thus they were symbolic of a Chinese identity regardless of the food quality. For instance, participant \#10 thought that despite how bad the stinky tofu tasted at the Night Market, the taste was still Chinese because Canadians did not eat stinky tofu. In her analysis of food and festivals in three American communities, Douglas (1984) drew a similar conclusion that "the foods are always symbolic of tribal identity, not simply because they are tasty, but because whites rarely eat buffalo and never eat dog" (p. 92). Therefore, the food items are authentic to the participants regardless of the taste because they are explicitly associated with a Chinese identity and recognizing the food made the participants different from non-Chinese attendees at the Night Market. As participant \#5 noted: "The Shaobing was authentic, but the taste was mediocre. Since it was not made from scratch, it just tasted like the grab-and-go food I had in China."

The participants often considered the geographic context and the consistency with the established conventions and traditions of the food together when assessing the authenticity of Chinese food in Ottawa. For example, one participant praised a Jiangxi ${ }^{23}$ restaurant as authentic because the food was consistent with the established conventions in Jiangxi. Another participant, on the contrary, found a Cantonese restaurant inauthentic because the food did not follow the traditions in Guangdong ${ }^{24}$. Place-specific food, as the participants agreed upon, represents the

\footnotetext{
23 A province in China.

24 Cantonese cuisine is from both Guangdong province in China and Hongkong.
} 
version of the food that is different from elsewhere. The people from the specific place are most familiar with the characteristics of the food (Johnston \& Baumann, 2010). Additionally, authentic food should be prepared with a set of established standards, conventions, and traditions, and should not be modified in response to new local conditions and ingredients (Heldke, 2005). Therefore, because of the diversity of Chinese cuisines, the participants often felt that they were only qualified to assess the authenticity of the food if they had the 'authentic version' before, and this 'authentic version' nevertheless depended on the place and the tradition.

For participant \#6, the hot dog style sausage ${ }^{25}$ and other Taiwanese food at the Night Market were authentic because they tasted similar to the version he had in Taiwan. Likewise, for participant \#8, those Chinese foods in Ottawa that tasted closer to the foods he liked in China were authentic. In contrast, another participant thought that they were inadequate in assessing the authenticity of the spicy tofu pudding they had at the Night Market because that was their first time having it and they could not compare it to the 'authentic version.' However, this participant felt adequate as a Cantonese person to tell that the Cantonese cuisine in Ottawa was less authentic than the Cantonese cuisine in Toronto because the ingredients were not fresh enough, and Cantonese cuisine is known for relying on fresh ingredients. In the same way, when consuming the typical food of their hometown, one participant cared a lot more about the established conventions and traditions in making the food authentic, as they noted: "Adding sausages into Jianbingguozi ${ }^{26}$ is nontraditional and thus making it not Jianbingguozi at all!"

Unsurprisingly, foods modified in response to the local conditions in Ottawa were inauthentic to some participants. For participant \#6, the charcoal grilled lamb kabob was authentic at the Night Market because it added aroma to the meat and it was the original Chinese

25 Dachangbaoxiaochang in Mandarin, which is a pork sausage wrapped in a glutinous rice sausage.

26 Chinese savory crepe. 
way of doing it, whereas modifying the method with the electric griller, as at some Chinese restaurants in Ottawa because of the fire hazard, made the kabob inauthentic. The Chinese dishes in Ottawa that the participants had never seen in China were the most typical examples of inauthentic Chinese food. These dishes were often defined by their use of Chinese ingredients that were more understandable to non-Chinese customers and their prevalence in the sweet and sour taste, as participant \#1 explained: "Some food courts claim to serve Chinese food such as Lemon Chicken and General Tao Chicken, but they are not Chinese food at all! We never had those foods in China. They are merely made for non-Chinese customers."

Through romanticizing traditions, the participants have certainly overlooked the complex historical, social, and cultural influences that the new local conditions can have on food habits (Heldke, 2005) while failing to acknowledge that the modern Chinese cuisines are also results of outside influences (Cheung \& Wu, 2004). Moreover, through emphasizing the specific geographic context, the participants could also mistake their interest in the discovery of new food for the appreciation of authentic cuisine, and the food that people identify as authentic is often simply what is foreign to them (Heldke, 2005). This was made clear when a participant who was unfamiliar with Cantonese cuisine before they came to Ottawa said that the Cantonese restaurants in Ottawa might be pretty authentic because the food tasted good.

However, when limiting authenticity within the specific geographic context and the established conventions and traditions, the participants were actually complaining about the Chinese food quality in Ottawa. In other words, for the participants, many Chinese foods in Ottawa were simply bad and when they were good, authenticity seemed less important to them. Participant \#10 said that authenticity had a weak influence on him when choosing Chinese foods in Ottawa and at the Night Market, and as long as the food was tasty, the associated conventions 
and traditions were by no means determinant. For participant \#12, the less spicy and oily Sichuan cuisine in Ottawa was more suitable for her taste even though she acknowledged that the dishes were not consistent with their established standards based on her trip to Sichuan. Some participants also commented that authenticity was open to personal perceptions, so it was hard to determine or define. As participant \#13 noted: "If I say something is inauthentic based on my previous experience with the food, others could also argue that what I used to eat was also inauthentic." Participant \#14 agreed that there was no fixed definition of authenticity, and he was satisfied with the lamb kabob at the Night Market although the meat chunks were bigger and the spice was different from the established standards.

In addition to the specific geographic context, culinary authenticity is also inseparable from the ethnicity of food producers (Johnston \& Baumann, 2010). As participant \#2 explained: "I like [the restaurant] Full House because the cuisine is very close to my taste and the owner and I are also from the same city, so the place is authentic to me." Another participant had a similar notion as they described their experience at an inauthentic Sichuan cuisine: "The dishes tasted very close to Cantonese dishes and later I found out that the chef was Cantonese. It made sense that a chef who's not from Sichuan didn't know how to make real authentic Sichuan dishes although the food was ok." This participant, whose hometown was well-known for Sichuan cuisine also thought that Sichuan restaurants in Toronto were pretty authentic and they could tell that the dishes were made by chefs from Sichuan. As can be seen, talking about place-specific authenticity is indeed reflecting on the nostalgia that the participants have for the unique flavor of that particular place (Trubek, 2005), not the least when it is their hometown, and only chefs from the specific place are seen as able to reproduce the flavor. 
Agreeing with Johnston and Baumann's (2010) finding that simple food is authentic, for the participants, simplicity is characterized by a home-like taste, which is distinguished from the commercial quality of restaurant food, and/or is made through a small-scale food production or preparation process. Participant \#5 thought that a Cantonese restaurant in Ottawa was authentic because the food there was less oily and tasted like homemade meal. The home-like taste creates nostalgia and leads to an emotional bond with the food, as participant \#5 explained: "I was not a fan of Chinese food even at home, so after I spent all these years in Ottawa, when I missed Chinese food, I was missing the taste that I was familiar with, but not because how good the food was." Home-like taste, as well as a small-scale food production process, also made the food more authentic for participant \#10 as he noted: "If you want more authentic Chinese food, you could choose the Chinese takeaways made by Chinese migrants in their home kitchen."

Some participants agreed with Johnston and Baumann's (2010) observation that authentic food of an ethnic cuisine should not only be made by, but also eaten by the corresponding ethnic group because the members of the ethnic group know the real taste. For participant \#3, some of her favorite Chinese restaurants in Ottawa were authentic because the target audience was Chinese customers, such as a Chinese BBQ place, which according to her had no English menu. Participant \#3 had also explored some Chinese restaurants that she was unfamiliar with, where most of the customers were non-Chinese, and she often found out that she did not like them because the food tended to be extra sweet and thus inauthentic. In contrast, the restaurants that participant \#3 ate at rarely had non-Chinese customers, and she described the demographics of the customers at Chinese restaurants in Ottawa as "very polarized." Participant \#7 had a very similar perception about the relationship between the demographics of the customers and authenticity, as she said: 
Having many non-Chinese customers in Chinese restaurants means the place is not good whereas having many Chinese customers in a Chinese restaurant means the place is good. This might be my personal bias but it is less likely to encounter westernized Chinese food in places having many Chinese customers.

Assuming that other Chinese customers will have similar attitudes toward food quality and authenticity as themselves, these examples from participant \#3 and \#7 reaffirm that authenticity is constructed through perceptions and linked to expectations (Johnston \& Baumann, 2010; Lu \& Fine, 1995). These expectations nevertheless reflect the imagined Chinese community in Ottawa that the participants have in mind. The strong influence of the ethnic social network helps Chinese students to resist nutrition transition, but at the same time impedes acculturation.

\subsection{Looking at dietary acculturation through a cultural lens}

This section, consisting three sub-sections, examines the relationship between cultural beliefs and nutrition transition, as well as the corresponding implications on the notions of cultural appropriateness, and the social relations established around food consumption.

Sub-section 4.4.1 deals with cultural beliefs and nutrition transition. A low rate in acculturation, characterized by not liking Canadian foods and not having many Canadian friends in general, while having strong ethnic ties with their compatriots leads to minimal nutrition transition found amongst the participants. Additionally, pre-existing cultural beliefs on health and nutrition are utilized to assess dietary changes. Nourishment describes the pleasure and comfort of consuming home culture food beyond the scientific notion of nutrition, and it is crucial for retaining a Chinese identity. When the Chinese meal structure is distorted, the notion of nutrition replaces nourishment.

The second sub-section reveals the participants' perceptions of cultural appropriateness from their experiences at the Night Market, and the implications for health communication and cultural learning. Cultural appropriateness informs health communication, and it also associates 
cultural sensitivity with ethnic identity by emphasizing the symbolic significance of traditional food habits in maintaining the ethnic identity. Claiming cultural appropriateness is attempting to subvert the subordinate position of the ethnic community in the host country. However, a Chinese identity is maintained at the expense of cultural learning skills, which hinders the participants from understanding local cultural norms and cultural diversity at the Night Market. The degree of acculturation among the participants still varies.

In the last section, I illustrate the benefits that the participants identified in relation to forming mononational friendship groups around sharing home culture meals. It is not the meal structure that facilitates sharing, but the types of social relations that the participants want to construct and maintain with the people with whom they are sharing meals. Hence, food sharing, as embedded in Chinese culture, is utilized to strengthen the social bonds amongst Chinese students. This relationship facilitates a sense of belonging among the participants, based on their similar cultural background and similar experiences as Chinese students in Ottawa. The emotional benefits could sometimes outweigh the undesirable consequences on language and culture learning.

\subsubsection{The role of culture in nutrition transition}

The definition of a nutritious meal often varies from culture to culture, shaped by agricultural practices, traditional beliefs about food and health, and social relations (Garnweidner

et al., 2012; Gilbert and Khokhar, 2008; Luo, 2002; Wu \& Smith, 2016). Through unpacking the nutrition related concerns in food consumption, I am interested in knowing the role that cultural beliefs play in the perception of health and nutrition among the participants, rather than evaluating the role of scientific knowledge in making food decisions. Informed by Visser's (1999) notion that changing diet will change the culture and vice versa, I looked through a 
cultural lens in assessing the reasons for (not) going through a nutrition transition. I argue that social relations and cultural beliefs transcend material conditions in determining nutrition transition, and the perceptions of nourishment and nutrition. Nevertheless, these findings were unique to the research population and should not be generalized to other populations because the capital resources that the participants possessed have inevitably contributed to the results.

No clear case of nutrition transition ${ }^{27}$ was found in this research, and no notable concern regarding the health impacts of nutrition transition mentioned either by the participants. Higher rate of acculturation, which is characterized by "speaking English, having lots of American friends, and liking American food, along with the length of stay in the USA" (Wu \& Smith, 2016, p. 332), was found to be associated with the negative health impacts of nutrition transition, such as obesity and chronic diseases (Wu \& Smith, 2016). In contrast, the less acculturated students are less likely to gain weight during their stay in the USA, and their friends are mostly of Chinese origin (Wu \& Smith, 2016). In the Canadian context, immigrants are less likely to be obese in their early days of immigration (Cairney \& Ostbye, 1999). Moreover, the substantial influences of ethnic group social networks have tempered the adaptation to the norms of a Canadian lifestyle, which is associated with excess weight gain with additional years in Canada (Cairney \& Ostbye, 1999; McDonald \& Kennedy, 2005).

As mentioned in section 4.1, the participants rarely mentioned that they liked Canadian food in general or had many Canadian friends, and the majority of them had been in Canada for six years or less. Besides, many of the participants had strong ethnic ties with their compatriots, and thus they could be rated low in acculturation regardless of their language fluency, which was unknown to this research. This relatively low rate of acculturation and the influence of a strong

\footnotetext{
27 Transiting from a healthy home culture diet toward a high-fat and energy dense diet under the globalization of western lifestyle (Popkin et al., 2001).
} 
ethnic social network might explain why the participants had no concern toward nutrition transition.

Nutrition transition is normally influenced by previously held culinary knowledge and food beliefs (Gilbert \& Khokhar, 2008). Although the changes in the food habits of the participants, as examined in section 4.1 (about becoming more hybrid), were unrelated to nutrition transition, the changes were still assessed by previously held knowledge and beliefs concerning food and health. Participants who used to consume lots of spicy foods claimed to consume much fewer spicy foods in Ottawa. In addition to consuming fewer spicy foods, participants \#14 and \#15 also described this change as eating more bland foods, which were less spicy and less oily. Both participants used the word bland to convey a sense of healthiness to their new dietary habit, even though for participant $\# 14$, this healthier choice was related to the low availability of spicy Chinese foods. Participant \#15 explicitly linked this dietary change to her health consideration. As she explained:

This happened because of the climate in Ottawa. We used to consume more spicy foods at home in order to reduce the humidity in our body. Whereas the air humidity in Ottawa is lower than the air humidity in my hometown, and consuming more spicy foods as I used to do would make me suffer from Shanghuo ${ }^{28}$.

Consuming more bland foods in order to balance the symptoms of Shanghuo resonates with Wu' and Smith's (2016) finding that Chinese students' perception of healthy food is strongly influenced by traditional Chinese medical belief system and the principle of "Yin-Yang", which value the balance between positive and negative elements in the body. According to Yates-Doerr (2012), not all communities accept the western notions of nutrition, and in this case, the

\footnotetext{
28 Shanghuo can be translated literally as having excessive internal heat. Applying the principle of Ying-Yang, higher air humidity adds more Ying elements into the human body while spicy foods are Yang elements that can help to shift the body back to the equilibrium. Thus, traditional Chinese herbal medical science believes that consuming a higher amount of spicy foods can lead to symptoms caused by Vitamin B2 deficiency such as dryness of the skin around the nose and mouth, dry tongue, vision problems, etc. (Pordes, 2014), and Shanghuo is a general yet vague description of these symptoms.
} 
participants still relied profoundly on traditional Chinese medical belief system. This is not always well integrated into nutrition communication, making health promotion related to diet less effective.

One participant used a pretty unhealthy description of their preferred Chinese food under the western notions of nutrition without expressing any concern regarding health or safety, as they pointed out: "I like the really oily and salty taste, ha-ha, right, taste really heavy and like gutter oil ${ }^{29}$." First of all, this perception reinforces the finding that Chinese diet is not inherently healthier than North American diet (Schultz et al., 1994) since children and adolescents in China were shifting toward overnutrition due to high intake of foods from animal sources and edible oil (Popkin et al., 2001). This shift is not only influenced by the globalization of a western lifestyle but is also encouraged by the greater market availability of energy dense foods in the traditional Chinese diet.

Secondly, as exemplified by participant who mentioned gutter oil, Bush et al.'s (1998) argument that health is mentioned as neither a major nor a minor concern when discussing the logic behind the preference of their home culture food is confirmed. Desirable home culture meal values nourishment over nutrition, because nourishment undergirds the pleasure and comfort of eating and cannot be scientifically measured (Yates-Doerr, 2012). Understanding the significance of nourishment in health communication, as Anderson (2003) argued, could avoid the potential of "victimizing the ethnic minority" (p. 313) when their cooking practices are deemed as unhealthy under the western notion of nutrition.

A completely different language was used when describing a healthy alternative cuisine, which contains food items and habits that are not what the participants grew up with, and is often

29 A term used in China to describe the illicit practice of recycling waste oil in restaurants, which are collected from animal fats and grease found in restaurant fryers, garbage, and even in sewer drains (Daro, 2013). 
assessed in biomedical terms as balancing vitamins and proteins (Bush et al., 1998). Likewise, as mentioned in 4.3.1, because the Chinese meal structure is distorted for practical reasons, and the characteristics that make a meal Chinese no longer exist, this participant regards their daily food consumption as not eating but surviving. This participant evaluates the healthiness of their food consumption correspondingly applying the notion of nutrition, which is a technical and scientific approach that is "centered upon vitamins and minerals" (Yates-Doerr, 2012, p. 294). This participant said that the negative impact of the absence of the parental supervision on their dietary habits was not eating regular meals or eating unbalanced meals, as they described: "If I want to only eat meat in the next couple of days, there won't be anyone to stop me from doing that." From contrasting the different attitudes toward the healthiness of Chinese food, it has been made clear that cultural beliefs transcend material conditions in determining the individual perspective on food and nutrition.

\subsubsection{The meanings of cultural appropriateness}

The participants have revealed their perceptions of cultural appropriateness in their experiences at the Night Market. Through uncovering these perceptions, I aim to understand the things that were deemed as culturally inappropriate at the festival, as well as the implications for health communication and cultural learning. Recognizing the differences in food habits would make the messages in health communication more comprehensible to the ethnic group while enhancing a sense of membership within the host country.

The definition of culturally appropriate food was similar to the definition of authentic food, as well as nostalgia for the Chinese food environment. For participant \#1, culturally appropriate food was characterized by the consistency with the established conventions and traditions, as she noted: 
I think the Night Market is pretty Chinese since the food was not purposefully tailored toward the preference of non-Chinese attendees. It would not be culturally appropriate to serve foods like General Tao chicken at the Night Market, because you are supposed to preserve the Chinese traditions on food habits.

The differences in the perception of Chinese food between Chinese attendees and non-Chinese attendees also underlined the importance of being culturally sensitive in health communication. As explained by Foronda (2008), adopting cultural sensitivity in health communication is understanding the cultural differences and tailoring the message to fit the group, which ultimately matches the advice given by local health practitioners with the native food culture of the group (Fagerli, Lien, \& Wandel, 2005).

Some participants thought that certain inauthentic foods were made in order to be more culturally appropriate for non-Chinese attendees at the Night Market. For example, participant \#9 and her friends believed that the reason of altering the methods of making the stinky tofu at the Night Market was because the non-Chinese attendees would not understand the process of fermentation on tofu and they would regard it as rotten tofu. Therefore, the vendor spread the stinky sauce over fresh tofu so that it became stinky, but the result was neither culturally appropriate nor tasty for the Chinese attendees. Participant \#11 agreed with this observation and added that serving the tofu with pickles was also inappropriate for Chinese attendees but fit the local food habit.

Cultural inappropriateness, in this case, simply meant tailoring the Chinese food habits to fit the local foodways, which made the food less desirable to the Chinese attendees. In Koc and Welsh's (2002) paper regarding the immigrant experience of food insecurity in Canada, they found that "finding familiar, culturally acceptable, and fresh foods" (p. 7) was important for immigrants. Moreover, the accessibility to culturally acceptable food was also an essential analytical tool for assessing the membership of the immigrants within the host country (Koc and 
Welsh, 2002). When consuming Chinese food in a multicultural setting, the participants have internalized the expectation that the culturally appropriate food habits need to be compromised for the mainstream acceptance. How one views membership also depends on the perception of the others (Koc and Welsh, 2002), and in this case what is culturally appropriate for the Chinese community is deemed as inappropriate or even inferior by the mainstream society. Emphasizing cultural appropriateness is not romanticizing authenticity, but reflecting the subordinate position of the Chinese community within the host country.

The participants evaluated the Night Market based on a typical Chinese Night Market that they had in mind and distinguished any atypical environmental elements at the Night Market as culturally inappropriate. However, the perceptions of cultural appropriateness on environmental elements were less consistent amongst the participants than their perceptions of cultural appropriateness on food habits. These variations have shown a great deal of diversity and complexity in the home culture that is subject to individual performance. Meanwhile, it also relates to the individuals' different rates of acculturation.

For instance, participant \#1 said that the Disco lights made the beer garden at the Night Market look like a club, which was weird compared with the Night Markets in China. For participant \#6, selling coffee and other non-Asian food items at the Night Market was irregular, let alone seeing non-food and non-festival related sponsors and activities, such as the Casino du Lac-Leamy and the baseball setup in front of the Royal Arch at Chinatown.

In addition to the setups, some participants also felt that calling the festival a night market was somewhat inappropriate because the Night Market lacked in the sense of folk culture that the participants usually saw in night markets in China. According to participant \#5, the festival attendees and the atmosphere were a bit too orderly and not as chaotic and bustling as she would 
expect to see at a typical night market in China. Installing flashing signs at each booth, according to participant \#5, would make the festival not only taste like but also feel Chinese. Participants \#7 and \#15 felt that not being able to sit down and chat with friends for a longer time at the Night Market as they would in China was a shame. However, unlike what participant \#5 found disappointing, participant \#7 enjoyed a less noisy and less chaotic Night Market, although she acknowledged that the chaos could also be seen as a unique character that many Chinese might enjoy. Participant \#9 also mentioned that the night markets in China needed improvements on cleanliness, where the Night Market had done an extraordinary job with that.

The participants who emphasized the standards of a Chinese night market with little consideration of cultural differences were more likely to have an ethnocentric evaluation of the Night Market compared to those who were more sensitive to cultural differences among the attendees. As discussed earlier, the development of cultural learning skills requires long-term, direct, and meaningful interactions with people from different cultural backgrounds and in unfamiliar contexts (Cushner \& Mahon, 2002). However, the low rate of acculturation among the participants, characterized by retreating into mononational friendship groups, discouraged language and cultural learning (Brown, 2008). Cultural learning skills are necessary for the participants to understand and respect cultural differences in multicultural settings like the Night Market. Migrants who do not exclusively socialize with their compatriots are more likely to develop better language skills and are able to better navigate the local cultural norms (Masgoret \& Ward, 2016).

In terms of sociability, Bond and Cheung (1983) have argued that people from individualistic cultures are more sociable than people from collectivist countries because observing and conforming the ideas of others are social techniques for acquiring acceptance by 
others in individualistic society. This argument might explain the little attempt performed by the participants to have meaningful interactions with people from different cultural backgrounds. As members of a collectivist culture, they already had similar worldviews with their compatriots. As discussed earlier, educational institutions should pay more attention to cultural learning while also recognizing the benefits of forming mononational friendship groups, which are demonstrated in the next section.

\subsubsection{Eating together}

The participants who recreated the structure of a Chinese meal were those who had roommates or close friends with whom to share home-cooked meals. Roommates shared meals not only because they lived together, but also because they were friends. Getting along well with each other was more important than living together in respect of sharing meals, considering the complex duties associated with sharing meals, such as the labor division, the time and effort spent for negotiation, and the sharing of the financial burden. According to Visser (1999), we usually feel time-related pressures when meeting someone over a meal, because meals have always been "an essential medium for social sharing and relationship" (p. 4). The emotional benefits of forming mononational friendship groups, as exemplified by the friendships strengthened from food sharing, could sometimes countervail the undesirable consequences on language and cultural learning.

Chinese students have noted the influence of roommates on food choices during their sojourn overseas (Wu \& Smith, 2016). As participant \#4 revealed, he was the only one who cooked amongst his roommates, yet they always shared meals and his roommates did the dishes. However, for participant $\# 12$, having roommates who were also Chinese did not lead to shared Chinese homemade meals. During school days, participant \#12 usually cooked foods that were 
both handy and better suited for eating alone such as noodle soup but when she was less busy, she would cook stir-fry dishes for herself. However, she and her roommates did not share meals, as she described: "My roommates all know how to cook, and we occasionally try each other's food if we make extra, but we just don't eat together."

It was not that Chinese food was meant to be shared with compatriots as Counihan and Van Esterik (1997) argued, but whether or not sharing Chinese food implied the types of social relationships that the participants wanted to construct and maintain with the people they shared meals with. For those participants who shared meals regularly with others, the food they consumed also strengthened their friendships. Participant \#14 spent more time cooking with his friends at their apartment than eating at his own place. The meal was essentially a team effort, and the labor division between the four of them was balanced, as he clarified: "We all prepare the meal together. Some of us do the chopping and the others do the stir-frying, and basically each one of us contributes one dish to the meal as a whole." In this case, eating together was not only a cost-efficient food consumption strategy but also an essential medium for the relationship.

In terms of the financial division, participant \#10 believed that regularly sharing meals at home required the roommates to be less calculative on the expenditure for grocery shopping, as he noted:

We always split the bill after my roommate went grocery shopping and then we could use everything together in the fridge. I used to go with him, but after I realized that this made no difference to the foods we bought, I stopped going choosing to instead wait at the home and split the bill.

Participant \#10 also revealed that coming from the same region in China, where the food habits and even lifestyles were similar, made things more comfortable between him and his roommate. When they cooked at home, the roommate's girlfriend also sometimes joined them, and the three 
of them often hung out together with other friends. Likewise, participant \#14 ate out frequently with the peers he shared homemade meals with, as he mentioned:

Before we moved off campus, we ate together at the school cafeteria, and we also sometimes ate out together. We ate noodle frequently because there were several noodle places nearby, or we shared Chinese meals at restaurants. Besides, we went out occasionally for western foods such as steak.

As argued by Julier (2013), social networks could be established through shared meals both at home and in public, and for the participants, the social networks formed around food were also extended to other activities. Many participants had other activities with their friends before or after attending the Night Market, which reaffirmed their festival motivation of hanging out with friends. As mentioned by one participant, they and their friends went watch the sunset at a nearby beach after eating at the Night Market, and another participant took a trip to the Casino after attending the Night Market as this was part of their original plan regardless of the Casino booth at the festival. Additionally, one participant attended the Night Market with friends after they went to an escape room, and they barely ate but went along for the ride. All in all, hanging out with close friends who shared both similar cultural background and similar experiences as Chinese students in Ottawa attached a sense of belonging to the participants, which sometimes outweighed the negative impacts on language and culture learning.

The findings presented in this chapter reveal a complex relationship the participants have with food and I next turn to drawing some conclusions from these findings. 


\section{CHAPTER 5: CONCLUSION}

Through looking at food festival-related activities and interviewing post-secondary Chinese international students (Chinese students) in Ottawa regarding their dietary acculturation process, this research has explored the roles that ethnic food festivals, traditional festivals, and festival foods play in the hybridization and identity formation of Chinese students. The findings suggest that Chinese students have become more "hybrid" in their food practices resulting from an increased consumption of various Chinese regional cuisines and Asian cuisines, and less so from incorporating Canadian food habits. However, becoming more hybrid does not weaken the participants' Chinese identity; rather they retain it through attending the Night Market, celebrating traditional Chinese festivals, and maintaining cultural beliefs related to food choices, health and nutrition. This study confirms that hybridization is distinct from identity formation, and suggests that hybridization involves multi-cultural and multi-dimensional influences.

Relying on a constructivist worldview, this research aimed to unpack the ways in which the participants construct meanings at the 2018 Ottawa Night Market Chinatown (the Night Market) and in their daily social settings. The methods chosen for the data collection included participant observation and semi-structured interviews. The research data comprised my field notes of the participant-observation at the Night Market and the fifteen transcripts of interviews conducted with self-identified Chinese students in Ottawa, who also attended the Night Market.

The participants become more hybrid from their increased understanding and appreciation of Asian cuisines and other Chinese regional cuisines in Ottawa. The dominance of Cantonese cuisine shows that regional hierarchy is still at play among the Chinese diaspora in Ottawa. Asian cuisines and other Chinese regional cuisines were not only consumed outside the home, but were also incorporated into the participants' daily diet through cooking. The capital resources 
that the participants obtain, i.e., their post-secondary education and their relatively comfortable financial situation, have nonetheless facilitated this hybridity. Still, the difficulties of completely retaining the home country culture, which could be even harder than adopting the host country culture, as well as the diversity and the complexity of home culture should also be recognized in the future research on dietary acculturation.

This contemporary definition of hybridity complicates the role of food consumption in hybridization, which has often been framed as a dichotomy between home culture and host country culture in previous studies (see Cleveland, Laroche, Pons, and Kastoun, 2009; Ustuner \& Holt, 2007). The more complex definition provides a unique opportunity for future research not only in the field of food, but in the fields of migration, globalization, and identity formation by and large in ways in which that hybridization should be no longer seen as a two-way-flow process.

Learning to cook was significant for keeping the participants' original dietary habits and food preferences. Familiar dishes they consumed at home were replicated, and this selfsustaining lifestyle also made the participants feel emotionally satisfied. Additionally, some participants had modified local ingredients with familiar preparation methods, and transformed foreign elements into culturally appropriate meals (Garnweidner et al., 2012). The participants' knowledge of local food and food conventions did grow as they stayed longer in their host country. Cultural appropriateness played a more prominent role than material availability in making food decisions, because the participants were willing to put more effort into finding their ingredients of choice, and resisted being limited by what was immediately available to them whenever the extra effort was affordable. The taste of home constantly reminded the participants 
of their good memories at home, whereas the absence of the taste in Ottawa also enhanced the feelings of grief for leaving home.

Becoming more hybrid in food consumption did not weaken the participants' Chinese identity, which also confirms Cleveland et al.'s (2009) argument that identity and acculturation are two distinct processes and migrants who become more hybrid through consumer acculturation can also retain their ethnic identities. The Night Market reinforced the participants' collective consciousness as Chinese students in Ottawa and attached a sense of belonging to the attendees through intercultural exchanges, consuming home culture food, and socializing with compatriots.

Consuming Chinese food, especially festival food, and celebrating Chinese festivals are ways of maintaining Chinese customs and traditions, strengthening the social ties with other Chinese students in Ottawa, and ultimately maintaining a Chinese identity, but they are not used to reject the host culture. Chinese New Year is still the most important Chinese traditional festival that the participants celebrated in Ottawa. The participants mentioned the lack of the festive atmosphere in Ottawa as well as the absence of family members as notable differences compared to the Chinese New Year in their hometowns. Having strong social ties with other Chinese students in Ottawa, flexible schedules, and a high accessibility to festival food items are crucial for maintaining the participants' customs and traditions. This research did not find the negative health impacts of the overconsumption of festival foods as argued by Azar et al.'s (2013) because other than Jiaozi, the participants rarely incorporated other festival foods into their daily food consumption patterns.

Through mostly consuming festival related commodities, celebrating festivals rooted in local traditions has little impact on the majority of the participants' Chinese identity because the 
participants consume local culture as a form of commodity and have a weaker symbolic attachment to the festivals. Limited social and cultural capitals, such as not having many nonChinese friends, have nevertheless hindered the participants from understanding the cultural conventions of the festivals. For one participant whose sense of being a global citizen is greater than their sense of Chineseness, celebrating local festivals intensified their pre-existing identity as well, rather than altering it.

In order to provide a more thorough interpretation of the food behavior of Chinese students, the boundaries between a social constructivist worldview, structuralism, and materialism were challenged and re-described in this research. This research recognizes the meanings of food as intertwined with social structures, material availabilities, and personal constructions. Utilizing the commonalities between a social constructivist worldview, structuralism, and materialism, instead of highlighting their differences, has given this research a more nuanced theoretical lens.

As aforementioned, cultural beliefs had a more substantial influence on food choices than material conditions. The participants' choices of food are linked to social bonds and social hierarchy rooted in Chinese food habits, while local limits are navigated through these habits. Raised in a culture that embraced sharing meals, eating together signifies socialization and belonging for the participants. The limited availability of Chinese retail food stores and the lack of diversity in regional cuisines perpetuate not only culinary hierarchy, but also social hierarchy within the Chinese community in Ottawa. This is the case because the access to a vehicle privileges some Chinese students in retaining original food habits, and also because the dominance of Cantonese cuisine in Ottawa is linked to the geo-political and economic developments of Hong Kong immigration to Canada. Through reserving fancy western 
restaurants for special occasions, the standards of a good taste in the host culture are also adopted that make the participants more hybrid, but have little impact on their Chinese identity.

Gender dynamics had no evident influence on the participants' food preparation habits as Bourdieu (1984) would suggest. The seeming gender equality amongst the participants could be affected by the absence of the economic and generational hierarchy in the setting of international students living with peers. At the same time, the participants' food choices were also, though to a lesser degree, influenced by material conditions such as location, taste, efficiency, and price, as well as the skill and information available for food preparation. Harris' (2007) notion of rationality was by no means the only factor in shaping the food consumption patterns, and if it were, the participants would not make any additional effort for purchasing Chinese ingredients.

Likewise, the perception of authentic Chinese food for the participants is also socially and culturally constructed since it is signified by factors such as the symbolic significance to the Chinese identity, the geographic context, the consistency to the established conventions and traditions, the ethnicity of the food producers, the simplicity of the production process, and the popularity within the Chinese community. Those criteria of authenticity overlook the outside influences on Chinese food in a global context, while reinforcing the common nostalgia that the participants have for their home culture food, which is unique to their identity as Chinese students in Ottawa.

Social relations and cultural beliefs transcend material conditions in shaping health-related dietary changes and food decisions, and they are also significant in understanding the different perceptions toward nourishment and nutrition. However, these findings are unique to the research population and should not be generalized because the participants are middle-class students possessing specific capital resources. The relatively low rate of acculturation and the 
influence of a strong ethnic social network might explain the absence of nutrition transition found in this research. Accordingly, cultural beliefs, and especially traditional Chinese medical belief system, were influential in assessing the changes of Chinese dietary habits, and they sometimes contradicted the western notion of health and nutrition. Nevertheless, biomedical terms were applied when assessing the healthiness of an alternative cuisine, which has reaffirmed the urgency of adopting a culturally sensitive health communication strategy. The implementation of such a strategy requires further research on the social relations and cultural beliefs of migrants.

The participants' perception on culturally appropriate food habits exhibited at the Night Market was similar with their perception on authentic Chinese food, whereas their notion on the environment of the Night Market regarding cultural appropriateness was less consistent than their view on food habits, which implied the complexity of home culture in individual performance. The participants have also internalized the expectation that the culturally appropriate food habits need to be compromised for the mainstream acceptance and this expectation reflects the subordinate position of the Chinese community within the host country. Recognizing the differences in food habits would enhance Chinese students' sense of membership within the host country.

Sharing meals with compatriots strengthened friendships as it required teamwork and compromises for things like time, labor, and finances. The relationship established around food was often extended to other dimensions, which made the leisure life of the participants more active and at the same time attached a sense of belonging. However, the participants gained emotional benefits from retreating into mononational friendship at the expense of language and cultural learning, which hindered them from participating equally in the host society. Migrants 
who do not exclusively socialize with their compatriots are more likely to develop better language skills and are able to better navigate the local cultural norms (Masgoret \& Ward, 2016).

One of the potential next steps of this research is to find better explanations for the lack of inter-cultural interaction. The geographical and cultural distance with the host country and the collectiveness of Chinese culture as identified in this research are possible factors influencing language proficiency and meaningful inter-cultural interaction. Moreover, if inter-cultural interaction is dominated by emotional isolation as suggested by Myles and Cheng (2003) in their study about the concerns of non-native English-speaking students in Canada, it further encourages Chinese students to retreat into mononational friendship groups. Beyond examining the food journey of Chinese students in Ottawa, the research needs to identify the motivations as well as barriers for Chinese students to engage in inter-cultural interaction, and to provide solutions correspondingly.

In retrospect, the data would have been richer if I asked the questions more flexibly during the interviews. In this case, this research has been transformative for me as a researcher, since I learned the value of probing the interviewees in order to uncover the underlying meanings of their answer rather than mostly sticking to the interview guide. I could have given the interviewees a more considerable space to fully explain their answers, and consequently rely as much as possible on their perspective.

During the research, my insider bias inevitably shaped my understating of the experiences of the participants. I found myself sympathizing with the participants when we had similar experiences. However, this drawback of insider bias cannot take away the benefits of understanding the social settings of the interviewees better than non-Chinese researchers. For instance, I am in a better position pertaining to receiving opinions about Chinese restaurants and 
retail food stores in Ottawa during the interviews than non-Chinese researchers. Likewise, nonChinese researchers would also have a hard time understanding the Chinese food and festivals terminology (see Appendix A) even when the terms were translated into English, because meaning gets lost in translation (Nes, Abma, Jonsson, \& Deeg, 2010), let alone the slang, jokes, and trendy phrases.

The attention and accommodations that Chinese students receive in the process of social and cultural adaptation are often lacking, which does not reflect the demographic reality in Canadian universities. As a Chinese student myself, I can relate to many of the findings in this research. I hope that my thesis can help international student services in the post-secondary institutions in Ottawa to better understand and accommodate the experiences of Chinese-international students and recent-Chinese-immigrant students. 


\section{REFERENCES}

Albala, K. (2015). Music About Food. K. Albala (Ed.). The SAGE Encyclopedia of Food Issues. SAGE Publications.

Allahar, A. (1994). More Than an Oxymoron: Ethnicity and the Social Construction of Primordial Attachment. Canadian Ethnic Studies, 26: 18-34.

Anderson, A. S. (2003). The challenge of assessing nutrient intake in ethnic minority groups. Journal of Human Nutrition and Dietetics, 16(5), 313-314.

Anderson, B. (1983). Imagined Communities: Reflections on the Origin and Spread of Nationalism. London: Verso.

Arcodia, C., \& Robb, A. (2000). A taxonomy of event management terms. J. Allen, R. Harris, L. K. Jago, \& A. J. Veal (Eds.). Events Beyond 2000: Setting the Agenda: Proceedings of Conference on Event Evaluation, Research and Education. Sydney: Australian Centre for Event Management School of Leisure, Sport and Tourism, University of Technology.

Arcodia, C., \& Whitford, M. (2006). Festival attendance and the development of social capital. Journal of Convention \& Event Tourism, 8(2), 1-18.

Askegaard, S., Arnould, E. J., and Kjeldgaard, D. (2005). Post-assimilationist Ethnic Consumer Research: Qualifications and Extensions." Journal of Consumer Research, 32 (June), 1607

Astrup, A., Dyerberg, J., Selleck, M., \& Stender, S. (2008). Nutrition transition and its relationship to the development of obesity and related chronic diseases. Obesity Reviews, $9(\mathrm{~s} 1), 48-52$.

Azar, K. M. J., Chen, E., Holland, A. T., \& Palaniappan, L. P. (2013). Festival Foods in the Immigrant Diet. J Immigrant Minority Health, 15: 953-960.

Backman, K. F., Backman, S. J., Uysal, M., \& Sunshine, K. M. (1995). Event tourism: an examination of motivations and activities. Festival Management and Event Tourism, 3(1): $15-24$.

Bankston III, C. L., Henry, J. (2000). Spectacles of ethnicity: Festivals and the commodification of ethnic culture among Louisiana Cajuns. Sociological Spectrum, 20(4), 377-407.

Barkataki-Ruscheweyh, M. (2013). Performing Identity: The Transformation of a Tangsa Festival in Assam, Northeast India. Asian Ethnology, 72(2), 241-258

Barthes, R. (1997). Toward a Psychosociology of Contemporary Food Consumption. C. Counihan, \& P. van Esterik. (Eds.). Food and Culture: A Reader. New York: Routledge, pp. $20-27$. 
Beardsworth, A., \& Keil, T. (1992). The Vegetarian Option: Varieties, Conversions, Motives and Careers. Sociological Rev., 40: 253-293.

Berkshire Partners. (2012). Berkshire Partners to Invest in Farm Boy. Berkshire Partners and Farm Boy vis Business Wire. (C) 2019 Berkshire Partners LLC. Retrieved from: http://www.berkshirepartners.com/berkshire-partners-to-invest-in-farm-boy

Bond, M. H., \& Cheung, T. (1983). College students' spontaneous self-concept: The effect of culture among respondents in Hong Kong, Japan, and the United States. Journal of CrossCultural Psychology, 14(2), 153-171.

Bourdieu, P. (1984). Distinction: A social critique of the judgement of taste. Cambridge, Mass: Harvard University Press.

Brown, L., Edwards, J., \& Hartwell, H. (2010). A taste of the unfamiliar. Understanding the meanings attached to food by international postgraduate students in England. Appetite, 54(1), 202-207.

Brown, L., \& Holloway, I. (2008). The initial stage of the international sojourn: excitement or culture shock. British Journal of Guidance and Counselling, 36(1), 33-49.

Brown, L. (2008). Language and anxiety: an ethnographic study of international postgraduate students. Evaluation and Research in Education, 2(3), 75-95.

Bush, H., Williams, R., Bradby, H., Anderson, A., \& Lean, M. (1998). Family hospitality and ethnic tradition among South Asian, Italian and general population women in the west of Scotland. Sociology of Health and Illness, 20(3), 351-380.

Cappellini, B., \& Yen, D. A. (2013). Little emperors in the UK: Acculturation and food over time. Journal of Business Research, 66(8), 968-974.

Cairney, J., \& Ostbye, T. (1999). Time since immigration and excess body weight. Canadian Journal of Public Health, 90(2), 120-124.

CBIE. (2017). A World of Learning: Canada's Performance and Potential in International Education. The Canadian Bureau for International Education.

Cheung, S. C. H., \& Wu, D. Y. H. (2004). The globalization of Chinese food. London; New York: Routledge Curzon.

Chin, J. (2015). Xi Jinping the Star in China's Lunar New Year TV Gala. The Wall Street Journal. Retrieved from: https://blogs.wsj.com/chinarealtime/2015/02/19/xi-jinping-thestar-in-chinas-lunar-new-year-tv-gala/

Chiswick, B. R., \& Miller, P. W. (2005). Do enclaves matter in immigrant adjustment. City \& Community, 4(1), 5-35. 
Cleveland M., Laroche M., Pons F., \& Kastoun R. (2009). Acculturation and consumption: textures of cultural adaptation. Inter J Interc Rel, 33(2009), 196-212.

Counihan, C., \& Van Esterik, P. (Eds.). (1997). Food and culture. New York: Routledge.

Creswell, J.W. (2014). The selection of research approach. Research Design: Qualitative, Quantitative, and Mixed Methods Approaches (4th Ed.). Thousand Oaks: Sage, pp. 3-22.

Culler, J. D. (1982). On deconstruction: Theory and criticism after structuralism. Ithaca, N.Y: Cornell University Press.

Cushner, K., \& Karim, A. (2004). Study abroad at university level. D. Landis, J. Bennett, \& M. Bennett (Eds.), Intercultural training. London: Sage, pp. 289-308.

Cushner, K., \& Mahon, J. (2002). Overseas student teaching: affecting personal, professional and global competencies in an age of globalization. Journal of Studies in International Education, 6(1), 44-58.

Daro, I. N. (2013). Chinese 'gutter oil' is even more disgusting than it sounds. Health. Canada.com. Retrieved from: https://o.canada.com/health-2/gutter-oil-is-even-moredisgusting-than-it-sounds

Dervin, F., \& Machart, R. (2015). Introduction: Omnipresent Culture, Omnipotent Cultures. Cultural Essentialism in Intercultural relations. Palgrave Macmillan, pp. 1-14.

Douglas, M. (1984). Food and culture: measuring the intricacy of rule systems. Food in the social order: Studies of food and festivities in three American communities. New York: Russell Sage Foundation, pp. 18-39.

Douglas, M. (1984). Food in the social order: Studies of food and festivities in three American communities. New York: Russell Sage Foundation.

Dovey, T. M., Staples, P. A., Gibson, E. E., \& Halford, J. C. G. (2008). Food neophobia and picky/fussy eating in children: a review. Appetite, 50, 181-193.

Durkheim, E., \& Fields, K. E. (1995). The elementary forms of religious life. New York: Free Press.

Eade, R. (2009). T\&T arrives with a bang. The Ottawa Citizen. Retrieved from: https://web.archive.org/web/20141129070044/http://www2.canada.com/ottawacitizen/colu mnists/story.html?id=06b0b484-4786-418a-b902-94652ca97c2d

Fagerli A. F., Lien M. E., Wandel M. (2005). Experience of dietary advice among Pakistani-born persons with type 2 diabetes in Oslo. Appetite, 45 (2005), 295-304.

Falassi, A. (1987). Festival: Definition and morphology. A. Falassi (Ed.). Time out of time. Albuquerque, NM: University of New Mexico Press. 
Fieldhouse, P. (1995). Biocultural perspectives on nutrition. P. Fieldhouse (ed.). Food and nutrition: Customs and culture (2nd ed.). London, United Kingdom: Chapman and Hall, pp. 1-29.

Formica, S., \& Uysal, M. (1996). A market segmentation of festival visitors: Umbria Jazz Festival in Italy. Festival Management and Event Tourism, 3(4): 175-182.

Foronda, C. L. (2008). A concept analysis of cultural sensitivity. Journal of Transcultural Nursing, 19(3), 207-212.

Franzen-Castle, L., \& Smith, C. (2014). Environmental, personal, and behavioral influences on BMI and acculturation of second-generation Hmong children. Maternal and Child Health Journal, 18(1), 73-89.

Fusch, P. \& Ness, L. R. (2015). Are We There Yet? Data Saturation in Qualitative Research. Qualitative Report, 20(9), 1408-1416.

Garnweidner, L. M., Terragni, L., Pettersen, K. S., \& Mosdøl, A. (2012). Perceptions of the host Country's food culture among female immigrants from Africa and Asia: Aspects relevant for cultural sensitivity in nutrition communication. Journal of Nutrition Education and Behavior, 44(4), 335-342.

Giddens, A. (1991). Modernity and self-identity: self and society in the late modern age. Cambridge: Blackwell.

Gilbert, P. A. \& Khokhar, S. (2008). Changing dietary habits of ethnic groups in Europe and implications for health. Nutr Rev, 66(2008), 203-215.

Goody, J. (1982). Cooking, cuisine, and class: A study in comparative sociology. New York; Cambridge [Cambridge shire]: Cambridge University Press.

Google Maps. (2018). Kowloon Market, 1: 500. Google Maps [online]. Retrieved from: https://www.google.com/maps/place/Kowloon+Market/@45.4284069,75.7161171,18.67z/data $=! 4 \mathrm{~m} 5 ! 3 \mathrm{~m} 4$ ! $1 \mathrm{~s} 0 \mathrm{x} 4 \mathrm{cce} 044 \mathrm{c} 18315 \mathrm{dab}: 0 \times 59 \mathrm{f} 9 \mathrm{e} 3 \mathrm{aa} 2 \mathrm{c} 37 \mathrm{ca} 5 \mathrm{c} ! 8 \mathrm{~m} 2$ !3d $45.4105206 ! 4 d-75.707 \quad 6798$

Google Maps. (2018). T\&T Supermarket, 1: 1000. Google Maps [online]. Retrieved from: https://www.google.com/maps/place/T\%26T+Supermarket/@45.3339133,75.6927785,17z/data $=! 3 \mathrm{~m} 1$ !4b1!4m5!3m4!1s0x4cce07d824eb2479:0x952e1 c077a03e4c7! $\underline{8 m 2 ! 3 d 45.3339133 ! 4 d-75.6905898}$

Hall, H. K., \& Sivakumaran, T. (2014) Social media use among international students. International Student Experience Journal, 2(1), 1-6.

Harris, M. (2007). Cultural materialism and behavior analysis: Common problems and radical solutions. The Behavior Analyst, 30(1), 37-47. 
Hartwell, H. J., Edwards, J. S. A., \& Brown, L. (2011). Acculturation and food habits. Lessons to be learned. British Food Journal, 113(11), 1393-1405.

Hassanab, S., \& Tidwell, R. (2002). International students in higher education: Identification of needs and implications for policy and practice. Journal of Studies in International Education, 6, 305-322.

Heldke, L. (2005). But is it Authentic? Culinary Travel and the Search for the 'Genuine Article. C. Korsmeyer (Ed.). The Taste Culture Reader: Experiencing Food and Drink. New York: Berg, pp. 385-394.

Himmelgreen, D. A., Perez-Escamilla, R., Martinez, D., et al. (2004). The longer you stay, the bigger you get: Length of time and language use in the U.S. are associated with obesity in Puerto Rican women. American Journal of Physical Anthropology, 125, 90-96.

Hobsbawm, E. (1983). Introduction: Inventing Traditions. E. Hobsbawm, \& T. Ranger (Eds.). The Invention of Tradition. Cambridge, England: Cambridge University Press, pp. 1-14

Huang, S., \& Yeoh, B. S. A. (2005). Transnational families and their children's education: China's 'study mothers' in Singapore. Global Networks, 5(4), 379-400.

Jamieson, K. (2004). Edinburgh: The festival gaze and its boundaries. Space and Culture, 7(1), 64-75. Johnston, J., \& Baumann, S. (2010). Eating Authenticity. Foodies: Democracy and Distinction in the Gourmet Foodscape. London: Routledge, pp. 69-96.

Jones, K. (Ed.). (2015). Preface. Holiday Symbols and Customs. Monigraphics. Retrieved from: http://ebookcentral.proquest.com

Julier, A. P. (2013). Eating together: Food, friendship, and inequality. Urbana: University of Illinois Press.

Kay, P., \& Kempton, W. (1984). What is the Sapir-Whorf hypothesis? American Anthropologist, $86,65-79$.

Kimberley, M., \& Parcell, L. M. (2014). The Pet Milk Company "Happy Family" Advertising Campaign. Journalism History, 40 (2), p. 70-84.

Kim, Y. Y. (2001). Becoming intercultural: An integrative theory of communication and crosscultural adaptation. Thousand Oaks, CA: Sage Publications.

Koc, M., \& Welsh, J. (2002). Food, Foodways and Immigrant Experience. Multiculturalism Program, Department of Canadian Heritage at the Canadian Ethnic Studies Association Conference. Ryerson University, pp. 1-15.

Lee, C. (2000). A comparative study of Caucasian and Asian visitors to a cultural expo in an Asian setting. Tourism Management, 21(2), 169-176. 
Lehrer, A. (1969). Semantic cuisine. Journal of Linguistics, 5: 39-55.

Lehrer, A. (1972). Cooking vocabularies and the culinary triangle of Levi-Strauss. Anthropological Linguistics, 14(5): 155-71.

Levi-Strauss, C. (1965). The Culinary Triangle. Partisan Review, 33: 586-95.

Li, M. Z. \& Stodolska, M. (2006). Transnationalism, Leisure, and Chinese Graduate Students in the United States. Leisure Sciences. Routledge: Taylor \& Francis Group. 28(1): 39-55.

Liu, J. (2011). Chinese Food. Cambridge University Press.

Locher, J., Yoels, W., Maurer, D., \& van Ells, J. (2005). Comfort foods: an exploratory journey into the social and emotional significance of food. Food and Foodways, 13(4), 273-297.

Louie, A. (2000). Re-territorializing Transnationalism: Chinese Americans and the Chinese Motherland. American Ethnologist, 27(3), 645-669.

Luo, S. (2002). The utilization of human excreta in Chinese agriculture and the challenge faced. EcoSanRes, pp. 1-4.

Lupton, D. (1996). Food, the Body and the Self. London: Sage.

Lu, S., \& Fine, G. A. (1995). The presentation of ethnic authenticity: Chinese food as a social accomplishment. The Sociological Quarterly, 36(3), 535-553.

Mahar, C., Harker, R., \& Wilkes, C. (1990) The Basic Theoretical Position. C. Mahar, R. Harker, \& C. Wilkes (Eds.). An Introduction to the Work of Pierre Bourdieu. Palgrave Macmillan, London.

Masgoret, A. M., \& Ward, Collen. (2016). Chapter 5: Culture learning approach to acculturation. D.L. Sam \& J. W. Berry. (Eds.). The Cambridge Handbook of Acculturation Psychology, pp. 58-77.

Mason, G., \& Lo, G. (2009). Sexual tourism and the excitement of the strange: Heterosexuality and the Sydney Mardi Gras Parade. Sexualities, 12(1), 97-121.

McClinchey, K. A. (2008). Urban Ethnic Festivals, Neighborhoods, and the Multiple Realities of Marketing Place. Journal of Travel \& Tourism Marketing, 25(3-4), 251-264.

McDonald, J. T., \& Kennedy, S. (2005). Is migration to Canada associated with unhealthy weight gain? Overweight and obesity among Canada's immigrants. Social Science \& Medicine, 61(12), 2469-2481.

McIntosh, A., \& Kubena, K. (1999). Food and ageing. J. Germov \& L. Williams (Eds.). A sociology of food and nutrition: the social appetite. Oxford: Oxford University Press, pp. 169-184. 
Meigs, A. (1997). Food as a Cultural Construction. Van Esterik, P., \& Counihan, C. (Eds.). Food and culture: A reader. New York: Routledge, pp. 95-106.

Mennell, S. (1985). All Manners of Food: Eating and Taste in England and France from the Middle Ages to the Present. Oxford: Basil Blackwell.

Mohr, K., Backman, K. F., Gahan, L. W., \& Backman, S. J. (1993). An investigation of festival motivations and event satisfaction by visitor type. Festival Management and Event Tourism, 1(3), 89-97.

Moxy. (2011). Map of the set end of downtown Ottawa. OpenStreetMap. Retrieved from: https://www.revolvy.com/page/Centretown

Myles, J., \& Cheng, L. (2003). The social and cultural life of non-native English speaking international graduate students at a Canadian university. Journal of English for Academic Purpose.

Neri, F. \& Ville, S. (2008). Social capital renewal and the academic performance of international students in Australia. The Journal of Socio-Economics. Elsevier. 37: 1515-1538.

Nes, F. V., Abma, T., Jonsson, H., \& Deeg, D. (2010). Language differences in qualitative research: is meaning lost in translation? European Journal of Ageing. Springer Netherlands, 7(4): 313-316.

Ottawa Asian Fest. (2018). Ottawa Asian Night Market. Ottawa Asian Fest - Food Festivals, Night Markets and Events in Ottawa. Retrieved from: http://www.ottawaasianfest.com

Pieterse, J. N. (2006). Globalization as hybridization. D., Kellner, \& M. G., Durham. (Eds.). Media and cultural studies: KeyWorks (Rev. ed.). Malden, MA: Blackwell, pp. 658-680.

Popkin, B. M., Horton, S., Kim, S., Mahal, A., \& Shuigao, J. (2001). Trends in diet, nutritional status, and diet-related noncommunicable diseases in China and India: the economic costs of the nutrition transition. Nutrition Reviews, 59(12), 379-390.

Pordes, P. M. (2014). Vitamin B2 (riboflavin). NetDoctor. London: Hearst UK. Retrieved from: https://www.netdoctor.co.uk/healthy-eating/a10923/vitamin-b2-riboflavin/

Quinn, B. (2003). Symbols, practices and myth-making: cultural perspectives on the Wexford Festival opera. Tourism Geographies, 5(3), 329-349.

Ragusa, A. (2005). Social change and the corporate construction of gay markets. The New York Times' Advertising Business News, Media, Culture \& Society, 27(5), 653-676.

Reilly, M. D., \& Wallendorf, M. (1987). A comparison of group differences in food consumption using household refuse. Journal of Consumer Research, 14(2), 289- 295. 
Rodgers, G. (2018). Words for Foreigners in Asia: Laowai, Farang, Gwai Lo, Buleh, and Others. TripSavvy. Retrieved from: https:/www.tripsavvy.com/asian-words-for-foreigners1458302

Ryan, J., \& Carroll, J. (2005). Canaries in the coalmine: international students in Western universities. J. Carroll \& J. Ryan (Eds.), Teaching international students: improving learning for all. Abingdon: Routledge, pp. 3-12.

Satia-Abouta, J, Patterson, R. E., Neuhouser, M. L., Elder, J. (2002). Dietary acculturation: applications to nutrition research and dietetics. J Am Diet Assoc, 102(2002), 1105-1118.

Savinovic, A., Kim, S., \& Long, P. (2012). Audience members' motivation, satisfaction, and intention to re-visit an ethnic minority cultural festival. Journal of Travel \& Tourism Marketing, 29(7), 682.

Schultz, J. D., Spindler, A. A., \& Josephson, R. V. (1994). Diet and acculturation in Chinese women. Journal of Nutrition Education, 26(6), 266-272.

Schuster, J. M. (1995). Two urban festivals: La Merce and First Night. Planning Practice \& Research, 10(2), 173-188.

Science of Cooking. (2018). Fermentation and Food. The Accidental Scientist. Exploratorium. Retrieved from: https://www.exploratorium.edu/cooking/pickles/fermentation.html

Shin, H. (2004). Cultural festivals and regional identities in South Korea. Environment and Planning D: Society and Space, 22(4), 619-632.

Tafarodi, R. W., \& Smith, A. J. (2001). Individualism, collectivism and depressive sensitivity to life events. The case of Malaysian sojourners. International Journal of Intercultural Relations, 25, 73-88.

Tam, S. M. (2004). Heunggongyan Forever: Immigrant Life and Hong Kong Style Yumcha in Australia. S. C. H., Cheung, \& D. Y. H., Wu. (Eds.). The globalization of Chinese food. London; New York: Routledge Curzon, pp. 131-151.

The Economist. (2017). Jewel in the crown: What China can learn from the Pearl river delta. The Economist. Retrieved from: https://www.economist.com/special-report/2017/04/08/whatchina-can-learn-from-the-pearl-river-delta

Tirelli, C., Pilar Martínez-Ruiz, M., \& Gómez-Ladrón-De-Guevara, R. (2013). Major influences on buying decision processes by international university students. Differences by continent of origin. Appetite, 71, 104-112.

Triandis, H., Bontempo, R., \& Villareal, M. (1988). Individualism and collectivism: crosscultural perspectives on self-ingroup relationships. Journal of Personality and Social Psychology, 54(2), 323-338. 
Trubek, A. (2005). Place Matters. C. Korsmeyer (Ed.). The Taste Culture Reader: Experiencing Food and Drink. New York: Berg, pp. 260-271.

Ustuner, T., \& Holt, D. B. (2007). Dominated consumer acculturation: The social construction of poor migrant women's consumer identity projects in a Turkish squatter. Journal of Consumer Research, 34(1), 41-56.

Usyal, M., Gahan, L., \& Martin, B. (1993). An examination of event motivations. Festival Management and Event Tourism, 1: 5-10.

Vijaygopal, R., \& Dibb, S. (2012). Exploring the role of acculturation in brand choice: A new perspective for targeting Indians living in the United Kingdom. Journal of Targeting, Measurement and Analysis for Marketing, 20(1), 47-56.

Visser, M. (1999). Food and Culture: Interconnections. Social Research, 66(1), 117-130.

Wansink, B., \& Kim, J. (2005). Bad popcorn in big buckets: Portion size can influence intake as much as taste. Journal of Nutrition Education and Behavior, 37(5), 242-245.

Warde, A. (1997). Consumption, food and taste. London: Sage.

Ward, C., \& Searle, W. (1991). The impact of value discrepancies and cultural identity on psychological and sociocultural adjustment of sojourners. International Journal of Intercultural Relations, 15, 209-225.

Ward, C. (2001). The impact of international students on domestic students and host institutions. Education Countes. Retrieved from: https:/www.educationcounts.govt.nz/publications/international/the impact_of internationa 1 sstudents_on_domestic_students_and_host_institutions

Welsh, J. et al. (1998). Food Security, Health and the Immigrant Experience. Centre of Excellence for Research on Immigration and Settlement.

Wobber, V., Hare, B., \& Wrangham, R. (2008). Great apes prefer cooked food. Journal of Human Evolution, 55(2), 340-348.

Wong, L. L. (2017). Trans-pacific mobilities: The Chinese and Canada. Vancouver [British Columbia];Toronto [Ontario]; UBC Press.

Wood, R. C. (1992). Dining Out in the Urban Context. British Food Journal, 94(9): 3-5.

Wood, R. C. (1995) Food and Social Theory: States of the Art. The sociology of the meal. Edinburgh: Edinburgh University Press, pp. 1-45.

Wu, B., \& Smith, C. (2016). Acculturation and environmental factors influencing dietary behaviors and body mass index of Chinese students in the United States. Appetite, 103, 324-335. 
Wu, D. Y. H. (2004). Improvising Chinese Cuisine Overseas. S. C. H., Cheung, \& D. Y. H., Wu. (Eds.). The globalization of Chinese food. London; New York: Routledge Curzon, pp. 56-68.

Yang, J. (2017). Census shows big changes in Scarborough's Little China. The Star. Toronto: Toronto Star Newspapers Limited. Retrieved from:

https://www.thestar.com/news/gta/2017/10/25/census-shows-big-changes-in-scarboroughslittle-china.html

Yates-Doerr, E. (2012). The opacity of reduction: Nutritional black-boxing and the meanings of nourishment. Food, Culture \& Society, 15(2), 293-313.

Zhang, Y.\& Guo, Y. (2015). Becoming transnational: exploring multiple identities of students in a Mandarin-English bilingual programme in Canada. Globalization, Societies, and Education. Routledge: Taylor \& Francis Group. 13(2), 210-229.

Zwingmann, C., \& Gunn, A. (1983). Uprooting and health: psychosocial problems of students from abroad. Geneva, Switzerland: WHO. 


\section{APPENDIX A: CHINESE FOOD, FESTIVALS, AND SLANG TERMINOLOGY ${ }^{30}$}

Choudoufu: Stinky tofu.

Chunwan: The Chinese New Year Gala, called Chunwan in Chinese is a 4-hour variety show broadcast by the central television broadcaster of People's Republic of China on New Year's Eve, which has been a tradition embraced by Chinese families since 1983. As one of the mostwatched shows in the world, the show contains as much overt political messages as entertainment (Chin, 2015).

Dachangbaoxiaochang: A pork sausage wrapped in a glutinous rice sausage.

Jianbingguozi: Chinese savory crepe.

Jiaozi: Dumplings.

Luchuan: Literally means sliding the meat off the skewer, and the Chinese phrase describes the practice of eating kabob with a group of people on the street.

Niangao: Sticky rice cakes.

Shanghuo: Shanghuo can be translated literally as having excessive internal heat. Applying the principle of Ying-Yang, higher air humidity adds more Ying elements into the human body while spicy foods are Yang elements that can help to shift the body back to the equilibrium. Thus, traditional Chinese herbal medical science believes that consuming a higher amount of spicy foods can lead to symptoms caused by Vitamin B2 deficiency such as dryness of the skin around the nose and mouth, dry tongue, vision problems, etc. (Pordes, 2014), and Shanghuo is a general yet vague description of these symptoms.

Shaobing: A baked Chinese flatbread made with either sweet or savory stuff, or it could also be made unstuffed.

Tangyuan: Glutinous rice balls made with sweet/salty fillings or with no filling, and are usually served in a bowl of soup in which the rice balls were boiled. Tangyuan is also called Yuanxiao or Tangtuan in Chinese.

Waiguoren: Literally means foreign person in Chinese, a commonly used phrase referring to Western tourists or foreigners in China (Rodgers, 2018).

Yuebing: Mooncakes are baked goods stuffed with sweet/salty fillings.

Zongzi: Glutinous rice cakes wrapped in reed leaves, which could also have sweet/salty filling.

30 The terminology referenced on this page is based on Mandarin. 


\section{APPENDIX B: INTERVIEW GUIDE}

Introductory Questions:

1. How long have you been in Canada?

2. How did you know about the Asian Food Festival? (Word of mouth? Social media? Local news coverage?)

3. How many times have you attended the festival?

4. When you attended this year, who did you attend the festival with? How long did you stay?

5. What are your motivations for going to the Asian Food Festival?

Festival Food Related Questions:

1. What foods have you tried at the festival? How do you like them? (probes)

a) Which food is your favorite at the festival and why?

b) Which food is your least favorite at the festival and why?

c) Are you familiar with most of the foods provided at the festival?

2. How are the foods similar or different with the foods you have in China? (probes)

a) There are regional differences in Chinese cuisine. How would you describe the foods served at the festival? Do you think the festival caters to different regions or different demographics?

b) Do you consider the foods served at the festival as authentic? Is the authenticity of the Chinese foods at the festival important to you?

3. Are there any foods you would consider not Asian at the festival?

Festival Atmosphere Related Questions:

1. How would you describe the people who were at the festival?

2. How is the atmosphere at the festival similar or different with the atmosphere of street foods in China?

3. Other than the foods, what are other things or activities happening at the festival that you think are noteworthy?

4. Do you think the name Asian Food Festival describes what happens at the festival fairly well?

5. Are there any other activities that you and your friends do before or after attending the festival?

Chinese and Local Traditional Festivals Related Questions:

1. Do you celebrate Chinese traditional festivals in Ottawa?

(probes)

a) What festivals do you celebrate the most? With whom? Doing what?

b) What do you eat on these festivals?

c) How do you get the foods? (Home cooking? Local Chinese food restaurant?)

d) Are they similar or different with the traditional festival foods that you had in China?

e) Do you also eat them during non-festival time?

2. Do you celebrate local festivals in Ottawa? (Such as Christmas and Thanksgiving.)

a) What festivals do you celebrate the most? With whom? Doing what? 
b) What do you eat on these festivals?

c) How do you get the foods? (Home cooking? Local Chinese food restaurant?)

Other Chinese Food Related Questions

1. What are the other means that you acquire Chinese food in Ottawa? (Home cooking? Local Chinese food restaurant?) (probes)

a) If cooking at home, how do you get the ingredients?

b) Can you describe your favorite Chinese restaurant in Ottawa?

2. Are the foods provided at the Asian Food Festival similar with or different from the foods served in local Chinese food restaurants?

3. Do you consider the foods served at the local Chinese restaurants authentic? Is this important to you?

4. How had your diet changed or stayed the same after you came to Canada?

5. This concludes the interview. Do you have anything to add? 


\section{APPENDIX C: LETTER OF INVITATION}

\section{Carleton \\ universitr \\ Canada's Capital University \\ Letter of Invitation}

Title: Post-secondary Chinese students negotiate culture and identity in Ottawa's Asian Food Festival (Project \#109025)

Date of ethics clearance: To be determined by the REB (as indicated on the clearance form)

Ethics Clearance for the Collection of Data Expires: To be determined by the REB (as indicated on the clearance form)

$05 / 10 / 2018$

Dear Sir or Madam,

My name is Shihan Liu and I am a Master's student in the School of Journalism and Communication at Carleton University. I am working on a research project under the supervision of Prof. Irena Knezevic.

I am writing to you today to invite you to participate in a study on multicultural identity formation through the practice of attending food festivals. This study aims to examine how food festivals facilitate the life of post-secondary Chinese students abroad.

This study involves one 40-60-minute interview that will take place in a mutually convenient, safe location. You will be given the option of being interviewed either in person or by phone. The researcher prefers in-person interviews yet it is entirely up to you to choose. With your consent, interviews will be audio-recorded. Once the recording has been transcribed, the audiorecording will be destroyed.

While this project does involve some mild professional and emotional risks, care will be taken to protect your identity. This will be done by keeping all responses confidential and allowing you to request that certain responses not be included in the final project. 
You will have the right to end your participation in the study at any time, for any reason, up until November $1^{\text {st }}, 2018$. If you choose to withdraw, all the information you have provided will be destroyed.

As a token of appreciation, I will be providing you with refreshments during the interview, and a $\$ 10$ gift card from Starbucks will also be given after the interview. No other compensation will be provided.

All research data, including audio-recordings and any notes will be passwordprotected. Any hard copies of data (including any handwritten notes or USB keys) will be kept in a locked cabinet at Carleton University. Research data will only be accessible by the researcher and the research supervisor.

This ethics protocol for this project was reviewed by the Carleton University Research Ethics Board, which provided clearance to carry out the research. Should you have questions or concerns related to your involvement in this research, please contact:

\section{CUREB-A:}

Dr. Bernadette Campbell, Chair

Research Ethics Board-A

Carleton University

Tel: $613-520-2600$ ext. 2517

ethics@carleton.ca

If you would like to participate in this research project, or have any questions, please contact me at shihanliu@cmail.carleton.ca.

Sincerely,

Shihan Liu 


\section{APPENDIX D: CONSENT FORM}

\section{Carleton \\ U N I V E R S I T Y}

Canada's Capital University

\section{Consent Form}

Title: Post-secondary Chinese students negotiate culture and identity in Ottawa's Asian Food Festival (Project \#109025)

Date of ethics clearance: July 19, 2018

Ethics Clearance for the Collection of Data Expires: July 31, 2019

I choose to participate in a study on multicultural identity formation through practices of attending food festivals. This study aims to examine how do the food festivals accommodate the life of post-secondary Chinese students abroad. The researcher for this study is Shihan Liu in the School of Journalism and Communication at Carleton University.

She is working under the supervision of Prof. Irena Knezevic in the School of Journalism and Communication at Carleton University.

This study involves one 40-60-minute interview. You will be given the option of being interviewed either in person or by phone. The researcher prefers inperson interviews yet it is entirely up to you to choose. With your consent, interviews will be audio-recorded. Once the recording has been transcribed, the audio-recording will be destroyed.

During this study, I will take precautions to protect your identity. This will be done by keeping all responses confidential and allowing you to request that certain responses not be included in the final project. Before the study results are published, I will email you the materials that use information from your interview. You will have the opportunity to review the findings if you wish, and confirm their accuracy.

You have the right to end your participation in the study at any time, for any reason, up until November $1^{\text {st }}, 2018$. You can withdraw by phoning or emailing the researcher or the research supervisor. If you withdraw from the study, all information you have provided will be immediately destroyed. 
As a token of appreciation, you will receive a $\$ 10$ Starbucks' gift card. This is yours to keep, even if you withdraw from the study.

All research data, including audio-recordings and any notes will be encrypted. Any hard copies of data (including any handwritten notes or USB keys) will be kept in a locked cabinet at Carleton University. Research data will only be accessible by the researcher and the research supervisor.

Once the project is completed, all research data will be kept for five years and potentially used for other research projects on this same topic. At the end of five years, all research data will be securely destroyed. (Electronic data will be erased and hard copies will be shredded.)

If you would like a copy of the finished research project, you are invited to contact the researcher to request an electronic copy which will be provided to you.

The ethics protocol for this project was reviewed by the Carleton University Research Ethics Board, which provided clearance to carry out the research. If you have any ethical concerns with the study, please contact Dr. Bernadette Campbell, Chair, Carleton University Research Ethics Board-A (by phone at 613520-2600 ext. 2517 or via email at ethics@carleton.ca).

Researcher contact information: Supervisor contact information:

Name : Shihan Liu

Department: Communication

Carleton University

Email: shihanliu@cmail.carleton.ca

irenaknezevic@cunet.carleton.ca
Name: Dr. Irena Knezevic

Department: Communication

Carleton University

Tel: 613-520-2600 x 4121

Email:

Are you over the age of 18 : Yes

Do you agree to be audio-recorded: No Yes No

Signature of participant

Date

Signature of researcher

Date 


\section{APPENDIX E: CUREB CERTIFICATE OF APPROVAL}

\section{Carleton \\ UNIVERSITY}

Canada's Capital University

Office of Research Ethics

5110 Human Computer Interaction Bldg | 1125 Colonel By

Drive Ottawa, Ontario K1S 5B6

613-520-2600 Ext: 2517

ethics@carleton.ca

\section{CERTIFICATION OF INSTITUTIONAL ETHICS CLEARANCE}

The Carleton University Research Ethics Board-A (CUREB-A) has granted ethics clearance for the research project described below and research may now proceed. CUREB-A is constituted and operates in compliance with the Tri-Council Policy Statement: Ethical Conduct for Research Involving Humans (TCPS2).

Ethics Protocol Clearance ID: Project \# 109025

Project Team Members: Ms. Shihan Liu (Primary Investigator)

Dr. Irena Knezevic (Research Supervisor)

Project Title: Post-secondary Chinese students negotiate culture and identity in Ottawa's Asian Food Festival [Shihan Liu]

Funding Source (If applicable):

Effective: July 19, 2018

Expires: July 31, 2019.

Please ensure the study clearance number is prominently placed in all recruitment and consent materials: CUREB-A Clearance \# 109025.

\section{Restrictions:}

This certification is subject to the following conditions:

1. Clearance is granted only for the research and purposes described in the application.

2. Any modification to the approved research must be submitted to CUREB-A via a Change to Protocol Form. All changes must be cleared prior to the continuance of the research.

3. An Annual Status Report for the renewal of ethics clearance must be submitted and cleared by the renewal date listed above. Failure to submit the Annual Status Report will result in the closure of the file. If funding is associated, funds will be frozen. 
4. A closure request must be sent to CUREB-A when the research is complete or terminated.

5. Should any participant suffer adversely from their participation in the project you are required to report the matter to CUREB-A.

Failure to conduct the research in accordance with the principles of the Tri-Council Policy Statement: Ethical Conduct for Research Involving Humans 2nd edition and the Carleton University Policies and Procedures for the Ethical Conduct of Research may result in the suspension or termination of the research project.

Upon reasonable request, it is the policy of CUREB, for cleared protocols, to release the name of the PI, the title of the project, and the date of clearance and any renewal(s).

Please contact the Research Compliance Coordinators, at ethics@carleton.ca, if you have any questions.

CLEARED BY:

Date: July 19, 2018

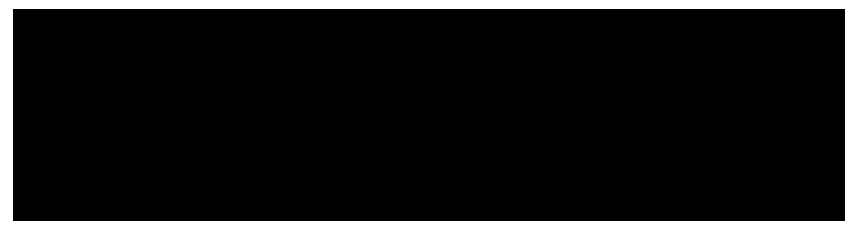

Bernadette Campbell, PhD, Chair, CUREB-A

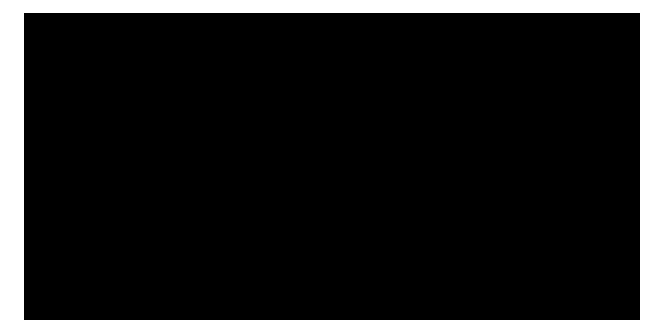

Andy Adler, PhD, Vice-Chair, CUREB-A 